\title{
PRINCIPAL DISCRETION AND THE USE OF OUT-OF-SCHOOL SUSPENSION IN PUBLIC HIGH SCHOOLS
}

A Dissertation
Presented to
the Faculty of the Graduate School
at the University of Missouri-Columbia
In Partial Fulfillment
of the Requirements for the Degree
Doctor of Education
beth Harrell
Dr. Bret D. Cormier, Dissertation Supervisor
MAY 2019


The undersigned, appointed by the dean of the Graduate School, have examined the dissertation entitled

\title{
PRINCIPAL DISCRETION AND THE USE OF OUT-OF-SCHOOL SUSPENSION IN PUBLIC HIGH SCHOOLS
}

\author{
presented by Seth Harrell \\ a candidate for the degree of doctor of education \\ and hereby certify that, in their opinion, is worthy of acceptance.
}

Dr. Bret D. Cormier, Chair

Dr. C.P. Gause

Dr. Paul Watkins

Dr. Lisa Bertrand

Dr. William Bratberg 


\section{Dedication}

To my wife Patty, for her ongoing support and encouragement. The opportunity to pursue this doctoral degree would not have been possible without you. To my awesome kids, Asa and Mary Claire, thank you for your patience and understanding as I have spent countless hours working on my "school work." You provided much encouragement to me in my last semester by consistently calling me, Dr. Seth Harrell. This gave me that extra push to finish.

To the rest of my family and friends, thank you for always being there for me and helping me develop into the person I am today. Your love and support does not go unnoticed.

To my colleagues, thank you for pushing me to be a better educator and leader. Your passion for educating students has continued to encourage me to maintain high expectations for myself. This has allowed me to continue to improve as an educator and find ways to influence others in the most positive way. 


\section{Acknowledgements}

To Dr. Brett D. Cormier, for his feedback and support throughout the dissertation process. To all Cohort 10 instructors, thank you for making this program a unique and meaningful learning experience.

To the members of my dissertation committee, Dr. C.P. Gause, Dr. Paul Watkins, Dr. Lisa Bertrand, and Dr. Bill Bratberg, thank you for your time and the guidance you have provided me. Your assistance and attention to detail has improved my ability to conduct research and be a contributing practitioner in the field of education.

To my coworkers Dr. Matt Lacy, Dr. John Link, Dr. Beth Emmendorfer, and Dr. Jessica Maxwell, thank you for your encouragement throughout doctoral coursework. Your support is truly appreciated.

To my Cohort 10 teammates, Dr. Robin Smith, Dr. Kyle Schneider, LeaAnne Lambert, and James Hamlin, thank you for your help and continuous encouragement throughout this challenging journey. 


\section{Table of Contents}

ACKNOWLEDGEMENTS........................................................

ABSTRACT ..........................................................................

SECTION ONE: INTRODUCTION TO THE DISSERTATION-IN-PRACTICE.........1

Background of the Study..................................................

Statement of the Problem................................................ 6

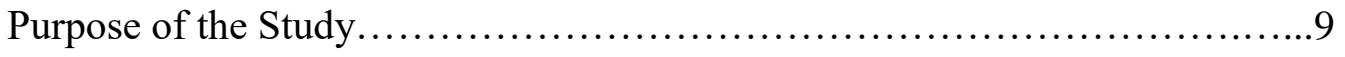

Research Questions...................................................11

Theoretical Framework.................................................12

Deterrence Theory...............................................13

Design of the Study ..................................................... 14

Site Description and Setting........................................16

Participant Sample...............................................17

Data Collection Tools...........................................17

Data Analysis................................................... 19

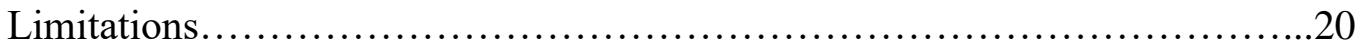

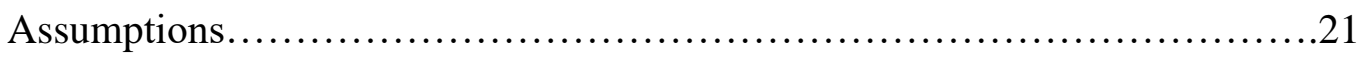

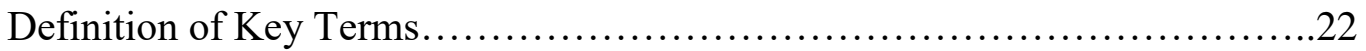

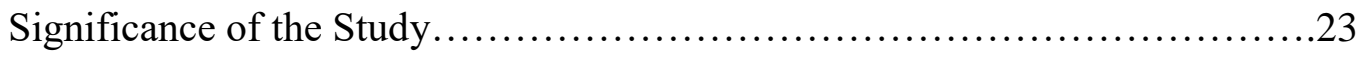

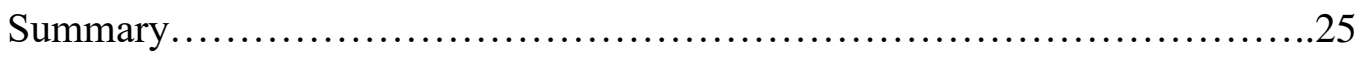

SECTION TWO: PRACTIONER SETTING FOR THE STUDY ...................................32

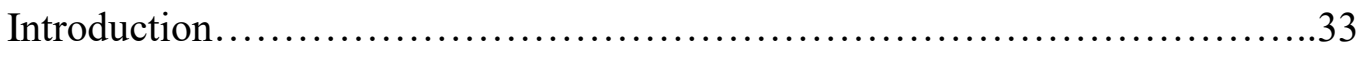


History of the Organization......................................... 34

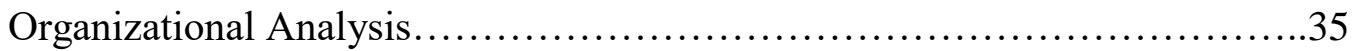

Leadership Analysis............................................. 37

Implications for Research in Practitioner Setting.........................38

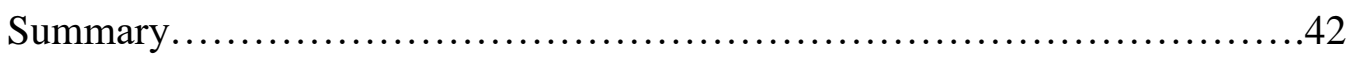

SECTION THREE: SCHOLARLY REVIEW FOR THE STUDY ..................46

Introduction...................................................47

Literature Review..............................................48

Education Policy...........................................48

Exclusionary Discipline....................................49

The Impact of School Exclusion..............................53

History of Zero-Tolerance Policies.............................53

The Impact of Suspensions on Students...........................55

Alternatives to Out-of-School Suspension..........................58

Summary ......................................................64

SECTION FOUR: CONTRIBUTION TO PRACTICE $\ldots \ldots \ldots \ldots \ldots \ldots \ldots \ldots \ldots \ldots \ldots . . \ldots$

Plan for Dissemination of Practitioner Contribution........................70

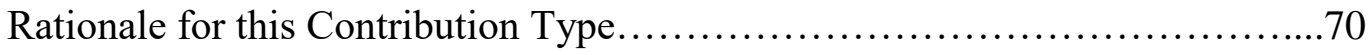

Theoretical Framework............................................... 74

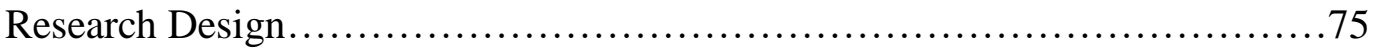

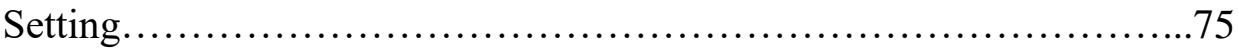

Data Collection Tools............................................76 
Data Analysis.................................................... 76

Limitations and Assumptions........................................ 78

Research Questions................................................. 79

Results........................................................... 80

Discussion and Recommendations...................................... 94

SECTION FIVE: CONTRIBUTION TO SCHOLARSHIP ........................99

Target Journal................................................... 100

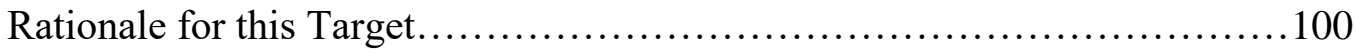

Outline of Proposed Contents........................................ 100

Plan for Submission............................................... 101

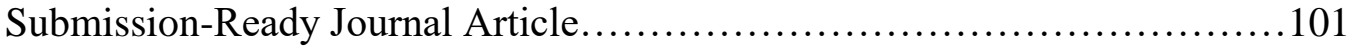

Summary .......................................................116

SECTION SIX: SCHOLARLY PRACTITIONER REFLECTION ..................120

Dissertation Influence as an Educational Leader...........................121

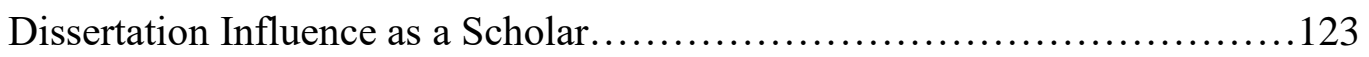

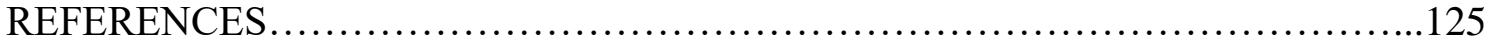

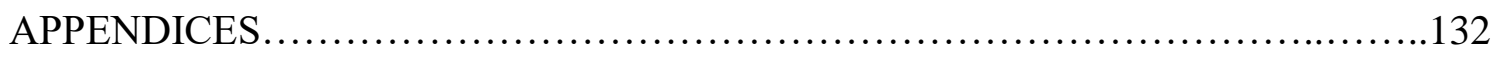

A: Interview Questions................................................. 132

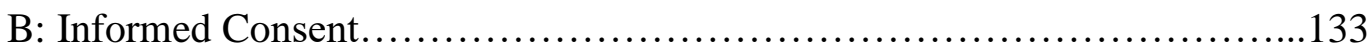

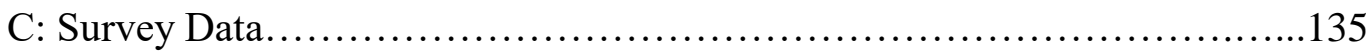

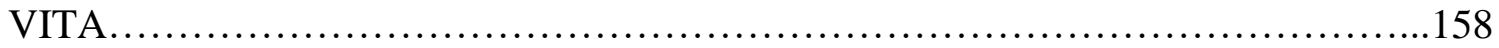


Principal Discretion and the use of Out-of-School Suspension in Public High Schools

\author{
Seth A. Harrell \\ Dr. Bret D. Cormier, Dissertation Supervisor
}

\begin{abstract}
The purpose of this mixed methods study was to analyze school principal's perception and use of out-of-school suspension as a consequence to address student misbehavior. This study was conducted on current acting high school principals in the southeast region of a Midwestern state. Participants completed a survey that consisted of items related to principal decision making as well as the use of zero-tolerance policies to determine discipline outcomes. Survey items were designed to determine how out-ofschool suspensions are used in relation to the use of principal discretion and zerotolerance policies. Principals in this study were given the opportunity to participate in follow-up interviews where principals were asked more specific questions about their use of out-of-school suspension as a form of student discipline.

Study results found that principals felt the use of out-of-school suspension were an effective consequence to address student misbehavior. Principals felt they had the autonomy to use their discretion to determine the most appropriate consequence to address student misbehavior in their respective schools. Opinions were mixed on the use of zero-tolerance policies. A majority of surveyed participants felt that zero-tolerance policies were an effective method used to address student misbehavior. However, principals who were interviewed preferred to use their discretion over zero-tolerance
\end{abstract}


policies when determining the most appropriate consequence because principals wanted to be able to consider all of the circumstances of a discipline situation. Principals concluded that out-of-school suspensions are necessary in-order to protect the learning environment for all students; however, there are inconsistencies in the use of such suspensions. These inconsistencies are present through the use of principal discretion and decision making, the use of zero-tolerance policies, the length of the suspension, and the unnecessary use of suspensions for minor discipline infractions. 
SECTION ONE:

INTRODUCTION TO THE DISSERTATION-IN-PRACTICE 


\section{Background}

Public schools across the nation are required to provide a quality education while promoting safe learning environments for students. Federal, state, and local policies have been established and are designed to help public schools maintain safe educational facilities. Even with these current policies, there continues to be "issues of safety and discipline" in public schools (Brent, 2016). In recent years, there has been an added emphasis on student misbehavior and the impact of exclusionary practices. To effectively manage student misbehavior, policies and procedures are designed to guide public schools as they determine appropriate student behavior and what is not appropriate student behavior. Schools are under increased scrutiny to improve student academic performance while ensuring student safety (Brent, 2016; Findlay, 2015). Schools are held to a high standard and are feeling the pressure of having to "implement and strictly enforce firm behavioral and academic standards" (Brent, 2016, p.524).

Federal and state education agencies hold public schools accountable for their performance. The pressure to perform well falls on school leaders such as the superintendent and building level principals tasked with leading these schools. Public school leaders are expected to not only effectively manage situations when they arise, but establish systems and protocols that proactively address issues before they become problematic. This can be a daunting task for public school leaders, especially as they develop and implement effective strategies to manage their schools and the students within. In public high schools, the principal is the educational leader tasked with ensuring that the school is safe for all students and effective teaching and learning is taking place. Principals are required to "maintain order and discipline" which requires principals to be 
great decision makers (Findlay, 2015). Federal, state, and local mandates put in place to regulate school districts have a heavy impact on the decision making of principals. Research will show that principals are under intense pressure when having to make decisions in schools, more specifically, the pressure of disciplining students who violate school rules.

Principals have a variety of options to choose from when deciding the most appropriate consequence for a discipline infraction committed by a student. These options can range from a conference with the student, which may result in a reprimand, to excluding that student from the learning environment. The exclusion of a student from the traditional classroom setting is mostly associated with an out-of-school suspensions (OSS). OSS is a form of exclusionary discipline and can be described as the removal of a student from the traditional classroom setting for a specific period time (Morrison \& Skiba, 2001). This study will investigate the perception current public schools principals have on the use of out-of-school suspension.

Principals have the responsibility to make the most appropriate discipline decisions which may result in consequences for student misbehavior. In some instances, these decisions may be made using the principal's professional and personal discretion. However, there are times when a specific infraction is severe enough that local school board policies mandate the consequence for that behavior. This means that principals must follow these policies; therefore, losing their ability to use their discretion. School policies with mandated consequences impact a principal's decision making regarding student discipline, as these policies have pre-determined consequences for students who misbehave. These consequences may result in the student being excluded from the 
education setting. This exclusion can result in an out-of-school suspension or expulsion. The most common form of exclusionary discipline is out-of-school suspension (Skiba, Chung, Trachok, Baker, Sheya, \& Hughes, 2014; Morrison \& Skiba, 2001). Commonly used mandated policies resulting in an out-of-school suspension are defined as zerotolerance policies.

The implementation of zero-tolerance policies were put in place as a deterrent in our society in the late eighties and early nineties, more specifically to address criminal behavior (Wallace, Goodkind, Wallace, \& Bachman, 2008, Skiba \& Peterson, 1999). These policies were established to address criminal behavior involving drugs, weapons, acts of violence, etc., (Rausch \& Skiba, 2006; Hoffman, 2014). Zero-tolerance policies were first being implemented in public schools at around the same time and were conceived from the criminal justice system (Evans \& Lester, 2012). These polices became more wide spread in public schools all across the United States when President Bill Clinton's administration created the Gun-Free Schools Act of 1994 which called for an automatic one-year expulsion for possessing a weapon in school (Skiba \& Peterson, 1999; Evans \& Lester, 2012; Hoffman, 2014). This mandate became a popular strategy for schools looking to establish safer learning environments and was designed to severely punish students for the use of weapons. Over time, mandated school policies were being used for violent offenses as well as other offenses as schools adopted the philosophy that they would have "zero-tolerance" when it comes to student misbehavior. Zero-tolerance policies were being implemented in schools with the assumption that "removal of disruptive students would result in a safer climate for others" (APA Zero Tolerance Task Force). School districts started expanding their use of zero-tolerance policies to address 
lesser violent offenses such as drug and alcohol possession, threats, fighting, insubordination, cursing, and defiance (Skiba, 2000; Evans \& Lester, 2012; Lauer, 2014; Skiba \& Morrison, 2001). It is the belief of many that schools should be "safe and supportive" in-order for effective teaching and learning to occur (U.S. Department of Justice). Zero-tolerance policies became the process to which schools could create safe learning environments while using a "get-tough" approach to address student misbehavior (Skiba \& Morrison, 2001).

The philosophy of zero-tolerance policies were designed so that if a student violated a particular school rule, they would receive a mandated, pre-determined consequence. In most cases, the result would be exclusion from the learning environment with out-of-school suspension begin the most common consequence. Brent (2016) notes that zero-tolerance policies have become a part of the schools' "natural environment." Public schools begun to adopt zero-tolerance policies to curb school violence while promoting school and student safety. Implementation of such policies gave the perception that schools are much safer with these policies in place. The use of zero-tolerance may have led schools and principals to believe that student discipline behavior would be easier to manage due to having pre-determined consequences for discipline infractions. However, due to zero-tolerance policies being used for a wide variety of discipline infractions, schools were using these policies more to manage student misbehavior, thus taking away school principal's abilities to use their discretion. (Evans \& Lester, 2012). Schools and principals that use zero-tolerance policies to manage student misbehavior may see an increase in student out-of-school suspensions. If a policy calls for a student suspension for a specific infraction, then it is the responsibility of the principal to enforce 
the policy. Therefore, more students may be suspended out-of-school as a result of the use of zero-tolerance policies.

Student out-of-school suspensions may not only affect the misbehaving student, but this form of exclusionary discipline may also impact the entire school culture. Research shows that suspended students are affected academically and socially. These students become more at-risk of dropping out, and repeated incidents of exclusion could lead to contact with the juvenile justice system, or possible jail time (Morris \& Perry, 2014; Skiba, et al., 2014; Skiba \& Peterson, 1999; Arcia, 2006). Principals continue to suspended students out-of-school even though research shows that it is ineffective and only creates more problems among the students. Broadly, this study will look at school suspension practices and discipline procedures in sixty-eight public high schools located in a Midwestern state. Further, this study will specifically examine two questions: How principals perceive the value of school suspensions and restrictive application of zerotolerance discipline policy?

\section{Statement of the Problem}

Out-of-school suspension is one of the most commonly used forms of discipline to address student misbehavior (Allman \& Slate, 2011; Morrison \& Skiba, 2001). The practice of suspending student's out-of-school has shown to be ineffective due to the negative impact this form of discipline has on students (Reyes, 2006; Allman \& Slate, 2011; Morrison \& Skiba, 2001; Skiba \& Peterson, 1999; Rausch \& Skiba 2006). Many researchers identify the use of out-of-school suspension as being inconsistently used among schools, and the school principals that are responsible for disciplining students (Reyes, 2006). This is especially true for racial-minorities and students of low- 
socioeconomic (SES) backgrounds (Evans \& Lester, 2012; Reyes, 2006). Sullivan, Klingbeil, and Norman (2013) explain that exclusionary discipline practices are disproportionately applied to the aforementioned social classes. This could be the result of principal discretion or the more prevalent use of mandated school discipline policies. It is possible that school district policies and procedures used to address student misbehavior may be outdated and may not be the most appropriate policies used to address student misbehavior. Exclusionary practices such as out-of-school suspension continues to be utilized based on policies and procedures that may have been created many years ago. As a result of these outdated discipline practices, students are negatively impacted academically, socially, and emotionally (Morris \& Perry, 2014; Arcia, 2006). There is evidence to show that there is short and long term "negative outcomes" to suspended students.

Out-of-school suspensions used to manage student misbehavior remains the most severe disciplinary measure that school administrators can use as exclusion continues to be a "substantial component of discipline" in public schools (Skiba, el al., 2014, pp. 640). These suspensions often times are the result of the use of zero-tolerance policies.

It is critically important that school administrators are properly trained to use appropriate discretion when managing student misbehavior. Exclusionary discipline was intended to be used for severe offenses; however, due to zero-tolerance policies, out-ofschool suspension is more commonly used as a discipline consequence to address student misbehavior that is considered to be minor (The American Academy of Pediatrics, 2013). There has been a lot of research conducted on the impact that exclusionary practices have on the students receiving an out-of-school suspension. However, there is little research on 
how exclusionary practices impact school climate. Removing a student from the regular school stetting may be detrimental to the overall school environment. A student who is suspended creates perceptions of a negative school climate (Skiba, et al., 2014; Steinberg, Allensworth, \& Johnson, 2013; Wallace, et al., 2008). This negative perception may not be the same at all schools. Some factors that could impact the school climate or culture negatively could be the size of the school. Schools with a small student population may be affected more by student out-of-school suspensions compared to those schools with a large student population. Also, the type of student who is disciplined could have more of an impact. For instance, a star athlete that gets suspended may have more of a negative impact on the entire school than will a student who is not well known or isn't involved in any clubs or organizations. School administrators should understand the negative impact that student suspensions have on the school culture. The impact suspensions have on the school culture must be considered when using discretion to address student misbehavior. This study will help identify characteristics that impact a principal's decision to use outof-school suspension as a consequence to student misbehavior.

School administrators that often use exclusionary discipline practices to address negative student behavior are not only negatively impacting the student and the school culture; they may also be diminishing others' perceptions of their ability to effectively lead the school. The decision to suspend a student out-of-school should be used only as a last resort (American Psychological Association, 2008). However, zero-tolerance policies do not allow for principal autonomy when deciding to suspend a student. Instead, the consequence for misbehavior is predetermined and ultimately, means some form of exclusion from school. Schools and principals that incorporate the use of zero-tolerance 
policies to address misbehavior does not allow principals to be able understand all of the circumstances of a discipline situation. Therefore, taking the freedom away from principals to use their discretion when deciding the most appropriate consequence for discipline infractions. Researchers, now, are placing more of an emphasis on student characteristics that may have influenced the negative behavior. School administrator's that use zero-tolerance policies do not have the flexibility to understand why a student is displaying disruptive behavior; therefore, strategies or interventions may not be in place for correcting this behavior. The problem with zero-tolerance policies is that they are implemented and used as a deterrent for behaviors that may not have an impact on school safety (Wallace, et al., 2008). In recent years, "schools have increasingly relied on suspensions" as a form of discipline for a wide range of school rules and student misbehavior. This trend of increasing student suspensions needs to change. Principals using mandated predetermined disciplinary consequences such as zero-tolerance policies to manage student misbehavior should understand that these policies do not deter student misbehavior (Hoffman, 2014).

\section{Purpose of the Study}

The purpose of this study was to analyze principal use of out-of-school suspension as a form of discipline for student misbehavior. A deeper analysis focused on principal discretion and the impact that mandated policies with predetermined consequences may have on the disciplinary decision-making process. "Little research exists" on the discretion used by principals when determining the appropriate discipline consequence for misbehaving students (Findlay, 2015). This study may help identify characteristics of decision making when out-of-school suspensions are a result of 
principal use of discretion. It is possible that this study will show that the use of out-ofschool suspensions as a form of discipline is ineffective and may have a negative impact on a student's attitude towards school and academic performance. Arcia (2006) states that student suspensions are counterproductive, and they negatively impact student academic achievement. Several researchers have proven this to be true. Morris and Perry (2016) have conducted years of research on the impact that out-of-school suspensions have on the academic achievement of different races. Dunbar and McNeal (2010) discuss how students from lower socioeconomic families are suspended out-of-school more frequently. Morris and Perry (2016) have been helpful in the review of literature on the racial disparities and student out-of-school suspensions. Other researchers have found that suspensions not only negatively impact students, but they also have a negative impact on the school culture. Morris and Perry (2014) discuss "collateral consequences" of student suspensions and how those suspensions impact others within the school. Furthermore, Roby (2004) explains how students who are absent from school are more at risk to have poor academic achievement due to the student not being in attendance at school.

Suspending a student out-of-school further impacts the student's daily attendance. This could be a systematic issue as schools are held accountable for overall student daily attendance by the State Department of Education. The decision to suspend a student could have differing effects based on the size of student population of that school. For larger schools, the overall impact of suspending students may not as detrimental as a student suspension may be at smaller schools. This may be due to the fact that a larger population of students do not notice or feel the impact of a student that is suspended. 
Whereas at a small school, it is possible that students may notice if a student has been suspended and this could have a negative impact on how the school is viewed. High schools within this study that only have a couple hundred students may be impacted more negatively with student suspensions. For a smaller school to suspend five students would mean a much higher percentage of the student population who has been suspended compared to five students who are suspended at a larger school with a student population over 1,000. The researcher in this study considered the impact that suspensions may have on both small and large schools in the southeast region of a Midwestern state. It is the belief of the researcher that principal perception could be impacted based on the size of their school's student population. Large schools will likely see more students committing school infractions which may result in a suspension. Therefore, principals in large schools will ultimately be tasked with using their discretion more frequently. Whereas small school principals may not see as many discipline infractions involving a suspension as a result of their use of discretion.

\section{Research Questions}

The research questions that are appropriate and will guide this study are:

1. Why do high school principals choose to use out-of-school suspension as a form of student discipline?

a. What are high school principals' perception on the use of out-ofschool suspension as a form of student discipline?

b. Is the use of out-of-school suspension a result of principal discretion, or mandated policies with pre-determined consequences? 
c. What characteristics influence the discretion used by principals when using out-of-school suspension as a form of discipline?

d. Do principals of large enrollment high schools in the southern region of a Midwestern state rely on strict application of zerotolerance policies related to out-of-school suspensions than principals of small enrollment high schools in the southern region of a Midwestern state?

e. Do principals of large enrollment high schools in the southern region of a Midwestern state rely on professional discretion related to out-of-school suspensions than principals of small enrollment high schools in the southern region of a Midwestern state?

f. Do principals of large enrollment high schools in the southern region of a Midwestern state rely on the student's patronage of influential adults related to out-of-school suspension than principals of small enrollment high schools in the southern region of a Midwestern state?

\section{Theoretical Framework}

Deterrence theory will serve as the theoretical framework for this study. The advocacy/participatory approach will be used for the research inquiry as the researcher aims to reform current discipline practices used by school principals. Creswell (2009) describes the worldview of advocacy/participatory as a way to advocate through "an action agenda to help marginalized people" (p. 9). This study is designed to bring change to the lives of the participants and the institutions in which the participants work 
(Creswell, 2009). The researcher in this study will analyze the use of out-of-suspension to determine whether the data collected aligns with empirical evidence that suspensions are unnecessarily used and that there may be a lack of consideration by principals given to alternative discipline consequences.

\section{Deterrence Theory}

Public school districts adopt board policies that have punitive consequences for students when these policies are violated. It is the belief of the researcher that the consequences for policy violations are meant to punish students for misbehavior as well as deter other students from misbehaving or violating school policies. This belief can be framed through the lens of Deterrence Theory. This theory developed within the criminal justice system and under the concept that people will not commit crimes because there are sanctions and consequences for doing so (Mathews \& Agnew, 2008). The connection between Deterrence Theory and public schools is that students will not misbehave because they understand they will receive the consequences associated with the misbehavior. The perception of the consequences impacts a student's decision to follow school rules. Students who do not follow school rules will be punished. For the sake of this study, that punishment may result in an out-of-school suspension. The use of out-ofschool suspensions as a form of discipline can be seen as a "get-tough" approach to managing student misbehavior (Skiba \& Peterson, 1999). Furthermore, the use of exclusionary discipline may be perceived by school principals as a deterrent to future behavior problems. It is assumed by principals that "removing students from school will deter other students from engaging in similar behavior" (Koon, 2013). 
Out-of-school suspensions may not always be the best form of punishment. Current research provides recommendations and alternative forms of discipline when dealing with students who violate school rules. Dupper, Theriot, and Craun (2009) outline forms of discipline that would reduce the number of out-of-school suspensions. Losen and Martinez (2013) discuss how student suspensions occur too frequently. Suspensions put students further behind, therefore, affecting their academic progress and achievement. Alternatives to out-of-school suspension may help address this concern. At the same time, these alternatives may be more beneficial to the school learning environment. At the conclusion of this study, it is possible that recommendations for alternative consequences to out-of-school suspension may be provided. Alternatives to out-of-school suspension can be utilized when principals are allowed to use their discretion, whereas zero-tolerance policies do not allow principal's the autonomy to make the most appropriate discipline decision. Zero-tolerance policies require principals to assign a mandated pre-determined consequence associated with the behavior covered by the zero-tolerance policy, which ultimately, results in an out-of-school suspension. This study will show that zero-tolerance policies are not an effective philosophy to address student misbehavior and that the use of principal discretion is more appropriate.

\section{Design of the Study}

The type of information that will be expanded upon in this study will be the use of out-of-school suspension by school principals, specifically principals' use of discretion in discipline decision making. Furthermore, the use of mandated policies with predetermined consequences will be investigated to determine principal perceptions on the use of such policies. Principal perception on student suspensions will also be 
analyzed. In order to obtain principals' perceptions on the use of out-of-school suspension as well as the use of principal discretion, this study applied a mixed method approach to collect and analyze data. A mixed method approach to research uses and combines both qualitative and quantitative research designs (Creswell, 2009). This approach is beneficial because it allows the researcher to develop a better understanding of a phenomenon while increasing the overall strength of the study that would not be possible by only conducting research either quantitatively or qualitatively (Creswell, 2009). For the purpose of this study, quantitative data was gathered and analyzed using a traditional survey instrument of school principals. Qualitative data collection was gathered from interviews of school principals. The data gathering procedure was based on the sequential explanatory mixed methods strategy. The purpose of using the sequential explanatory strategy is to allow the researcher the ability to "expand on the findings of one method with another method" (Creswell, 2009). In this case, the data collection and analysis through principal interviews (qualitative) during the second phase of the study was used to build upon the data collection and analysis through the use of a survey instrument (quantitative) during the first phase of the study.

Research was conducted using the grounded theory methodology. Grounded theory is a strategy of inquiry that can be described as "grounded in the data systemically gathered and analyzed" (Corbin \& Strauss, 1994). This process allows the researcher to identify categories and make connections between those categories. It is a process of constant refinement and data comparison of emerging categories to maximize the similarities and differences of information being gathered (Gentles, Charles, Ploeg, and McKibbon, 2015; Creswell, 2009). Researchers using this methodology are looking to 
identify or develop themes and categories, ultimately with the intent to develop new theories to describe to the phenomena. It is a flexible method for developing theory as it relates to social processes. This particular study using the grounded theory methodology will occur in a "bounded context" (Merriam, 2009). The bounded system is selected for this study for the purpose of the researcher only wanting to survey and interview principals in the southeast region of a Midwestern state. Therefore, there is a limit to those participating and a boundary has been established for gathering data.

\section{Site Description and Setting}

This study was bounded by the counties in the southeast region of a Midwestern state as defined by this Midwestern state's Regional Professional Development Center and include all public high schools within this boundary. There are over 80 school districts within this region and 68 of the districts have public high schools which served as the main target of data collection. All of the high schools have similar if not the same school district disciplinary policies as defined by or advised by the Midwestern states School Board Association. These schools are similar in their demographics: student population, socio-economic status, and ethnic subgroup sizes. This study analyzed the use of out-of-school suspension as a form of student discipline as well as the perception of out-of-school suspension by the principals leading these schools. Purposeful and convenient sampling was used to select participants. A convenience sample was used due to the participants being easily accessible (Fink, 2017; Creswell, 2009). With purposeful sampling, participants were chosen because of their ability to provide the best data for the researcher to understand the phenomena while helping to answer the research questions. (Creswell, 2009). 


\section{Participant Sample}

The number or participants for this study have been identified to include all secondary principals at public high schools in the southeast region of a Midwestern state. Purposeful sampling was utilized in this study to determine school principal perception of out-of-school suspension as a form of school discipline. Merriam (2009) states that purposeful sampling is an effective method for a qualitative study. There were 58 principals that participated in the survey instrument which was created using Qualtrics. The participants that were selected for the interviews were based on convenience sampling. All participants were asked through the survey if they would volunteer to participant in a follow up interview. There were 16 principals that volunteered to participate in a follow up interview. Of those, seven principals were contacted and interviewed as part of this study. The researcher tried to contact three other principal's, but was unsuccessful. The other participants were selected based on their ability to provide the most appropriate information for the researcher to be able to answer the research questions.

\section{Data Collection}

Data collection consisted of a survey instrument that was distributed to principals through email. The survey was created using Qualtrics and its intended purpose was to help determine "trends, attitudes, or opinions" of school principals and the use of out-ofschool suspension (Creswell, 2009). It was anticipated that the survey would produce data quickly due to the convenience to the participants. Each participant that received the survey was provided with a consent statement which allowed them to withdraw at any time. The participants gave consent to the researcher when they choose to participant and 
complete the survey. Gaining participant consent is important because it informs the participants of their rights and helps to ensure that the researcher respects those rights (Seidman, 2012). Due to the sensitivity of the information gathered within the study, some schools and principals may not have been willing to participate in parts or all of the study. When conducting this research, it was important for the researcher to utilize techniques that ensured the participant's privacy was protected, and the information gathered will be used as originally stated (Fink, 2017) Ensuring participant privacy and confidentiality is critically important, especially when using surveys (Fink, 2017). It was the intent of the researcher to contact as many school principals as possible within the southeast region of a Midwestern state. Since the researcher currently serves as a school principal within this region, data was collected from principals to whom the researcher may have previously established a professional relationship with. The connection to these principals could have had an impact in the number of principals that participated in this study. However, the relationship with the researcher and the participants within this study could have been a conflict of interest, thus providing a limitation to the study. The survey served as the first method of data collection. The selection of participants for the survey distribution was a non-probability sampling; more specifically, convenience and purposive sampling as the population was easy to reach through email. Once survey results were collected and analyzed, follow-up interviews were conducted for the researcher to collect the necessary qualitative data for the study. The participants for the interview portion of this study were selected using purposeful sampling. 


\section{Data Analysis}

This mixed methods approach consisted of a survey instrument using Qualtrics and interviews which produced the data critical to the research questions. Quantitative data was analyzed using Qualtrics. Qualitative data through interviews were conducted on seven acting school principals. Seidman (2012) discusses how interviews are a great way for others to tell a story. Furthermore, interviewees can "symbolize their experience through language" (Seidman, 2012). This provides the interviewer with authentic responses from individuals who have or have had an experience with the topic being studied. Interviews lasted between 10 and 30 minutes. Participants were allowed to talk as long as they wanted so as long as they were engaged in the interview and providing good data. Seidman (2012) acknowledges that those who are beginners at conducting interviews tend to seek out participants that they already have established a relationship with. He continues by stating that these interviews can be more challenging to conduct (Seidman, 2012). It was the intent of the researcher to select participants to which the researcher does not know personally or professionally. Of the seven interviews, the researcher did not have any prior working relationship with five of the participants. Interview questions were developed and aligned to the central research questions. Respondents' answers to the interview questions were recorded and transcribed. Coding was used to analyze the data collected from the interviews. Coding is the process of assigning a description, word, phrase, or theme to the data so that the researcher can easily "retrieve specific pieces of the data" (Merriam, 2009). Merriam (2009) further explains that coding is the process of marking notations next to the data gathered to determine if it is relevant information as it pertains to the research questions. This process 
helps the researcher make connections with the information gathered through interviews as well as the surveys.

A survey instrument was used for this study to collect information "directly from people" with knowledge of the topic being studied (Fink, 2017). The survey was distributed through email and included a section describing the consent that would be granted if the participant chose to complete the survey. The survey consisted of 34 items and the subject pool consisted of a convenient sampling given to secondary school principals, grades 9-12. Survey items focused on principal's use of out-of-school suspension as a form of discipline. Furthermore, items were specific to principal's discretion when determining student discipline. Data collected assisted the researcher in being able to better understand principal's philosophies as instructional leaders and school managers as well as the impact that suspensions may have on the schools they lead. The survey items that served as the quantitative data in this study were created using a Likert scale. This data was used to look for patterns and/or themes that relate to or correlate with the qualitative data that was collected. The use of surveys, interviews, and the review of literature was used to increase credibility. This is defined by Merriam (2009) as triangulation, which is the use of three methods of data collection for the purpose of comparing and cross-checking data.

\section{Limitations}

This study was conducted on principals serving in school districts located in the same region as the primary researcher, who is also a principal. Participants may not have been willing to provide accurate or reliable information due to the possibility that information may portray their leadership ability or their school district in a negative way. 
This study is specific to out-of-school suspensions and principals' perception of the use of this form of student discipline. Principal discretion in this study could produce mixed results due to decision making being subjective and the fact that each discipline infraction may contain multiple circumstances that lead to the misbehavior by student(s). Findlay (2015) mentions that decisions are made within a context that is established by social, organizational, individual, and other values. Principals have to take several factors into consideration when choosing to use out-of-school suspension as a form of discipline. The sample size or participation of principals could also be a factor that could limit desirable results. Lastly, the researchers own bias as an acting principal should be considered as a limitation due to the researchers experience and philosophy on education; however, all considerations were made to ensure that the researcher's bias was not present in this study. Another form of bias that could be present in this study is convenience sampling. This type of sampling defined as by Fink (2017) is "unconvincing unless you prove otherwise". Strategies were used to ensure credibility in the sampling of participants.

\section{Assumptions}

The decision to suspend a student out-of-school will deter students from misbehaving as well as deterring the defending student from engaging in the same behavior that resulted in a suspension. Principals who use exclusionary discipline may be doing so in-order to send a message to other students that if you engage in this type of negative behavior than the outcome will be severe in nature. Due to the seriousness of exclusionary discipline and the negative connotation that may exist with its use, it's critical that principals who participate in this study were honest with their responses. 


\section{Definition of Key Terms}

Definition of terms is intended to define special terms in this study that may be used differently in the discipline or are different from those in common use. For example, zero-tolerance has a different meaning for law enforcement than it has for schools. The following terms will be used frequently in this study.

Discipline Policies: School district policies "adopted by the Board that establish the framework for what is to be done" (States School Boards' Association, 2000). These policies and procedures can also be called the student code of conduct. They describe discipline infractions, what constitutes an infraction, and what the possible consequences may be for that infraction.

Exclusionary Discipline Policies: "Discipline codes that address the consequences, including suspension and expulsion, for students whose conduct" results in a violation of such policies. (States School Boards' Association, 2000).

In-school-Suspension: A form of discipline where the student is removed from the traditional classroom setting and instead is educated in an alternative classroom. Students may receive varying "lengths of time" in ISS, "ranging from part of the day to several days". (Blomberg, 2003).

Out-of-school Suspension: A form of discipline where the student is removed from the school setting in an "effort to maintain a safe school environment" (Allman \& Slate, 2011). The suspended student is not allowed back onto school property until the conclusion of the suspension.

Traditional Education Setting or Education Setting: The learning environment that all students have access to within a public school. This means that each 
student that attends school will receive a free and appropriate public education and will be granted the same access to classroom teachers, instruction, and school personnel.

Principal Discretion: School principal's use of personal judgement when deciding outcomes to student misbehavior (Findlay, 2015)

Zero-tolerance Policies: mandatory discipline policies with pre-determined consequences used to address student misbehavior in school (Payne \& Welch, 2017; Rausch \& Skiba, 2006; Evans \& Lester, 2012; Skiba \& Peterson, 1999; American Academy of Pediatrics, 2013; Hoffman, 2014).

\section{Significance of the Study}

The significance of this study was to analyze the use of out-of-school suspension as a form of student discipline. Little research has been conducted on the "exercise of discretion by principals in their disciplinary decision making" (Findlay, 2015). This study looked at principal discretion and school discipline policies as two factors that contribute to students being suspended out-of-school. The results of this study will add to the literature that already exists regarding the use of suspensions and the negative impact on students. According to the American Academy of Pediatrics (2013), students who are suspended out-of-school are placed in the same environment that may have contributed to their negative behavior in the first place. This study will fill a gap in literature that exists when considering principal discretion and the use of out-of-school suspensions. Through this study, the researcher will analyze the use of out-of-school suspensions as a result of principal discretion as well as the use of school board policies that have pre-determined consequences. It is important to note that such board policies may be outdated. 
Much literature exists on exclusionary discipline and the negative impact this discipline consequence has on students. Researchers have discovered that exclusion not only impacts suspended students, but may also impact students who do not get in trouble while at school. Through a survey of secondary school principals, this study will help to identify important factors that impact a principal's decision to use out-of-school suspension. Also, negative student impacts may be identified from survey responses. The information gathered within this study may show a correlation between student suspensions and the negative impact suspensions have on a student's academic achievement. This is an important component to consider because students who attend schools with high suspension rates will have lower academic achievement even if they have not been suspended themselves (Morris \& Perry, 2014). The authors further explain that “...no studies have examined how non-suspended students fare in high-suspension environments..." (Morris \& Perry, 2014, p.1071). This study will not be able to fill this literature gap on the effect of non-suspended students, but it's possible that the responses from participants may show that non-suspended students are in fact impacted from the use of out-of-school suspension as a result of principal discretion or mandated, predetermined school policies. At the conclusion of this study, it is hopeful that data will provide insight into the use of out-of-school suspension and the effectiveness on the use of this form of exclusionary discipline. The recommendations provided will be supported by the data present in this study and will show that student out-of-school suspensions may be an ineffective practice of improving or changing student behavior. It is the hope of the researcher that the data contained within this study will guide school leaders and policy makers to look at changing school discipline practices and procedures. By doing 
so, school leaders will become more aware of the impact suspensions have on students and schools while also helping principals improve their decision making when considering whether to suspend a student. As a current school principal located in the same region as the principals being surveyed, the researcher intends to use this data to show other school leaders alternative forms of discipline that may be more effective in managing student misbehavior. Data collected in this study has identified characteristics that may impact principal discretion and this information may be beneficial in improving the decisions made by principals who are considering discipline consequences to address student misbehavior.

\section{Summary}

Federal regulations and mandates established by the Department of Education have been put in place to guide state education agencies in their pursuit to educate students while providing safe learning environments. These regulations and mandates impact local school districts in each state and the principals tasked with enforcement. Local school districts have some freedom as well as the responsibility to develop school board policies and procedures that meet the requirements set forth by their respective state, at the same time, meeting the needs of their local school and community. School leaders must be knowledgeable in implementing these policies and procedures so that they can meet the needs of each student, especially when it involves disciplining students for misbehavior. School board policies that have been adopted to address student discipline should be specific and allow for school administrators to be able to enforce such policies using their discretion when managing instances of student violence or other treats to student safety. Principal discretion was analyzed to determine how out-of-school 
suspensions are utilized in public high schools as well as the impact zero-tolerance policies have on the decision making-process.

As research has shown, out-of-school suspension may not be the most effective form of discipline (Morrison \& Skiba, 2001; Massar, McIntosh, \& Brent, 2015; Rayes, 2006; Allman \& Slate, 2011; Skiba \& Peterson, 1999; Rausch \& Skiba 2006). Therefore, if certain characteristics influence principal decision making and allow for students to be suspended, then considerations should be made to ensure that appropriate decisions are being made when addressing student misbehavior. The same could be said for discipline policies that may be outdated or poorly written. Skiba, et al. (2014) states that if schools determine that certain school characteristics are factors that influence student suspensions, then school policies and practices may need to be modified or changed. School districts must be willing to look at their current discipline policies and determine if they are appropriate and effective. It may be necessary that schools identify alternative forms of discipline when addressing negative student behavior. This study will help professionals within the field of education understand the impact that outdated school policies may have on student discipline. It is the intent of the researcher to provide an analysis of school principal's perception on the use of out-of-school suspension as well as the established board policies that impact the discretion used when deciding whether to suspend a student for misbehavior. 


\section{References}

Allman, K.L., \& Slate, J.R. (2011). School discipline in public education: A brief review of current practices'. International Journal of Educational Leadership Preparation, V.6 (2).

American Academy of Pediatrics. (2013). Out-of-school suspension and expulsion. Council on School Health. Pediatrics 2013; 131; e1000. doi: 10.1542/peds.20123932

American Psychologist Association Zero-tolerance Task Force (2008). Are zerotolerance policies effective in the schools? An evidentiary review and recommendations. American Psychologist, 63(9), 852-862. DOI: 10.1037/0003066X.63.9.852.

Arcia, E. (2006). Achievement and enrollment status of suspended students: Outcomes in a large, multicultural school district. Education and Urban Society 38:359-69. SAGE. doi:10.1177/0013124506286947

Balfanz, R., Byrnes, V., \& Fox, J. (2014). Sent home and put off-track: The antecedents, disproportionalities, and consequences of being suspended in the ninth grade. Journal of Applied Research on Children: Informing Policy for Children at Risk, 5(2), Article 13.

Blomberg, N. (2003). Effective discipline for misbehavior: In school vs. out of school suspension. Concept: An Interdisciplinary journal of graduate studies. Villanova University.

Brent, J.J. (2016). Placing the criminalization of school discipline in economic context. Punishment \& Society, 18(5) 521-543. SAGE. doi 10.1177/1462474516642858 
Corbin, J., \& Strauss, A. (1994). Grounded theory methodology. Handbook of qualitative research, 17, 273-285

Creswell, J.W. (2009). Research design: Qualitative, quantitative, and mixed methods approaches. ( ${ }^{\text {rd }}$ Ed.). Los Angeles, C.A. SAGE

Dunbar, C., \& McNeal, L. (2010). In the eyes of the beholder: Urban student perceptions of zero-tolerance policy. Urban Education. 45(3) 293-311. SAGE. DOI: $10.1177 / 0042085910364475$

Evans, K.R., \& Lester, J.N. (2012). Zero-tolerance: Moving the conversation forward. Intervention in School and Clinic. 48(2) 108-114. SAGE. DOI: $10.1177 / 1053451212449735$

Findlay, N.M. (2015). Discretion in student discipline: Insight into elementary principals' decision making. Educational Administration Quarterly. 51(3) p. 472-507. SAGE. DOI: $10.177 / 001316 X 14523617$

Fink, A. (2017). How to conduct surveys: A step-by-step guide. Sage Publications.

Gentles, S. J., Charles, C., Ploeg, J., \& McKibbon, K. A. (2015). Sampling in qualitative research: Insights from an overview of the methods literature. The Qualitative Report, 20(11), 1772-1789. http://nsuworks.nova.edu/tqr/vol20/iss11/5

Hoffman, S. (2014). Zero benefit: Estimating the effect of zero-tolerance discipline policies on racial disparities in school discipline. Educational Policy 28(1) 69-95. SAGE. doi: 10.1177/0895904812453999

Massar, M.M., McIntosh, K., \& Eliason, B.M., (2015). Do out-of-school suspensions prevent future, exclusionary discipline? Positive Behavior Interventions \& Supports, 2015. 
Mathews, S.K. \& Agnew, R., (2008). Extending deterrence theory: Do delinquent peers condition the relationship between perceptions of getting caught and offending? Journal of Research in Crime and Delinquency, 45(2), 91-113

Merriam, S. B. (2009). Qualitative research: A guide to design and implementation. San Francisco, CA: Jossey-Bass.

Morris, E. \& Perry, B. L (2014) Suspending progress: Collateral consequences of exclusionary punishment in public schools. American Sociological Review 79:1067-87. Oxford Press. doi: 10.1177/0003122414556308

Morris, E. \& Perry, B. L. (2016). The punishment gap: School suspension and racial disparities in achievement. Social Problems 63(1): 68-86. Advance Access. doi:10.1093/socpro/spv026

Morrison, G.M., \& Skiba, R. (2001). Predicting violence from school misbehavior: Promises and perils. Psychology in the Schools, 38(2), 173-184. Doi:10.1002/pits.1008

Payne, A.A. \& Welch, K., (2017). The effect of school conditions on the use of restorative justice in schools. Youth Violence and Juvenile Justice, 1-17. DOI: $10.1177 / 1541204016681414$

Rausch, M. K., \& Skiba, R. J. (2006). Exclusion is not the only alternative: The children left behind project. Discipline, achievement, and race: Is zero-tolerance the answer? Early Childhood Research Quarterly 105-126.

Reyes, A. H. (2006). Discipline, achievement, and race. Lanham, MD: Rowman \& Littlefield. Reynolds, AJ (1992). Comparing measures of parental involvement 
and their effects on academic achievement. Early Childhood Research Quarterly, 7(3), 441-462.

Roby, D. E. (2004). Research on school attendance and student achievement: A study of Ohio schools. Educational Research Quarterly, 28(1), 3.

Seidman, I. (2012). Interviewing as qualitative research: A guide for researchers in education and the social sciences $\left(4^{\text {th }} \mathrm{Ed}\right.$.). New York, NY: Teachers College Press.

Skiba, R.J. (2000). Zero tolerance, zero evidence: An analysis of school disciplinary practice. Policy Research Report, Indiana Education Policy Center, Smith Research Center, August, 2000.

Skiba, R.J., \& Peterson, R. (1999). The dark side of zero-tolerance: Can punishment lead to safe schools? Phi Delta Kappan, 80(5), 372-376.

Skiba, R.J., Chung, CG., Trachok, M., Baker, T.L., Sheya, A., Hughes, R.L., (2014). Parsing disciplinary disproportionality: Contributions of infraction, student, and school characteristics to out-of-school suspension and expulsion. American Educational Research Journal, 51(4), 640-670. doi:10.3102/0002831214541670

Steinberg, M.P., Allensworth, E., \& Johnson, D.W., (2011). Student and teacher safety in Chicago public schools: The roles of community context and school social organization. May 2011. Consortium of Chicago of School Research at the University of Chicago Urban Education Institute.

Sullivan, A.L., Klingbeil, D.A., \& Van Norman, E.R. (2013). Beyond behavior: Multilevel analysis of the influence of sociodemographics and school 
characteristics on students' risk of suspensions. School Psychology Review, 42(1), pp. 99-114.

Wallace, J.M., Jr., Goodkind, S.G., Wallace, C.M., \& Bachman, J. (2008). Racial, ethic, and gender differences in school discipline among American high school students: 1991-2005. Negro Educational Review, 59, 47-62. 


\section{SECTION TWO:}

PRACTITIONER SETTING FOR THE STUDY 


\section{Introduction}

Public schools have the responsibility of educating all students who live within the boundaries of the local school district. Students are required to attend school up until the age of 17 (SDOE website, 2019). This includes students of varying demographics such as students of different ethnicities, nationalities, differing levels of socio-economic status, and differing needs, etc. Public schools cannot deny a student from enrolling into the local school district as long as that student lives within the boundaries of the school district. One exception that may prohibit a student from being able to enroll would be a previous discipline infraction that is classified as a violation of the Safe School Act or if a student was expelled from another school district due to a serious discipline infraction. A safe school's violation is the result of a student committing one of eight violent offenses as determined by law and the Safe Schools Act that was established within this state (SDOE, 2018). It is the responsibility of school districts to enroll students as quickly as possible in order to decrease the amount of time that a student is out of the classroom; therefore, impacting the learning of that student.

As part of the enrollment process, students and their parents/guardians are presented with a student handbook that outlines the expectations, policies, and procedures of that particular school and school district (Shaughnessy, 2002). It is the responsibility of the student to know and understand the expectations as outlined within the handbook which serves as the "operational policies and procedures" of the school (Shaughnessy, 2002). Many schools require a student and/or a parent signature acknowledging that the student has knowledge of and is aware of the expectations and policies of the school to which they will attend. Students and parent's acknowledgement of the expectations 
within handbook is designed to inform families of important information such as discipline policies and procedures. This can be described as the student code of conduct (Hoffman, 2014). By signing this document, students and parents acknowledge that they are aware of the school's discipline policies and the consequences associated with student misbehavior.

The student handbook serves as the driving force for student discipline within each school. The main purpose of providing families with discipline policies and procedures prior to enrollment is to ensure that students understand the consequences that would follow discipline infractions. It is important to note that discipline procedures contained in the student handbook only serve as a guide for school principals. These procedures are created by the local school boards and are broad in nature so that principals have some autonomy to use their discretion when disciplining students for misbehavior. Consequences listed for most infractions allow principals to use their discretion to determine the most appropriate consequence to address student misbehavior. However, there are certain discipline infractions listed in the student handbook where the consequence is determined by a mandated policy that has a pre-determined consequence. Principals must adhere to the exact language contained within the established discipline policies created by the school board and, when necessary, their discretion must be used appropriately and fairly when managing student misbehavior and deciding the most appropriate consequence.

\section{History of the Organization}

The Constitution of this Midwestern state includes a requirement of establishing a governing board and states that "the supervision of instruction in the public schools shall 
be vested in a state board of education" (SDOE website, 2019). The State Board of Education has "general authority" over all public schools from preschool to post-secondary (SDOE website, 2019). This study will focus on the principals at the secondary level, grades 9-12. The state Board of Education sets the operational policies for the State Department of Education (SDOE, 2018). DOE is the agency tasked with carrying out these policies set forth by the state board as this agency "works with educators, legislators, government agencies, community leaders, and citizens to maintain a strong education system" (SDOE, 2018). All public k-12 school districts in this Midwestern state must adhere to the policies and regulations that have been put in place by SDOE. Policies provide guidance for school districts to operate as effective instructional institutions. For the purpose of this study, policies related to student discipline will be examined. More specifically, the discretion used by school principals as well as the mandated discipline policies with predetermined consequences will be more closely analyzed.

\section{Organizational Analysis}

This study consisted of an analysis of high school principals currently serving in public high schools (9-12) located in the southeast region of a Midwestern state. There are 68 high schools within this region. Not all high schools were represented in this study. The student population of the schools in the southeast region of this Midwestern state range from 100 students to 1,832 students. These high schools, like all other public high schools in this state seek the services of the State's School Board Association (SSBA) for general guidance. SSBA is the governing body that oversees the State Department of Education (SSBA, 2017). It is the responsibility of SSBA to implement state and federals laws and policies as they relate to the State's public school districts (SSBA, 2017). Local school 
districts align their policies and procedures based on the recommendations provided by SSBA. When new legislation is passed from the state government or important school related issues arise, SSBA develops school policies to provide "general guidance" to school districts as they work to adopt and develop their own policies which helps manage each school within the school district (eBOARDsolutions.com, 2017). Public schools have very similar, if not the exact same policies, especially policies that are specific to the management of student behavior. Certain policies are exactly the same in each district because these policies are required by state or federal laws and regulations (eBOARDsolutions.com, 2017). The policies used for school district operations are the foundation of effective school management. Once policies are implemented, it then becomes the responsibility of the school principal to appropriately interpret and adhere to those policies. School leaders who do not follow local school board policies increase the chance that a lawsuit will be filed against the school district for being negligent or noncompliant.

This study looked at the use of out-of-school suspension and whether the decision to suspend a student is more of a result of principal discretion or if suspensions are more of a result school district discipline policies that require a mandated, predetermined consequence. A deeper analysis looked at the discretion used by principals in their discipline decision making as well as principal's perception on the use of out-of-school suspensions. The researcher looked to identify why principals use suspensions and their overall opinion on its use as a form of discipline. The discretion used by principals who enforce discipline policies was studied to see if inconsistent use was present in the enforcement of such policies. School discipline data was analyzed to see what factors may 
have impacted a principal's decision to suspend a student and whether principals feel the use of suspension is an appropriate and effective consequence for student misbehavior.

\section{Leadership Analysis}

Each school district in this Midwestern state has a local school board consisting of elected community members living within that district. These individuals ensure that the policies established by SDOE and SSBA are being implemented and properly managed by school district administrators. School district leadership begins with the position of superintendent. School superintendents are the "primary educational leader" as this position is considered the "chief administrative officer of the entire school district" (Kowalski, 2006). Larger school districts require additional administrators to help with the management of the school district. Typically, large school districts will have assistant or associate superintendents to assist the superintendent. There are many responsibilities in large school districts; therefore, superintendents need assistants to help with the operation and management of the district.

To help with effective school management, superintendents rely on building level administrators, or principals. Superintendents are tasked with managing the entire school district whereas principals only focus on their individual school building(s). School principals must have a master's degree or higher with an emphasis in education administration and must obtain administrator certification through SDOE. Some schools may only have one principal responsible for managing the school. However, in larger schools, principals rely on assistant principals to help with day to day management. The more administrators that work within a school district or school building, the more contrasting their leadership styles may be. Consistency is crucial when working with 
people and ensuring that school rules and regulations are properly managed. This is especially true when dealing with students that display inappropriate behavior that may result in discipline. School principals must treat all students fairly and with equity when determining the most appropriate discipline consequence. Failure to do this could result in a negative school culture. This is especially true in school districts that have high rates of student discipline resulting in out-of-school suspensions (Skiba, et al. 2014). Principals' decision to use out-of-school suspension as a form of discipline as well as principal perception of out-of-school suspension was addressed in this study.

\section{Implications for Research in Practitioner Setting}

The use of exclusionary practices such as out-of-school suspension as a form of discipline is "still remarkably high" within public schools (Payne and Welch, 2017). As Brent (2016) discussed, schools are using "harsher forms of punishment" such as out-ofschool suspension to discipline students who violate school policies. Exclusionary discipline used by school officials may be a result of mandated school policies that have predetermined consequences. (Evans and Lester, 2012; Payne and Welch, 2017; American Academy of Pediatrics, 2013; Skiba, et al. 2014; Morris \& Perry, 2014; Hoffman, 2014). These mandated polices can be described as zero-tolerance policies.

\section{Zero-Tolerance Policies}

School districts have the responsibility to use all means necessary to maintain "safe and disciplined learning environments" (APA Zero-tolerance Task Force, 2008). Increased pressure to address acts of violence led to the Gun-Free Schools Act of 1994 which required a one-calendar year expulsion for the possession of a fire arm and in recent years, amendments to this bill expanding to include any "instrument that may be 
used as a weapon" (Skiba, 2000.) The Gun-Free Schools Act of 1994 can be considered the most important contributing factor to the use of zero-tolerance policies in schools. As years went by, schools began implementing zero-tolerance policies for lesser violent offenses which may include but not limited to: drug and alcohol use or possession, threats, fighting, or defiant behavior (Skiba, 2000; Rausch \& Skiba, 2006; Hoffman, 2014; Evans \& Lester, 2012). As zero-tolerance policies were being used more and more to address a variety of minor offenses, these policies became the norm in public schools as a way to address student misbehavior (Skiba, 2000; Evans \& Lester; Skiba, et al., 2014). The increased use of these policies placed more responsibility on school principals and teachers to follow these polices to manage students and protect the safety of the school. The responsibility to create safer schools became more challenging for principals to address in recent years due to severe acts of violence occurring in schools including mass school shootings.

One of the most analyzed historical events involving a mass school shooting occurred in April of 1999 at Columbine High School in Colorado. The tragedy that took place at Columbine claimed the lives of 12 students and one teacher and heightened the pressure on public schools to implement safety measures to try and avoid future incidents where acts of violence pose a threat to the safety of others. However, even with the use of zero-tolerance policies, school shootings continue to occur including one of the most recent mass shootings which occurred in Parkland, Florida. This school shooting resulted in the death of 17 students and staff. These severe acts of violence continue to make school leaders and students nervous about the potential threat of violence in their own schools (Skiba \& Peterson, 1999). Therefore, school districts continue to take an 
aggressive approach by implementing proactive strategies to "preserve the safety of students" and staff on school grounds. These strategies may include increased security measures, the hiring of school resource officers, and aggressive discipline policies such as zero-tolerance policies. These policies were established so that harsh punishment would be used to address acts of violence and create safer learning environments. Zerotolerance policies may seem appropriate in theory, but there is a lack of "empirical support" showing that these policies are effective in establishing safer schools (Mayer \& Jimerson, 2018). Zero-tolerance policies have consistently been at the center of controversy due to the fact that research has shown that these polices have not "increased the consistency of school discipline" (APA Zero-tolerance Task Force, 2008). Zerotolerance policies may be appropriate to use for violent offences that threaten the safety of students and staff, but the application of these policies for minor offenses may create inconsistencies in its use. Minor discipline infractions could be better addressed through the use of principal discretion. Zero-tolerance policies take away the ability of principals to be able to use their past experiences and discretion to make the most appropriate decision.

The use of zero-tolerance policies do not give autonomy to principals when deciding the most appropriate consequence to use when addressing student misbehavior. Thus, taking away a principal's ability to use their discretion in decision making process. Ultimately, school leaders begin following a pattern of ineffective use of school discipline consequences resulting in student exclusion from the learning environment as a result of these mandated policies. Zero-tolerance policies call for the use of exclusionary practices to address student misbehavior with the most used consequence as a result of 
these policies being out-of-school suspension. Much research has been conducted and the results have shown that out-of-school suspensions are an ineffective form of discipline. (Reyes, 2006; Perry and Morris, 2014; Evans and Lester, 2012; Payne and Welch, 2017; American Academy of Pediatrics, 2013; Skiba, et al. 2014; APA Zero-tolerance Task Force, 2008; Sullivan, et al. 2013; Arcia, 2006; Hoffman, 2014). If out-of-school suspensions are deemed to be ineffective, then mandated policies such as zero-tolerance policies may also be ineffective if such policies contribute to an increase to suspension rates. (Blomberg, 2013).

The continued use of exclusionary discipline as a result of zero-tolerance policies as well as aggressive principal discretion must be considered when addressing negative student misbehavior. Exclusionary discipline "fails to reduce school violence and misbehavior" and might even increase the "frequency" of violence and student misbehavior (Payne and Welsh, 2017). School districts and its leaders must be willing to implement other alternatives to address disruptive students. Principals responsible for managing student behavior must be willing to consider all options prior to making a decision that results in the removal of a student from the learning environment. Skiba, et al., (2014) found that out-of-school suspension rates were lower and "the use of preventative measures where more frequent" in schools where its principals felt that suspensions were unnecessary. Payne and Welsh (2017) recommend that “...schools need to reconsider their responses to student misbehavior" (p.2). Payne and Welch have done extensive research on school discipline, more specifically, the use of restorative practices as an alternative to exclusionary discipline when addressing student misbehavior. The intent of this study was not centered on alternative options to out-of- 
school suspension; however, literature review on alternative options as well as possible recommendations may be included. One particular strategy that has increasing gained attention for its effectiveness in managing student behavior is restorative practices, which are proactive strategies used to address negative student behavior. Restorative practices may be a more appropriate alternative to out-of-school suspension. Mirsky (2007) explains that "restorative practices place responsibility on the students, using a collaborative response to wrong doing" (p.6). For restorative practices to work, a philosophical shift must occur among school leaders. School principals need to be confident and willing to look at other alternatives when considering the most appropriate consequence to address student misbehavior.

\section{Summary}

Public school policies established at the federal, state, and local level were designed to ensure that school districts are consistent in their approach of providing a safe and positive learning environment. It is the responsibility of school principals to know and understand school board policies, effectively implement these policies, and use appropriate discretion when making decisions regarding the most appropriate form of discipline to use when managing student misbehavior. To effectively do this, principals must fully understand all circumstances related to each situation when principal discretion is being used to determine the outcome of student behavior. Appropriate use of principal discretion and clearly written board policies will help establish equitable, appropriate student discipline consequence to address student misbehavior. 


\section{References}

American Academy of Pediatrics. (2013). Out-of-school suspension and expulsion. Council on School Health. Pediatrics 2013; 131; e1000. doi: 10.1542/peds.20123932

American Psychologist Association Zero-tolerance Task Force (2008). Are zerotolerance policies effective in the schools? An evidentiary review and recommendations. American Psychologist, 63(9), 852-862. DOI: 10.1037/0003066X.63.9.852.

Arcia, E. (2006). Achievement and enrollment status of suspended students: Outcomes in a large, multicultural school district. Education and Urban Society 38:359-69. SAGE. doi:10.1177/0013124506286947

Blomberg, N. (2003). Effective discipline for misbehavior: In school vs. out of school suspension. Concept: An Interdisciplinary journal of graduate studies. Villanova University.

Brent, J.J. (2016). Placing the criminalization of school discipline in economic context. Punishment \& Society, 18(5) 521-543. SAGE. doi 10.1177/1462474516642858

Department of Elementary and Secondary Education, (2018). www.dese.mo.gov

Evans, K.R., \& Lester, J.N. (2012). Zero-tolerance: Moving the conversation forward. Intervention in School and Clinic. 48(2) 108-114. SAGE. DOI: $10.1177 / 1053451212449735$

Hoffman, S. (2014). Zero benefit: Estimating the effect of zero-tolerance discipline policies on racial disparities in school discipline. Educational Policy 28(1) 69-95. SAGE. doi: 10.1177/0895904812453999 
Kowalski, T.J., (2006). The school superintendent: Theory, practice, and cases $\left(2^{\text {nd }}\right.$ Ed.). Thousand Oaks, CA. Sage Publications.

Mayer, M.J., \& Jimerson, S.R., (2018). School safety and violence prevention: Science, practice and policy. American Psychological Association.

Mirsky, L. (2007). SaferSanerSchools: Transforming school culture with restorative practices. Reclaiming Children and Youth, 16(2), 5-12.

Morris, E. \& Perry, B. L (2014) Suspending progress: Collateral consequences of exclusionary punishment in public schools. American Sociological Review 79:1067-87. Oxford Press. doi:10.1177/0003122414556308

Morrison, G.M., \& Skiba, R. (2001). Predicting violence from school misbehavior: Promises and perils. Psychology in the Schools, 38(2), 173-184. Doi:10.1002/pits.1008

Payne, A.A. \& Welch, K., (2017). The effect of school conditions on the use of restorative justice in schools. Youth Violence and Juvenile Justice, 1-17. DOI: $10.1177 / 1541204016681414$

Shaughnessy, M.A. (2002). School handbooks: Legal considerations. (2 ${ }^{\text {nd }}$ Ed.) National Catholic Educational Association. Washington, D.C. www.ncea.org

Skiba, R.J., Chung, C.G., Trachok, M., Baker, T.L., Sheya, A., Hughes, R.L., (2014). Parsing disciplinary disproportionality: Contributions of infraction, student, and school characteristics to out-of-school suspension and expulsion. American Educational Research Journal, 51(4), 640-670. doi:10.3102/0002831214541670

Sullivan, A.L., Klingbeil, D.A., \& Van Norman, E.R. (2013). Beyond behavior: Multilevel analysis of the influence of sociodemographics and school 
characteristics on students' risk of suspensions. School Psychology Review, 42(1), pp. 99-114. 


\section{SECTION THREE:}

SCHOLARLY REVIEW FOR THE STUDY 


\section{Introduction}

In recent years, public schools have experienced an increased pressure to address the many concerns that are associated with student out-of-school suspensions (BakerSmith, 2018). The pressure placed on schools is a result of schools relying on the use of out-of-school suspensions as a consequence for a wide range of discipline infractions (Koon, 2013). Out-of-school suspensions have increased about 40\% from 1972-2009 (Cohen, 2016). The negative impact of out-of-school suspension has been and continues to be a highly debated and researched topic. The controversial use of out-of- suspension as a form of student discipline has initiated public school administrators to modify or change their current discipline practices including the use of alternatives to out-of-school suspensions (Baker-Smith, 2018). Changes being implemented by schools may include but not limited to: non-punitive approaches to discipline, eliminating the use of suspensions for minor offenses, more use of in-school suspension, limits being placed on the use of suspensions, restorative practices, and the implementation of positive behavior interventions and supports (PBIS) (Lauer, 2014; Blomberg, 2003; Cohen, 2016).

Restorative practices can be defined strategies that are used to engage people by working together to establish positive relationships while also helping to repair relationships as a result of a discipline infraction (Mirsky, 2007). This approach to student discipline focuses on school staff engaging in positive dialogue with misbehaving students to help them understand the harm they may be doing to others. Another alternative approach to school suspension is the use of positive behavior interventions and supports which consists of prevention-based practices aimed at teaching students appropriate expectations and behaviors in an effort to "reduce student problem behavior" 
(Massar, McIntosh, \& Eliason, 2015). The use of out-of-school suspension is a discipline consequence that is either determined by mandated school discipline policies that have pre-determined consequences or through the use of principal discretion in the discipline decision making process. For the purpose of this study, out-of-school suspension as a result principal discretion occurs when the principal determines that the misbehaving student is disrupting the learning of others and the most appropriate consequence is to remove the misbehaving student from the learning environment. Zero-tolerance policies in this study are mandated school board policies that have predetermined consequences.

\section{Literature Review}

\section{Education Policy}

Federal, state, and local policies and procedures are modified regularly with changes being made that impact local school districts in each state. At the local level, school boards of education are responsible for following these policies and procedures. Failure to do so would mean that the school district is not in compliance with the guidelines outlined in these policies and procedures. This study will be conducted on public high schools in the southeast region of a Midwestern state. The researcher of this study will investigate the school board discipline policies of these public high schools as well as school principal use of exclusionary discipline consequences used to address student misbehavior. Access to the school districts board polices can be found on the districts website.

At the state level, the State Department of Education (SDOE) regulates local school districts. All schools located in the state where this study occurred have to follow the guidelines and mandates established by SDOE. For this study, data was obtained from 
the SDOE due to this information being available to the public. Some of the information obtained from the SDOE that maybe helpful to the researcher to analyze is demographic data, student enrollment, student discipline, and school academic achievement on the school districts being studied. This descriptive data is important for establishing a high school profile of the schools and principals participating in this study.

Federal programs and initiatives have been established over the years through the Department of Education (DOE). The mandates set forth by the Department of Education are the driving force for states as they regulate public schools. The department continues to implement measures to ensure that states are regulating student discipline, academic achievement measures, and overall school performance. Even though schools have to follow these guidelines, they are able to apply their discretion in addressing student behavior. Special attention should be placed on the frequency of discipline, especially out-of-school suspensions.

\section{Exclusionary Discipline}

Student discipline policies developed by local school districts serve as a guide for school administrators when having to manage negative student behavior. Many of these policies are broad in nature and may not specifically outline what the consequence should be for each infraction. However, written within these policies are general recommendations or options that can be used to manage student misbehavior. Some of the most common options that principals can chose from when deciding the most appropriate consequence are: a verbal or written warning, student/parent conference, detention, assignment to Saturday school, in-school suspension, out-of-school suspension, or in severe instances, expulsion. Some of the most serious student offenses 
as stated by board policy call for a certain consequence for the infraction such as out-ofschool suspension. This means that if a student violated this particular policy, then they would receive the punishment that is written within the board policy. This would be described as a mandated school board policy. Furthermore, the consequence has been predetermined for this particular infraction. An example of this would be a weapons or drug violation. Many times, the consequence for violation of mandated policies results in some form of exclusionary discipline. School exclusion can be defined as the removal of a student from the "traditional classroom setting" (Cohen, 2013). School districts that use mandated discipline policies that result in student exclusion from the learning environment is problematic.

For the purpose of this study, mandated school discipline policies will be classified as zero-tolerance policies. As stated by Skiba and Peterson (1999), there is not much evidence to support that harsh policies, such as zero-tolerance policies, are effective in improving school safety. They further state that there is serious concern with the long-term effects of "one of the cornerstones" of zero-tolerance, "school exclusion" (Skiba \& Peterson, 1999, p. 376). Research shows that the use of harsh, mandated policies that result in student exclusion from the learning environment is popular not because of its effectiveness, but because of the idea that such policies will deter other students from misbehaving. To reiterate, Skiba and Peterson (1999) state that the prevalent use of zero-tolerance policies are used by school leaders because of the "image it portrays" (p. 376). Discipline policies that result in student exclusion has increased drastically from 1970-the early 2000s with student exclusion rates being "remarkably high" (Payne \& Welch, 2017). 
For clarity within this study, the removal of a student from the education setting is either the result of principal discretion or the use of zero-tolerance policies. Zerotolerance policies will be described as any policy or practice that is implemented by school principals which requires the use of mandated, pre-determined consequences for student misbehavior. These mandated consequences call for the removal of the offending student which has violated a zero-tolerance policy. This removal is mandated by the local school boards' policies and requires principals to follow these mandates and remove the student from the traditional education setting. If a student infraction does not violate a zero-tolerance policy, but the consequence results in that student being removed from the education setting, then this would be consider a discretionary removal carried out by the school principal. This means that the principal used his discretion to make the decision to exclude and remove the student from the education setting.

School principals are responsible for managing the behavior of all students. Discipline policies with predetermined consequences eliminate principal discretion as well as the opportunity for principals to make a more appropriate decision. To effectively handle disciplinary incidents with students, public school administration requires a lot or responsibility and attention to detail. Because of this, power and control are two things that principals may want to establish. This can be accomplished by showing authority to others and principals do this by displaying their ability to effectively enforce school rules. Thus, principal discretion in enforcing school rules may not be used in the most appropriate way. It is the opinion of the researcher that some individuals in leadership positions want to appear more superior to others and give off the persona that they are "in charge." School principals that have this attitude welcome the opportunity to use by zero- 
tolerance policies and the enforcement of discipline which results in exclusion from school such as out-of-school suspension. Suspension can be defined as "complete removal of the student from any environment where instructional or social activities" take place within a school (Tobin \& Vincent, 2011). School principal's attitudes towards students and their philosophy for disciplining students is an important component when addressing student misbehavior. As stated by Skiba, et al., (2014), variations of attitudes by school principals appear to have an impact on the rate of school suspensions.

School principals have different philosophies on how they manage and lead their respective schools. These philosophies may be developed based on previous experiences within the field, through acquired educational degrees, or by their personality characteristics. Rausch and Skiba (2006) conducted surveys on 325 principals in the state of Indiana. Their results showed that school principals have differing perspectives on “school discipline." Most importantly, principal attitudes are directly associated to student out-of-school suspensions (Rausch \& Skiba, 2006; Skiba, et al., 2014). Attitudes shown towards the use of zero-tolerance policies by this group of principals was "evenly split" on whether they felt zero-tolerance policies sends a clear message to "disruptive students" about appropriate behavior in schools (Rausch \& Skiba, 2006). There is a lot of discretion that takes place when principals are tasked with disciplining students who engage in inappropriate behavior at school. The attitude of principals is important when interacting with the students who have violated school policies. Ultimately, the principal is responsible for deciding whether it is justifiable to suspend a student out of school. 


\section{The Impact of School Exclusion}

Emily Arcia (2006) found that student suspensions are "ineffective and counterproductive" (p.359). She continues by stating that suspending students out of school has a negative impact on the student's academic achievement. Students who are suspended from school and are not allowed to complete their assignments are going to fall behind. Research in the field of education shows the importance of attending school and how that affects a student's academic performance. The researcher in this study reviewed a local school district that does not allow the students to make-up the work for credit. This school district considers out-of-school suspension to be an "unexcused" absence and the district policy states that students are not allowed to make-up work for unexcused absences. This is problematic because of the impact this absence will have on student learning and the overall academic achievement of the student. Also, in such cases where the suspension was a result of the discretion used by the principal, it's difficult to rationalize that the absence is truly unexcused. Some school districts allow for full credit on the school work, others only allow a percentage to count towards the student's grade. Students who are suspended from school should be allowed to make-up any assignment or test that they missed. This is especially true for discipline incidents that do not impact school or student safety.

\section{History of Zero-Tolerance Policies}

Zero-tolerance policies in public schools stemmed from "federal drug enforcement policies in the 1980's" (Skiba \& Peterson 1999). Zero-tolerance became more prevalent in public schools after the passing of the Gun-Free Schools Act of 1994 (Evans \& Lester, 2012). This act required all states receiving federal funding to 
implement a mandatory discipline policy with a pre-determined consequence of one-year expulsion from school if a student possessed a weapon while at school (Evans \& Lester, 2012; Allman \& Slate, 2011). Over time, schools began to use zero-tolerance policies for other school offenses that were considered to be less violent such as drug possession, alcohol possession or consumption, fighting, making threats, among other offenses (Payne \& Welch, 2017; Rausch \& Skiba, 2006; Evans \& Lester, 2012; Skiba \& Peterson, 1999; American Academy of Pediatrics, 2013; Hoffman, 2014). The use of zerotolerance policies to address these behaviors result in students being suspended out-ofschool. The removal of students from the learning environment can have a negative impact on their performance at school. Zero-tolerance policies were implemented to ensure that schools are safe learning environments. However, as previously mentioned, many of these offenses that result in out-of-school suspension are considered to be "minor incidents that do not threaten school safety" (Skiba \& Peterson, 1999). Therefore, zero-tolerance policies are not being utilized as they were once intended, which was to protect the safety of students and schools through the use of aggressive discipline consequences for students who possessed or used a weapon on school grounds.

An abundance amount of research has been conducted on the use of zerotolerance policies and student exclusionary practices. This research has proven to show that these discipline practices are ineffective, and schools should move away from using these practices as a deterrent to student misbehavior (Evans \& Lester, 2012; APA, 2008; Skiba, 2010; Morris \& Perry, 2016; Hoffman, 2014). Rausch and Skiba (2006) reiterate this by saying that even though zero-tolerance policies have proven to be ineffective, they are still being heavily used and are a popular approach for school principals. It's hard to 
contemplate why such a practice would still be used given the fact that it is not an effective strategy to deter negative and inappropriate student behavior. It seems even more shocking that it has been over 25 years since zero-tolerance policies were first utilized and many political figures and school principals continue to believe that the practice is effective (Rausch \& Skiba, 2006). It is easy to see why such a policy would be put in place, especially for the purpose to severely punish those students who bring weapons to school with the possible intent to harm others. Zero-tolerance does send a strong message that if you commit a violent offence at school that you will immediately be punished for that incident. However, many school principals are applying zerotolerance discipline consequences to lesser offenses that are not considered to be violent or threaten the safety of students, staff, or the school.

\section{The Impact of Suspensions on Students}

There have been several studies conducted that show the negative impact suspensions have on students. Students who have been suspended from school are more likely to suffer academically, experience grade retention, develop negative attitudes towards school and its faculty, increased chances of dropping out, and possible criminal infractions placing the student in the juvenile justice system (Rausch \& Skiba, 2006; Morris \& Perry, 2014; Morris \& Perry, 2016). Most importantly, as stated by the American Academy of Pediatrics (2013), students who are suspended from school are placed back in the environment that probably contributed to their negative behavior. A student's negative behavior may be a result of the learned behaviors at home and lack of parenting or a lack of a positive influence at home. This may be especially true for 
students from low socio-economic families or homes. Out-of-school suspensions tend to be more frequent for low socio-economic students (Skiba, et al., 2014).

Not only does suspensions impact those students being suspended, but it also may affect students in school that does not misbehave. Students who are enrolled at schools with "high rates of out-of-school suspension" have lower academic achievement even if they have not been suspended themselves (Morris \& Perry, 2014). This is described by the same authors that out-of-school suspensions create "collateral consequences for the academic success of all students" (Morris \& Perry, 2014, p. 1068). They use the term, "collateral consequences" to describe how the suspensions affect the culture of the school and therefore affecting all the students within that school. The same authors stated in a different study that suspensions create inequalities in learning for minority students. They further conclude that minority students are suspended more often than non-minority students (Morris \& Perry, 2016; Hoffman, 2014; Arcia, 2006; Wallace, et al., 2008; Tobin \& Vincent, 2011). This research has been expanded to show that students from low-socioeconomic families are also suspended more frequently (Dunbar \& McNeal, 2010). This is problematic because it widens the "achievement gap" between students that are suspended and students who are not suspended (Morris \& Perry, 2016). In the study conducted by Morris and Perry (2014), 42\% of African American students in their sample had been suspended at least once. They conclude that this may show an inequality among students and schools; therefore, creating an even larger achievement gap between minority and non-minority students. Other research has shown that minority students are further behind than their peers in the area of reading in elementary grades (Arcia, 2006). If these students are already behind in certain academic areas, then they are going to fall 
further behind if they are unnecessarily suspended and are not allowed to complete their school work for credit.

Many school districts have policies in place that do not allow students to make up assignments, or if they do, they cannot turn those assignments in for credit. Eugene Bardach (2012) mentions "equality, equity, fairness..." when examining and addressing policies. The policy of not allowing students the opportunity to complete their work while on suspension can be viewed as not providing equality to all students. Many times, students are suspended for conflicts with teachers rather than violent acts towards others (Dupper, Theriot, \& Craun, 2009). The negative behaviors that result in a suspension, ultimately should not have a negative impact on a student's academic performance. There may be an underlying factor that may contribute to the negative behavior and should be addressed by school staff through a more appropriate strategy aimed at correcting the negative behavior. Students should not be punished academically for inappropriate classroom behavior. This has been referred to this as "double jeopardy" (personal communication, 2016). The discipline that is given to misbehaving students should be addressed so that the behavior does not continue to occur. However, students should not be punished by receiving "zeros" on all assignments throughout that time. Often times, zero-tolerance consequences may result in ten or more days of out-of-school suspension. This could be detrimental to a student's overall academic career.

Emily Arcia (2006) conducted a study over a three-year period that analyzed the impact suspensions had on student academic performance. In her study, Arcia (2006) concluded that suspended students do in fact fall behind their peers academically, especially in reading. Her study included all students who had been suspended at least 
once over that time period. She also analyzed the students reading scores $(n=49,327)$. The comparison group consisted of students who did not receive an out-of-school suspension in that same time period $(n=42,809)$. Those students reading scores were also analyzed. Findings were noted in four areas. First, there was a "clear association between pre-suspension reading achievement and suspension rates" (p. 367). Secondly, students who had lower academic achievement were suspended more frequently. Next, she found that students who were suspended for more days dropped-out of school at a higher rate. Finally, she found that students who were suspended 51 or more days scored 327 points below the non-suspended students. Arcia (2006) concluded that suspended students were five grade levels below their non-suspended peers after the three-year time period. The impact out-of-school suspensions have on a student's academic achievement can increase the chances that the student will fall further behind in school. Not only do suspensions impact student academic performance, they can also impact a student's social skills, such as their level of aggression and classroom behavior (Koon, 2013). These factors must be taken into consideration by principals when deciding to use suspension as discipline consequence. It is possible that alternatives to out-of-school suspension may be more appropriate.

\section{Alternatives to Out-of-School Suspension}

Research has shown that suspending student's out-of-school has a negative impact on the student. Student exclusion from school "results in serious academic consequences" for those students who have been excluded (RMC Health, 2014). School principals should look to establish more effective strategies and interventions to address student misbehavior. Exclusionary discipline practices have a negative impact on both the school 
and students, and because of this, Payne and Welch (2017) explain that schools should "reconsider their response to student misbehavior" (p. 2). Dupper, et al., (2009) discuss how "preventative school-based alternatives" should be implemented to include both student and school-based strategies (p. 8). Restorative practices place an emphasis on building positive emotions in students and schools such as "empathy and excitement" and deemphasizing negative emotions such as "anger and humility" (Payne \& Walsh, 2017). In doing this, teachers and principals will establish positive working relationships with students while establishing proactive approaches to address negative student behavior.

Public schools around the country have shown an increased interest in implementing proactive strategies to address student misbehavior such as School-Wide Positive Behavior Support systems (SWPBS) or Positive Behavior Intervention and Supports. Positive behavior support systems serve as a proactive approach to student behavior. PBIS strategies teach students appropriate behaviors and how to make better decisions (American Academy of Pediatrics, 2013). The use of positive behavior supports places an emphasis on prevention strategies when working with student behavior, rather than always focusing on punitive consequences to address student misbehavior. It has been my experience that these supports work well with all student's, but is mostly utilized at the elementary school level. The benefits to these strategies is that it promotes positive interactions with students and staff; therefore, decreasing negative student behaviors which will ultimately improve the overall school climate. The school climate is important to the overall functioning of the school. This is defined by Bear, Yang, Pell, and Gaskin (2014) as the "learning environment at the school-wide level" (p. 340). 
Students, parents, and teacher perception is an important component to the school climate or culture (Bear, et al., 2014).

School principals may be able improve the overall school climate while increasing student academic performance and decreasing negative student behavior by implementing research based proactive strategies such as positive behavior interventions and supports. This requires principals to decrease the use of zero-tolerance policies and focus on alternatives to out-of-school suspension. Using alternatives to out-of-school suspension is more effective because these alternatives may be able to meet the social and emotional needs of students by focusing on conflict resolution, establishing mutual respect, and providing counseling services (Evans \& Lester, 2012).

For schools to be effective in providing additional supports to students, they need to ensure that school faculty and staff are properly trained. Proper training is one of the most important components when working with students and being able to better understand student behavior. In the study conducted by Rausch and Skiba (2006), principals felt that only $29 \%$ of teachers were effectively trained to "deal with student misbehavior." Research shows that establishing positive relationships helps with dealing with negative student behavior. Evans and Lester (2012) discuss how student behavior is a form of communication. If faculty and staff have been successful in effectively establishing positive relationships with students, then communication will be easier for everyone. Staff members must be trained so that they can understand why students are displaying certain behaviors and then determine the best response to that behavior. This requires the staff to be able to effectively understand what the student is trying to communicate which can be accomplished through ongoing training. Decision making to 
support or to provide interventions for student misbehavior may involve several stakeholders such as teachers, administrators, counselors, or other community members (Evans \& Lester, 2012). This support should be able to improve negative student behavior due to the fact that several experienced professionals will have an interest in the decision-making process as well as meeting the needs of the student.

Not only is it important to establish positive relationships with students, it is also critically important to establish positive relationships with parents. This can be challenging because some parents may not have had a positive experience while they were in school; therefore, it may be difficult to gain their support when working with their child. Rausch and Skiba (2006) point out that it is important for principals to work with parents prior to a student being suspended. This can be challenging with zerotolerance policies due to the fact that zero-tolerance policies were designed to use "mandated predetermined consequences" to address student misbehavior (Hoffman, 2014). Consequences as a result of zero-tolerance policies do not allow principals the time or opportunity to meet and work with parents prior to the student being suspended. Therefore, principals may have a hard time establishing or re-establishing a positive rapport with the families impacted by the consequences of the student's misbehavior. Evans and Lester (2012) made an interesting statement when they stated that students who are consistently excluded "from the school environment without fully understanding" the reason for the consequences may hinder the relationship with teachers which can lead to further negative interactions (p. 112).

There are other discipline alternatives that may prove to be more effective in deterring negative student behavior. These alternatives to suspending a student out-of- 
school could be in-school suspension, after school or lunch detention, and/or parent/community involvement through conferencing. These consequences allow the student(s) to continue to benefit from remaining in the learning environment. With these alternative strategies, principals and teachers can work to develop more positive interactions with the student to better understand why the student is misbehaving while also being able to identify the appropriate steps that can be used in the future to help reduce or eliminate the problem behavior. Rausch and Skiba (2006) state that students will be more willing to "communicate potential problems" to teachers and principals if positive relationships have been established. In-school suspension (ISS) is a consequence where students are removed from the traditional classroom setting and are placed in a designated room to complete school work. This placement can be for any length of time and can be effective because students can receive assistance on their school work from school staff while also having the opportunity to receive "rehabilitative" support. (Blomberg, 2003). More importantly, ISS is a more appropriate approach than OSS because it keeps the student(s) in the educational environment, addresses inappropriate behavior, and allows for school principals to "intervene in a positive manner" with the student(s) (Blomberg, 2003).

Eliminating the use of out-of-school suspension all together may not be possible, especially when dealing with more serious discipline infractions where the removal of the offending student may be the most appropriate consequence. This is especially true for schools that have implemented zero-tolerance policies which call for the removal of the offending student from the traditional classroom environment (Dunbar \& McNeal, 2010). Students that are removed from the classroom and school as a result of an out-of-school 
suspension may notice a negative impact on academic performance. Not all schools allow students to earn credit for assignments and academic work that was missed due to an outof-school suspension. Students suspended in one Midwestern state are not allowed to receive credit for work that is missed therefore receiving a "zero" (personal conversation, 2015). Other schools in this state take off a certain percentage of a student's grade. For instance, at some schools students will receive a $1 \%$ or even a $10 \%$ grade deduction for each day the student is suspended (personal communication, 2015). Mary Claire, a participant in this study, is an assistant principal in a high school where they allow students to make up the work that is classified as "summative" which counts as $75 \%$ of a student's overall grade. Students are not allowed to make up the remaining $25 \%$ of work classified as daily practice. It is not clear why such policies are in place, however some schools consider OSS to be an unexcused absences with the reduction of points serving as a form of punishment for missing school. School policies that do not allow students to receive full credit for missing assignments are going to fall behind academically due to being removed from the learning environment. Wallace, et al., (2008) further reiterate that suspended students heavily impacts a "students' short-term academic performance" (p. 2). Therefore, it's important that students even while suspended are exposed to educational content so that learning can still take place. When these suspensions occur, students should be allowed to receive all assignments and should receive credit for that work. Some schools allow students to receive the assignments they will miss and by doing this, the students would still be exposed to the content that is being taught and it would allow them to somewhat stay on track with their peers. More importantly, teachers would still be able to assess student learning. Allowing students to do this will make the 
transition back into the traditional classroom setting easier not only for the student, but for the teacher, and the other students in the classroom. Ultimately, allowing students to complete their assignments for credit will not have as much as a negative impact on the students' academic performance, nor will it have as much of a negative impact the overall school culture.

\section{Summary}

Student out-of-school suspensions have doubled since 1970 (Morris \& Perry, 2014). This exclusionary practice is being unnecessary used and is used far too often. School board policies need to be re-examined so that alternatives are in place when students violate school rules that may result in an out-of-school suspension. As stated by Evans and Lester (2012), zero-tolerance policies have failed to prove that suspending students helps "to create safe schools" (p. 112). Not only does exclusionary discipline practices fail to make the school safer, many researchers will argue that schools with high suspension rates have a negative impact on the academic achievement on the nonsuspended students. High suspension schools increase the anxiety level on all students and "creates unstable, socially fragmented environments" (Morris \& Perry, 2014, p.1083). The development of more appropriate school policies should be designed to also eliminate "discriminatory educational...practices" (Sullivan, Klingbeil, \& Van Norman, 2013, p.112). This will ensure that school policies are equitable for all students. It's important to keep in mind that parental support and guidance is a vital component to a student's overall success in school. School principals must place an emphasis on establishing learning environments centered on improving instructional practices and strategies to effectively manage all students' behavior. This can't be accomplished if 
exclusionary discipline is the main component to student discipline. As stated by Perry and Morris (2016), student suspension should be used only as a last resort. 


\section{References}

Allman, K.L., \& Slate, J.R. (2011). School discipline in public education: A brief review of current practices'. International Journal of Educational Leadership Preparation, V.6 (2).

American Academy of Pediatrics. (2013). Out-of-school suspension and expulsion. Council on School Health. Pediatrics 2013; 131; e1000. doi: 10.1542/peds.20123932

American Psychologist Association Zero-tolerance Task Force (2008). Are zerotolerance policies effective in the schools? An evidentiary review and recommendations. American Psychologist, 63(9), 852-862. DOI: 10.1037/0003066X.63.9.852.

Arcia, E. (2006). Achievement and enrollment status of suspended students: Outcomes in a large, multicultural school district. Education and Urban Society 38:359-69. SAGE. doi: 10.1177/0013124506286947

Baker-Smith, E.C., (2018). Suspensions suspended: Do changes in high school suspension policies change suspension rates? Peabody Journal of Education, 93(2), 190-206. DOI: 10.1080/0161956X.2018.1435043

Bardach, E. (2012). A practical guide for policy analysis: The eightfold path to more effective problem solving (4th Ed.). Los Angeles: Thousand Oaks: Sage; CQ Press

Bear, G. G., Yang, C., Pell, M., \& Gaskins, C. (2014). Validation of a brief measure of teachers' perceptions of school climate: Relations to student achievement and suspensions. Learning Environments Research, 17(3), 339-354.

doi:10.1007/s10984-014-9162-1 
Blomberg, N. (2003). Effective discipline for misbehavior: In school vs. out of school suspension. Concept: An Interdisciplinary journal of graduate studies. Villanova University.

Cohen, R.W. (2013). Reframing the problem: New institutions and exclusionary discipline in schools. Journal for Educational Controversy V 7: $N$ 1. Article 6. University of Texas at Austin.

Department of Elementary and Secondary Education, (2018). www.dese.mo.gov

Dunbar, C., \& McNeal, L. (2010). In the eyes of the beholder: Urban student perceptions of zero-tolerance policy. Urban Education. 45(3) 293-311. SAGE. doi: $10.1177 / 0042085910364475$

Dupper, D.R., Theriot, M.T., \& Craun, S.W. (2009). Reducing out-of-school suspension: Practice guidelines for school social workers. Children Schools. 31(1), p. 6-14 doi:10.1093/cs/31.1.6

Evans, K.R., \& Lester, J.N. (2012). Zero-tolerance: Moving the conversation forward. Intervention in School and Clinic. 48(2) 108-114. SAGE. DOI:

$10.1177 / 1053451212449735$

Hoffman, S. (2014). Zero benefit: Estimating the effect of zero-tolerance discipline policies on racial disparities in school discipline. Educational Policy 28(1) 69-95.

SAGE. doi: 10.1177/0895904812453999

Koon, D. S-V., (2013). Exclusionary school discipline; An issue brief and review of literature. The Chief Justice Earl Warren Institute on Law and Social Policy. University of California, Berkeley School of Law. www.warreninstitute.org. 
Lauer, P. (2014). Out-of-school suspensions: Consequences and alternatives. RMC Health. Retrieved from rmchealth.org.

Massar, M.M., McIntosh, K., \& Eliason, B.M., (2015). Do out-of-school suspensions prevent future, exclusionary discipline? Positive Behavior Interventions \& Supports, 2015.

Mirsky, L. (2007). SaferSanerSchools: Transforming school culture with restorative practices. Reclaiming Children and Youth, 16(2), 5-12.

Morris, E. \& Perry, B. L (2014) Suspending progress: Collateral consequences of exclusionary punishment in public schools. American Sociological Review 79:1067-87. Oxford Press. doi:10.1177/0003122414556308

Morris, E. \& Perry, B. L. (2016). The punishment gap: School suspension and racial disparities in achievement. Social Problems 63(1): 68-86. Advance Access. doi:10.1093/socpro/spv026

Payne, A.A. \& Welch, K., (2017). The effect of school conditions on the use of restorative justice in schools. Youth Violence and Juvenile Justice, 1-17. DOI: $10.1177 / 1541204016681414$

Rausch, M. K., \& Skiba, R. J. (2006). Exclusion is not the only alternative: The children left behind project. Discipline, achievement, and race: Is zero-tolerance the answer? Early Childhood Research Quarterly 105-126.

Skiba, R.J., \& Peterson, R. (1999). The dark side of zero-tolerance: Can punishment lead to safe schools? Phi Delta Kappan, 80(5), 372-376.

Skiba, R.J., Chung, CG., Trachok, M., Baker, T.L., Sheya, A., Hughes, R.L., (2014). Parsing disciplinary disproportionality: Contributions of infraction, student, and 
school characteristics to out-of-school suspension and expulsion. American

Educational Research Journal, 51(4), 640-670. doi: 10.3102/0002831214541670

Sullivan, A.L., Klingbeil, D.A., \& Van Norman, E.R. (2013). Beyond behavior:

Multilevel analysis of the influence of sociodemographics and school characteristics on students' risk of suspensions. School Psychology Review, 42(1), pp. 99-114.

Tobin, T.J., \& Vincent, C.G., (2011). Strategies for preventing disproportionate exclusions of African American students. Preventing School Failure, 55(4), 192201. DOI: 10.1080/1045988X.2010.532520

Wallace, J.M., Jr., Goodkind, S.G., Wallace, C.M., \& Bachman, J. (2008). Racial, ethic, and gender differences in school discipline among American high school students: 1991-2005. Negro Educational Review, 59, 47-62. 


\section{SECTION FOUR:}

CONTRIBUTION TO PRACTICE 


\section{Plan for Dissemination of Practitioner Contribution}

Who: Members of the state's Association of Secondary School Principals

When: During the 2019-2020 school year.

Submission Deadline: Fall 2019

How: Through PowerPoint presentation

\section{Rationale for this Contribution Type}

Public school principals burden a lot of responsibility due to the fact that public schools have "many strategies and policies" used for "stopping or preventing" negative student behavior (Blomberg, 2003). The results of this study will serve as a resource to help school principals improve student discipline practices and procedures within their respective schools. More specifically, the information will be used to improve discipline practices within the district of the researcher in this study. The researcher serves as a principal in a large public high school that continues to see an increase in the number of students enrolled in the district. Therefore, it is appropriate and necessary to re-evaluate current discipline practices relating to the use of out-of-school suspension. One of the goals of the researcher within this study was to show that there are inconsistencies among school principals on the use of out-of-school suspension. This study identified factors that impact a principal's decision to suspend a student and will help principals evaluate their use of out-of-school suspension to ensure that this exclusionary practice is used appropriately. Therefore, it will be beneficial for principals to develop a better understanding of the decision-making process when choosing to use out-of-school suspension as a form of student discipline. 


\section{RPDC Principals}

Results of this study will be shared with secondary school principals within the southeast region of this Midwestern state at the local secondary school principal's meeting as this group of principals were the targeted group of participants for this study. The results will be shared via an executive summary or one-page memo. It may be possible to personally follow-up with the individuals who participated in an interview. The distribution of the information within this study may be determined based on the results of the study. It is appropriate to distribute this information to those that participated in the study and those that serve in leadership roles at schools where the study took place because the information may be most meaningful to them as they have a connection to the information that was provided. The results of this study may serve as a great resource for beginning school principals. Many of the principals within this group are members of the state's Association of Secondary School Principals. Monthly meetings take place each month from October-April of the academic school year. The researcher plans to present the findings of this study at one of the monthly meetings. A power point will be the format used to present the findings. The presentation will consist of background information, the design of the study, literature review, and the results of the study. Recommendations to improve practice and alternatives to out-of-school suspension may be provided.

\section{Lakeshore High School}

The information within this study will also be shared with secondary school principals working at Lakeshore High School which is in the same region where this study was conducted. This group consist of 13 secondary principals serving grade levels, 
5-12. Also included in this group is the district superintendent, assistant superintendent, and associate superintendent. The results of this study will be a useful resource for our district to use to help improve our use of out-of-school suspension as a consequence to address student discipline. Due to the relevance of this topic, the results of this study can be put into practice immediately and without a complete overhaul of board policies on discipline practices. The presentation of the information contained within this study will focus on current policies being used to manage student misbehavior as well as the discretion used by principals in the discipline decision making process. It is the hope of the researcher to be able to determine through this study the factors that impact the decisions made by principals when deciding to use out-of-school suspension as a discipline consequence.

Results of this study show that students are being suspended more from principal discretion. This information is helpful for principals to be able to identify the factors or characteristics that may impact their decision to suspend students. It is not possible to exclude discretion from the decision making of a principal. Most of all responsibilities of an acting principal requires "some measure of discretion" (Findlay, 2015). Principals must be able to use appropriate discretion when making a decision, especially when the outcome impacts student learning. This study addressed inconsistencies with principal discretion and the use of out-of-school suspension as a form of punishment.

Results of this study show that students are not being suspended more from mandated policies. It is still important for principals to analyze their discipline policies to determine if policies are outdated or if policies need to be modified. The results contained in this study may show that mandated policies such as zero-tolerance policies might need 
to be phased out to allow more flexibility in decision making being used by principals. Balfanz, et al., (2014) suggested that the way "schools are organized and operate plays a significant role in determining suspension rate" (p.7). They further explain that school districts need to review current policy and practice to ensure that they are holding students "accountable" while not "explicitly" disciplining students which increase the chances of the students not graduating. It is the hope of the researcher that the results of this study will encourage principals to review and evaluate current school practices related to student discipline.

\section{Theoretical Framework}

Those that support zero-tolerance policies believe that suspensions not only stop misbehavior, but deters "other students from misbehaving" (Skiba, Peterson, \& Williams, 1997). However, research does not support the use of out-of-school suspension as an effective form of discipline in "reducing or eliminating student misconduct" (Blomberg, 2003). Blomberg (2003) continues by stating that zero-tolerance policies are mandated and consist of predetermined consequences used to address student misbehavior and that these policies must be followed, with no exceptions. Predetermined discipline consequences sends a message to students that certain discipline infractions will have severe consequences and that principals cannot deviate from those consequences. It is the belief of some principals that these policies have such severe consequences and will deter students from misbehaving. This can be described as Deterrence theory which was first applied to the criminal justice system to address criminal behavior.

Deterrence theory in the criminal justice system was based on the assumption that stiff punishments for certain crimes will deter others from committing those crimes. 
Furthermore, it's the idea that the threat of punishment or "sanctions" deters criminal behavior (Mathews \& Agnew, 2008). For the purpose of this study, Deterrence theory will be used as the theoretical framework guiding this research. There is not much research documented on Deterrence theory being applied to the public school setting, but the threat of punishment for a violation of school rules carries the same intent which, in theory, is designed to deter students from misbehaving.

\section{Research Design}

\section{Setting}

This study will be bounded by the counties in the southeast region of a Midwestern state as defined by the state's Regional Professional Development Center and will include all public high schools within this boundary. There are over 80 school districts within this region and 68 of the districts have public high schools that will serve as the main target of data collection. All of the high schools have similar, if not, the same discipline policies as defined by or advised by the State School Boards Association. These schools are similar in their demographics: student population, socio-economic status, and ethnic subgroup sizes. This study will analyze the use of out-of-school suspension as a form of student discipline in these schools as well as the perception of out-of-school suspension by the principals leading these schools. Purposeful and convenient sampling was used to select participants. A convenience sample was used because the participants were easily accessible (Fink, 2017; Creswell, 2009). With purposeful sampling, participants were chosen because they provide the best data for the researcher to be able to understand the phenomena and to help answer the research questions that guided this study (Creswell, 2009). 


\section{Data Collection Tools}

Data collection consisted of a survey instrument that was distributed through email to principals currently serving in public high schools. The survey instrument was created using Qualtrics. The survey items were designed to collect data related to the research questions, more specifically the use of out-of-school suspensions by acting principals and the effectiveness when using out-of-school suspensions. One survey item asked participants if they would be interested in participating in a follow up interview where they would be asked open-ended questions about their personal experience using out-of-school suspensions as a form of student discipline. Seven principals volunteered to be interviewed by the researcher.

\section{Data Analysis}

Quantitative survey data collected on principal perception and use of out-ofschool suspension was analyzed using Qualtrics. Qualitative interview data was coded and categorized into themes. This data was then compared to the survey data to identify similarities and/or differences among principal perception on the use of out-of-school suspension as a discipline consequence. Triangulation was used to compare and crosscheck data from this study along with the review of literature on the use of out-of-school suspension.

\section{Interviewed Participants}

John Paul

- High school principal, grades 9-12

- Eight years in current position

- School Demographics

○ Total number of students: 289

○ White: $93.4 \%$

○ Black: $3.1 \%$ 
○ Hispanic: $1.7 \%$

- Students eligible for free or reduced lunch price: $24.2 \%$

- Number of students suspended 10+ days in 2018: 9 (3.1\%).

$\mathrm{Al}$

- High school principal, grades 9-12

- Second year in current position

- School Demographics

○ Total number of students: 959

○ White: $96.7 \%$

○ Black: .08\%

○ Hispanic: $1.4 \%$

- Students eligible for free or reduced lunch price: $48.9 \%$

- Number of students suspended 10+ days in 2018: 18 (1.9\%).

Mary Claire

- High school assistant principal, grades 9-12

- Over 12 years in current position

- School Demographics

○ Total number of students: 906

○ White: $94.9 \%$

○ Black: $1.8 \%$

○ Hispanic: $2.1 \%$

- Students eligible for free or reduced lunch price: $30.5 \%$

- Number of students suspended 10+ days in 2018: 11 (1.2\%).

Rick

- High school principal, grades 9-12

- First year in current position

- School Demographics

○ Total number of students: 237

○ White: $97.0 \%$

- Black: 0\%

- Hispanic: 0\%

- Students eligible for free or reduced lunch price: $44.6 \%$

- Number of students suspended 10+ days in 2018: 4 (1.7\%). 
Carl

- High school principal, grades 7-12

- Fourth year in current position

- School Demographics

- Total number of students: 111

○ White: $99.0 \%$

○ Black: 0\%

○ Hispanic: $0 \%$

○ Students eligible for free or reduced lunch price: $99.0 \%$

○ Number of students suspended 10+ days in 2018: 1 (.09\%).

Asa

- High school assistant principal, grades 9-12

- Third year in current position

- School Demographics

○ Total number of students: 931

○ White: $57.7 \%$

○ Black: $31.8 \%$

○ Hispanic: $4.7 \%$

○ Students eligible for free or reduced lunch price: $56.1 \%$

○ Number of students suspended 10+ days in 2018: 21 (2.3\%).

$\operatorname{Kim}$

- High school principal, grades 9-12

- Fourth year in current position

- School Demographics

- Total number of students: 518

O White: $64.3 \%$

○ Black: $27.4 \%$

○ Hispanic: $7.1 \%$

- Students eligible for free or reduced lunch price: $72.6 \%$

○ Number of students suspended 10+ days in 2018: 14 (2.7\%).

\section{Limitations and Assumptions}

To ensure validity of this study, an appropriate sample size was included in the data analysis. Survey Data was collected from 58 acting principals and interviews were conducted on seven acting principals. Data collection consisted of several surveyed items 
and questions that potentially challenged the decision making or philosophies of principals and their management of misbehaving students. Due to the subjectivity of managing student misbehavior, participant responses could have been generalized as it is difficult to analyze every discipline situation that may or may not involve the use of outof-school suspension. Of the seven interviews, two of the participants had a professional working relationship with the researcher. This may have impacted the quality of the response given by the participant.

\section{Research Questions}

1. Why do high school principals choose to use out-of-school suspension as a form of student discipline?

a. What are high school principals' perception on the use of out-ofschool suspension as a form of student discipline?

b. Is the use of out-of-school suspension a result of principal discretion, or mandated policies with pre-determined consequences?

c. What characteristics influence the discretion used by principals when using out-of-school suspension as a form of discipline?

d. Do principals of large enrollment high schools in the southern region of a Midwestern state rely on strict application of zerotolerance policies related to out-of-school suspensions than principals of small enrollment high schools in the southern region of a Midwestern state? 
e. Do principals of large enrollment high schools in the southern region of a Midwestern state rely on professional discretion related to out-of-school suspensions than principals of small enrollment high schools in the southern region of a Midwestern state?

f. Do principals of large enrollment high schools in the southern region of a Midwestern state rely on the student's patronage of influential adults related to out-of-school suspension than principals of small enrollment high schools in the southern region of a Midwestern state?

\section{Results}

Data collected in this study shows that 54 of 57 of surveyed participants have used out-of-school suspension as a consequence for student misbehavior. One participant did not answer this survey item, but answered other items within the survey. Furthermore, the seven principal's that participated in an interview have all used OSS as a discipline consequence. Of those that participated in the survey, $77 \%$ felt that OSS is an effective consequence used to discipline students. The researcher of this study determined based on the data collected that the most common infractions that resulted in an out-of-school suspension were: safety concerns to students and staff, repeated instances of misbehavior, use or possession of drugs or alcohol, possessing a weapon on campus, threats made towards students or staff, and when the student's behavior negatively impacted the learning of other students. The following themes were identified by the researcher through data collection: education setting, principal discretion, zero-tolerance policies, and the impact on the decision to suspend. Data collected in this study will not be able to 
answer research questions aimed at comparing the use of discretion or zero-tolerance policies in large and small schools. Also, the researcher was not able to determine if a student's patronage to an adult had an impact on the decision to suspend that student.

\subsection{Education Setting}

The researcher in this study determined that principals choose to use OSS the most when a student's misbehavior substantially disrupts the education setting or the learning of other students. Principals feel the responsibility to ensure that the learning of other students is continuously being disrupted as a result of a student's misbehavior. On of the main reasons for the use of OSS by these principals was to ensure that other students' learning was not disrupted as a result of the students' behavior. Most of the participants discussed how student safety is also an important factor when considering to suspend a student. Carl serves in a high school of approximately 100 students stated that OSS is used when a student's behavior is "a safety concern to other students." Rick, principal of a school serving 237 students, mentioned that "safety is going to be a big one [factor]" when deciding to use OSS. Even considering the safety of others, most of the behaviors that were discussed by principals and punishable by suspension were considered to be less violent offenses. Therefore, participants stressed the importance of trying to remove the student from the learning environment only when their actions and behaviors were considered to be a "major discipline issue" that has created a disruption to the learning of others. These major discipline issues consist of, but are not limited to, threats towards others, fighting, drug or alcohol use, or racial slurs. Other behaviors that may disrupt the learning environment may include disrespect towards other students and staff, insubordination, defiant behavior towards staff, or repeated distracting behavior that 
restricts teachers from being able to instruct students. Kim, a principal at a high school with approximately 520 students, stated that he uses the phrase "the disruption they cause substantially disrupts the education setting at school" when making the decision to suspend a student. Asa is a principal at a high school with a student population of around 930 students and he feels that the purpose of OSS is "to remove students who are disrupting the learning environment." Blomberg, (2013) supports these statements made by principals by stating that the purpose of suspending a student is based on their actions severely disrupting the classroom setting and learning of others.

There is a lack of research on the impact suspensions have on the educational setting or the overall school culture. This study shows that principals do not feel suspensions have a negative impact on the school culture or other students. Survey data shows that only $20.69 \%$ of principals feel that OSS has a negative impact on the overall school culture. Furthermore, $77.58 \%$ of principals do not feel OSS negatively impact other students in the school that have not misbehaved or violated school rules. When discussing the impact of OSS on others, Kim stated, “... as a whole and as a school district, it [OSS] takes that discipline away so it's no longer there for the other students." The consensus among principals through this study was that OSS is used to remove the misbehaving student from the students who do not misbehave.

\section{2 - Principal Discretion}

Interview data shows that all participants feel they have the autonomy to make discipline decisions which may result in an out-of-school suspension. Survey data showed that $67 \%$ of principals surveyed feel most of the suspensions issued were as a result of principal discretion. Two principals that were interviewed referenced having the 
ability to suspend students through the use of their discretion in at least $90 \%$ of the discipline infractions that occurred in their school. Almost all interviewed participants make mentioned to the fact that school board policies are written in a way that allows for school leaders to use their discretion when deciding whether to suspend a student. Participants also mentioned that in most cases, they have the autonomy to act independently and make their own decisions when addressing student misbehavior. Mary Claire, an assistant principal in a school of over 900 students, when asked about using discretion stated that, “... when you start picking and choosing when you are going to suspend and when you are not, then that gets you in a whole heap of trouble.” Mary Claire's statement reiterates the importance of following board policies and ensuring that principals are consistent in their decision to suspend. Some of the infractions that were mentioned where discretion may be used and the consequence could result in a suspension were threats, inappropriate conduct, repeated behavior of the same activity, and disrespect towards staff. These discipline infractions are covered under school board policies and it is up to the principal to determine based on their discretion whether the infraction is serious enough to result in an out-of-school suspension.

Almost all the participants stated that these infractions coupled with the disruption to the learning environment were the most important factors when deciding to suspend a student. The goal of using out-of-school suspension as identified by the researcher in this study is to remove the disrupting student from the traditional classroom setting so that other students are able to learn without being impacted by the disrupting behavior. Blomberg (2003) mentions that the purpose of suspending a student is due to their actions "severely disrupting" the classroom setting and "only the removal of that student can 
allow learning to continue" (p.2). The decision to suspend a student requires much deliberation and often times may require principals to seek advice from peers.

Principals were asked if teachers, parents, assistant principals, superintendents, or other adults are involved in the decision making process. The data shows that principals do not include others in the decision making process unless it is necessary and that these principals act independently when determining discipline consequences. Mary Claire as well as Al, a principal at a high school with a student population of 959, will include other principals to "bounce" ideas around. Many of the other principals also mentioned that they will rely on another administrator to help in the decision making. All principals with the exception of John Paul, do not include the parents in the decision making process, nor do they include the classroom teacher. John Paul, a principal in a school of almost 300 students, may involve the parent in the decision making process if the infraction deals with substance abuse. He allows the family to make a choice of receiving treatment for the substance abuse, or taking the suspension. Classroom teachers are not involved in the discipline making process unless as stated by Kim, "only to provide clarity." The data shows that other administrators are the only adults that the disciplining principal may rely on. However, this may be problematic in small schools due to the fact that there may not be another principal to consult.

Three principals that were interviewed, work at what is considered by the researcher in this study as a small high school. Because of the size of the school, the principals may not have assistant principals to consult with when deciding to suspend a student. As stated by Carl, “I'm the principal, we don't have an assistant principal." It was important for the researcher to seek out these principals because their discretion in 
decision making can be more closely analyzed because they are managing situations on their own and possibly having to use more discretion.

In small schools, it may be appropriate to consult with the superintendent more often when deciding to suspend a student if there are no assistant principal to consult. Carl mentions that when there is a discipline situation he consults with the superintendent to determine not only what is best for the student, but what is best for the school. Rick discussed how he will consult with the superintendent if he feels the suspension may require more the ten days. The maximum number of days a principal can suspend a student is 10, as defined by the States School Board Association. Discipline infractions that may require more than 10 days of OSS would include threats towards the school and staff, drug or alcohol use, weapons, vandalism, actions that are racial in nature. One survey item and interview question that was important to the researcher was whether principals have the freedom to issue suspensions under 10 days without the approval of the superintendent. Rick mentioned that he has the autonomy to suspend up to ten days without having to consult with the superintendent and can rely on an assistant principal or middle school principal to help in this situation. It must be noted that all principals can suspend a student for up to ten days. John Paul likes the fact that he is the only principal in his school managing discipline and it is his philosophy that he wants to be the only one responsible for disciplining students so that his staff can focus on being advocates for their students. In larger schools, principals can rely on assistant principals to bounce ideas around to determine the most appropriate consequence for the misbehaving student. It is the opinion of the researcher that deciding to suspend the student may not be as challenging as deciding the length of the suspension. 
Once the decision has been made to suspend a student, principals have to determine the length of the suspension. The length or number of OSS days assigned to a student is arbitrary and usually based on the number of days that have been given in years past for the same offense (personal communication, 2019). One constant contributing factor when using suspensions as a consequence and the length of the suspension as discussed by principals in this study is the motivation behind the student's behavior. Many participants discussed how "premeditation" impacted the length of the suspension. Premeditation for the purpose of this study can be described as the prior actions by the offending student which showed that the student had intentions to violate school rules. This could include a student sending another student text messages or messages through social media where the student may make mention to committing an act that would violate school rules. Premeditation could also include a student who changes up their normal routine to engage in an act that results in a violation of school rules. This may include a student that changes their normal route to school or class or goes out of their way to confront another student which may lead to a fight. In some instances, other students may be present when a violation of school rules occurs. If the principals investigating the situation speak to witnesses, they may be able to determine through questioning whether there was premeditation to commit the school violation. This may include comments made by the offending student to the witnesses. The principals in this study felt that if a student had previously been warned then the suspension would be longer in length. Prior warnings identified in this study were associated with student altercations or fights. It was described to the researcher that sometimes staff hear about altercations taking place in school which resulted in those students being "counseled" and 
warned about the consequences of fighting. If the students ultimately ended up in a fight, then the punishment would be more severe due to the fact that the students were warned previously.

Much discussion from the interviewed principals centered on "engaged students." The principals felt that out-of-school suspension was often a common punishment given to students who were "disengaged" in school. Disengaged students can be defined as students who are failing classes, have poor attendance, and may have had previous discipline issues. These students already lack a motivation to be at school and typically have attendance issues. Therefore, they are disengaged in school and an out-of-school suspension is only "giving them what they want." Making the decision to suspend these students may not be in the best interest of the student. Other forms of discipline may be more appropriate such as in-school suspension, detentions, or face-to-face conferences may be necessary and more effective in trying to keep these students in school while also holding them accountable for their actions. This is especially true for students who may come from broken homes or homes where there is not much structure or support from the students' parents.

A student's situation at home was another characteristic that principals considered when determining whether to suspend a student. A few principals mentioned that a student's home life may be a contributing factor to the student's behavior which may have led to a suspension. A students' parents or guardians may have a negative influence on the student and this could be a contributing factor to the student's misbehavior. Research studies have shown that the behavior of parents and "parenting style or parental control" are important characteristics of "preventing or facilitating" negative student 
behavior (Ngai \& Cheung, 2005). If, through the use of discretion, a principal determines that the parents of a student may in fact be part of the problem, then suspending that student may not be the best option. The decision to suspend would place the student back in the environment that contributed to the misbehavior at school (American Academy of Pediatrics, 2013). Instead, it may be best to keep the student at school where they are exposed to caring adults who have the student's best interest in mind. Another important characteristic of a student's home life to consider is whether an adult will even be present to supervise a suspended student. If a student is misbehaving to the point that they have to be removed from school, sending that student to a home with no adult supervision would not be in the best interest of the student. Keeping a student in school ensures that they will be monitored, supervised, and exposed to opportunities to receive care and support by school staff.

Principals in this study acknowledged that if a suspension was the most appropriate consequence and there were concerns about the circumstances at home, the length of the suspension may be reduced. This is an arbitrary decision made by principals that may conclude that students who are suspended for a longer period of time by be more negatively impacted than if they were only suspended for a shorter period of time. It's also to take into consideration that schools have more positive resources available to students than the homes they come from. The resources that schools have that can benefit students is onsite counselors, teachers, and staff members that are trained in how to develop positive relationships with students. Principals must be aware of a student's home life while also being able to involve parents while effectively communicating expectations when using suspension as a consequence. 
All interviewed principals mentioned parental involvement in some way. When principals make the decision to suspend a student, they need to communicate their decision with the student's parents. However, if parents do not agree with the school's decision to suspend their child, then the behavior may not be corrected because the parents feel that the school is making the wrong decision and this message may be communicated to the student. As one principal mentioned, the parents didn't agree, therefore the student "got four free days of school where he hunted and fished and enjoyed their self." Almost all principals realize the importance of developing positive working relationships with parents. This is challenging when having to discipline students. However, one participant, John Paul, creates situations where the parents and students have a choice on the consequence of the discipline infraction.

It was identified through this study that suspensions were mostly associated with major discipline infractions such as the use of a weapon, drugs or alcohol. With situations involving the use of drugs or alcohol, John Paul offers students and parents a choice. Even though some infractions may violate zero-tolerance policies, some principals are looking for other resources and interventions to help address the problem behavior rather than suspending the student. These interventions may include required counseling sessions or students may have to participate in a drug or alcohol treatment program. John Paul explained that he tries to offer students and parents a choice that if a student agrees to a drug or alcohol treatment program or counseling then he would reduce the length of the OSS. He feels that OSS may not the most appropriate consequence for a student involved in the use of drugs or alcohol. When dealing with a student that had been drinking alcohol, John Paul gave the student and their parent(s) choice. The student "can 
take three days out or he can go get evaluated for this." The choice provided still has an element of punishment involving out-of-school suspension, but the most appropriate decision from John Paul is to encourage the student much needed help and support.

\section{3 -Zero-tolerance Policies}

All interviewed principals acknowledged the impact zero-tolerance policies have on the decision to suspend a student. The discipline infractions identified through interviews in this study were: weapons, drugs, alcohol, threats, racial comments, and destruction of school property. It's important to note that some infractions by students are considered safe school violations which are classified as criminal offenses resulting in a student being charged with a crime and call for an automatic long-term suspension (SBOE website, 2019). The previously mentioned discipline infractions each result in an out-of-school suspension and are considered infractions that may impact the safety of others. These infractions can also be considered disruptions to the educational setting. School board policies that have been created to address serious offenses in school are necessary in-order to ensure students are safe at school. However, such policies take the decision making and autonomy away from principals. Kim mentioned that zero-tolerance policies "takes you out of it and sometimes that's not good" because it takes away your ability to use your discretion. He continues by saying that these policies take away his ability to look at all the facts to determine the best decision to be made. Survey data shows that almost $80 \%$ of school districts have zero-tolerance policies. Of those that responded, 73\% felt that zero-tolerance policies are an effective tool for managing student misbehavior. This was further explained in follow up interviews as principals felt it was easier to assign discipline on a constant basis when there is a policy that establishes 
a pre-determined, mandated consequence. It must be noted that $10 \%$ of surveyed participants did not have an opinion on the effectiveness of zero-tolerance policies. Other principals empathetically discussed how zero-tolerance policies take away the use of "common sense." Principals feel that when they are allowed to use their discretion, they are able to look at all of the circumstances of a situation and are able to make the most appropriate decision. Zero-tolerance policies do not allow principals to be able to consider the circumstances of a discipline situation because they are required to discipline the student according to the policy the student violated. Findlay (2015) mentions that principals use of discretion is "vital" and "necessary in order for them to be fair and reasonable in their disciplinary decision making" (p. 472). Principals in this study referenced many times in the interview that it is challenging to use zero-tolerance policies when dealing with "humans" because there are certain circumstances that must be considered when deciding on the most appropriate discipline consequence. One participant, Mary Claire, stated several times that "when you are dealing with humans, not everything fits in a policy." Even considering how zero-tolerance policies may take out the common sense in decision making, all participants discussed the importance of following the policies as they are written in the student handbook and approved by the local school board.

\section{4 - Impact on the Decision to Suspend}

The principals that participated in an interview did not feel that OSS had much of an impact on students because the student's negative behavior did not change after the suspension. They felt that the suspension serves more as a deterrent to the other students in the school because students hopefully saw that if they engaged in that same behavior, 
they too would may be suspended. There is no evidence within this study that can prove suspensions deter other students from misbehaving. Each had their own opinion regarding the impact or lack thereof on a student that had been suspended, but the researcher concludes that the participants did not feel that the suspension given to a student changed that student's behavior. It was mentioned a few times by participants that the infractions that lead to a suspension were committed by students that have a tendency to act out. They further explained that suspensions do not impact students who do not misbehave because those students do not engage in behavior that would result in a suspension. If suspensions had a negative impact on other students, then it can be assumed that suspension negatively impact the overall school culture. However, based on the data gathered within this study, there was no perceived positive or negative impact on the school culture.

Only $20 \%$ of surveyed principals felt that suspensions had an impact on the overall school culture. Participants felt that students who consistently misbehave need to be removed from the learning environment, so they do not impede the learning of other students. This removal sends a message to other students that there are consequences to negative behavior and that consequence could result in an out-of-school suspension.

Through the data collected in this study, it was concluded that the impact of suspensions on other students was not negative; however, it is possible that suspensions may deter other students from misbehaving. This may be especially true for infractions that violate a zero-tolerance policy because there are mandated, predetermined consequences for that particular infraction. This study or the participants within this study were not able to produce evidence to show that suspensions deterred other students from 
misbehaving. Most of the interviewed participants as well as $71 \%$ of surveyed principals felt that out-of-school suspensions deter other students from misbehaving. However, some feel that students that are focused on earning good grades will not engage in behaviors that will result in an out-of-school suspension. Participant Kim stated that "good students" are worried about their grades and "they're not going to do anything" that would result in an OSS. All interviewed participants agreed that suspension negatively impacts academic performance due to the fact that the student is not receiving direct instruction from a classroom teacher nor are they in a learning environment while serving a suspension. Of those surveyed, almost $75 \%$ felt that suspension has a negative impact on student academic performance. It's important to note that $15 \%$ of surveyed principals were neutral on the academic impact.

A highly debated topic among school leaders is whether students are allowed to complete school work while suspended and whether or not they will receive credit for the completed work. Of the principals that were interviewed, $71 \%$ stated that their school district allows students to complete their work for full credit. It should be noted that the researcher in their own experience has noticed that most suspended students do not complete the work that they miss while serving a suspension. Out-of-school suspensions seemed to negatively impact a student's academic standing more than any other factor. The data gathered within this study is inconclusive on whether a suspension improves that student's behavior after serving a suspension.

All participants within this study suggested that students are suspended because their actions were severe enough and the most appropriate consequence was for the student to be removed from the educational setting. It was rarely mentioned that a 
suspension was used to help correct a student's behavior. In fact, most participants did not feel that a student's behavior improved after an out-of-school suspension. Of those surveyed, $42 \%$ were neutral on whether a student's behavior improved and $38 \%$ somewhat agreed that behavior improved after the suspension. The change in behavior for a student can be deceiving as some schools have transition plans for students coming off of a suspension and have extra supports in place to help students correct the behavior. It is the belief of the researcher that students who are suspended for repetitive misbehavior will not correct their behavior without other supports and interventions in place to assist the student.

\section{Discussion and Recommendations}

Results of this study may serve as a resource for the principals that participated in this study as well as educators aspiring to become principals, and principal mentoring programs. Results show that principals feel the use of out-of-school suspension is an important and necessary consequence used to address student misbehavior. OSS is significant and because of that, it sends a message to students that misbehavior in school will not be tolerated and the outcome of such behavior may result in the removal of the disrupting student (Morrison \& Skiba, 2001). The removal of a disrupting student occurs when it is determined that their behavior is negatively impacting the learning of others and as a "last resort" a suspension is necessary to address the misbehavior. However, the concern over the use of OSS has increased across the United States and school districts are feeling pressure to evaluate the use of OSS while identifying more appropriate alternatives to address student misbehavior (Baker-Smith, 2018; Findlay, 2015; Allman \& Slate, 2011). 
Participants within this study mention that alternatives to OSS may be more appropriate. These alternatives may include student/parent conferences with the principal, detentions, or in-school suspension. This was especially true for students who were involved in substance abuse or their misbehavior may have been due to the student's mental health. Under these circumstances, principals felt that a more appropriate alternative was to provide counseling or support from outside agencies that specialize in drug and alcohol abuse as well as arranging for students to meet with mental health experts. These alternatives may serve as more appropriate options for principals looking to change the behavior of a student, while providing the student an opportunity for the student to get needed help. Also, some of the mentioned alternatives do not include exclusion of the student from the learning environment which would allow the student to continue to receive some form of instruction or time to work on assignments. One of the most used forms of discipline as an alternative to suspending a student out-of-school is to place the student in, in-school suspension.

In-school suspension (ISS) consists of removing the misbehaving student from the traditional classroom setting and placing the student in a separate classroom where their behavior is monitored more closely. In-school suspension classrooms in a high school setting are designed to restrict student's from having the freedom to walk the halls on their own between classes, attend lunch with their peers, and ISS takes away any free time available to the students. The supervisor or ISS teacher closely monitors the student(s) and when appropriate, provide "behavior changing strategies" for the student in hopes of changing the student's behavior so that exclusionary discipline can be avoided (Blomberg, 2003). The use of ISS also allows the student to continue working on 
their classroom assignments so that the student does not fall too far behind in their learning. ISS can be beneficial for misbehaving students and is an alternative option to suspending a student out-of-school as it keeps the student in school and allows for staff to work to change the students negative behavior. 


\section{References}

Allman, K.L., \& Slate, J.R. (2011). School discipline in public education: A brief review of current practices'. International Journal of Educational Leadership Preparation, V.6 (2).

American Academy of Pediatrics. (2013). Out-of-school suspension and expulsion. Council on School Health. Pediatrics 2013; 131; e1000. doi: 10.1542/peds.20123932

Balfanz, R., Byrnes, V., \& Fox, J. (2014). Sent home and put off-track: The antecedents, disproportionalities, and consequences of being suspended in the ninth grade. Journal of Applied Research on Children: Informing Policy for Children at Risk, 5(2), Article 13.

Baker-Smith, E.C., (2018). Suspensions suspended: Do changes in high school suspension policies change suspension rates? Peabody Journal of Education, 93(2), 190-206. DOI: 10.1080/0161956X.2018.1435043

Bardach, E. (2012). A practical guide for policy analysis: The eightfold path to more effective problem solving (4th Ed.). Los Angeles: Thousand Oaks: Sage; CQ Press

Blomberg, N. (2003). Effective discipline for misbehavior: In school vs. out of school suspension. Concept: An Interdisciplinary journal of graduate studies. Villanova University.

Creswell, J.W. (2009). Research design: Qualitative, quantitative, and mixed methods approaches. ( $3^{\text {rd }}$ Ed.). Los Angeles, C.A. SAGE

Department of Elementary and Secondary Education, (2018). www.dese.mo.gov 
Findlay, N.M. (2015. Discretion in student discipline: Insight into elementary principal's' decision making. Educational Administration Quarterly. 51(3) p. 472-507. SAGE. doi. 10.177/001316X14523617

Mathews, S.K. \& Agnew, R., (2008). Extending deterrence theory: Do delinquent peers condition the relationship between perceptions of getting caught and offending? Journal of Research in Crime and Delinquency, 45(2), 91-113

Morrison, G.M., \& Skiba, R. (2001). Predicting violence from school misbehavior: Promises and perils. Psychology in the Schools, 38(2), 173-184. Doi:10.1002/pits. 1008

Ngai, N.P., \& Cheung, C.K. (2005). Predictors of the likelihood of delinquency, A study of marginal youth in Hong Kong, China. Youth and Society, 36(4) 445-470.

Skiba, R.J., Peterson, R.L., \& Williams, T. (1997). Office referrals and suspension: Disciplinary intervention in middle schools. Education and Treatment of Children, 20(3), 295-315. 
SECTION FIVE:

CONTRIBUTION TO SCHOLARSHIP 


\title{
Contribution to Scholarship
}

\section{Target Journal}

The target journal for publication of this study is "The Journal of Educational Research.” This journal is published by Taylor \& Francis, LLC.

\section{Rationale for this Target}

The rationale for choosing "The Journal of Educational Research" is based on the intended audience being educational leaders in secondary schools. "The Journal of Educational Research" contains articles that are relevant to and "contributed to the advancement of" educational practice in secondary schools (www.tandfonline.com). This journal is a "respected periodical" and places an emphasis in the "evaluation of traditional practices" (www.tandfonline.com). The researcher in this study considers school discipline practices and procedures to be "traditional practices" in education; therefore, the evaluation of such practices within this study are appropriate for "The Journal of Educational Research”.

\section{Outline of Proposed Contents}

\section{Manuscript}

Title Page: Title of article, author, and affiliation - University of Missouri. Author contact information will be included on title page.

\begin{abstract}
Not to exceed 250 words. Subheadings: background, purpose of the study, research methods (setting, participants, design of study, data collection and analysis), findings and implications for practice. Five key words or phrases will appear after the abstract.
\end{abstract}




\title{
Manuscript:
}

1. Introduction

2. Review of literature

3. Data and Methods

4. Results

5. Summary

6. References

7. Appendices

\section{Plan for Submission}

Who: Seth Harrell

When: Upon defense of this dissertation

How: Online submission via Submittable

\section{Submission-Ready Journal Article}

\begin{abstract}
:
Exclusionary discipline practices in public schools has been a controversial topic for practitioners and scholars. Researchers have provided empirical data to show the negative impact exclusionary discipline has on students who have been removed from the traditional learning environment. This study placed an emphasis on the decision making by school principals that use the exclusionary practice of out-of-school suspension as a consequence to address student misbehavior. The unique perspectives provided by current acting secondary school principals throughout this study will shed light on the use of out-of-school suspension in both large and small public high schools in the southeast region of a Midwestern state. The results of this study will help inform principals on how
\end{abstract}


the use of suspensions are ineffective and have a negative impact on the suspended student. This study will also serve as a guide for principals when using their discretion to determine the most appropriate consequence to use when making discipline decisions.

\section{Highlights:}

- Only one principal in this study has not used out-of-school suspension as a form of punishment. All other principals have used out-of-school suspension as a form of student discipline.

- $78 \%$ of principals agree that out-of-school suspensions are an effective method used to address student discipline problems.

- $72 \%$ feel that out-of-school suspensions deter students from breaking school rules.

- $79 \%$ of principal's school district has zero-tolerance policies.

- Only $17 \%$ of principals feel that zero-tolerance policies are ineffective.

- Most of the suspensions assigned by principals in this study were assigned based on principal discretion. Survey results show that $22 \%$ of suspensions are NOT a result of principal discretion.

- Principals do not feel the size of the school has an impact on the use of out-ofschool suspension. The researcher was not able to determine if there was more of an impact in a large school compared to a small school and vice versa.

- The average number of days a student would be suspended based on data collected is 5-10 days (54\% of respondents). 
- Only $20 \%$ of principals feel that out-of-school suspension has a negative impact on the overall school culture with only $10 \%$ stating that out-of-school suspensions have a negative impact on students who do not break school rules.

- $54 \%$ of participants do not feel alternatives to out-of-school suspension is would be more effective.

- $20 \%$ of participants do not know when the last time school district leaders reviewed their discipline policies or procedures.

\section{Keywords:}

- Exclusionary discipline

- Out-of-school suspension

- Zero-tolerance policies

- Principal discretion

- Deterrence

\section{Introduction}

School principals are responsible for managing student behavior by implementing and adhering to the school districts discipline policies and procedures. Up until The Gun Free Schools Act of 1994, principals were able to solely use their professional discretion to discipline misbehaving students. However, due to an increase in school violence, The Gun Free School Act of 1994 as part of The Improving America's Schools Act of 1994 was created so that schools had to implement zero-tolerance policies; more specifically, to address a student who possessed a weapon at school (Skiba \& Peterson, 1999; Evans \& Lester, 2012; Hoffman, 2014). This approach to student discipline put pressure on public schools to implement such policies by the federal government due to the fact that the 
government was funding public schools and they made this part of the stipulation to receive money (U.S. Department of Education, 2018). Many states created their own Safe Schools Act including the Midwestern state in this study, which passed the state's Safe Schools Act in 1996 (DESE.mo.gov.) The purpose of these acts were designed to reform education policies in order to make schools safer. Schools began adopting zero-tolerance policies to help address student misbehavior for serious discipline incidents. These policies made it clear to students that there would be severe punishment serious infractions such as: weapons, drugs, or other violent offenses. Zero-tolerance polices establish mandated, pre-determined consequences and in most cases, exclusionary practices used as a consequence to address student misbehavior. These mandates provided guidelines for when and how long a student would receive consequences for misbehavior (Allman \& Slate, 2011). These consequences, ultimately resulted in student out-of-school suspension given by the principal or superintendent.

Principals have the ability to suspend a student out-of-school for up to ten school days. If the infraction is more severe and calls for a longer suspension, the decision would then be tasked to the superintendent of schools to determine how many more days were appropriate without exceeding 180 days. Any discipline over 180 days would have to be recommended to the board of education by the superintendent and left to the board to decide. Any suspension over 10 days is considered to be a long-term suspension. It is rare for the superintendent or school board to get involved with student discipline as many of the infractions being committed by students are not related to weapons, drugs, or violent acts. Most student discipline infractions are handled at the school level by principals who are given the autonomy to use their professional discretion. This could 
create inconsistencies in issuing discipline by school principals due to differing philosophies and interpretations of the policies and procedures associated to student discipline (Morrison \& Skiba, 2001). The use of principal discretion when deciding to suspend a student was the focus of this study which included current principals in the southeast region of a Midwestern state and their use of out-of-school suspension as a form of exclusionary student discipline.

\section{Exclusionary Discipline}

For several decades, schools and principals have increasingly used exclusionary discipline practices such as out-of-school suspensions as a discipline response to a wide range of school violations (Koon, 2013). Even though many researchers feel the use of exclusionary discipline is ineffective, out-of-school suspensions continue to be the most common form of student discipline (Skiba, et al., 2014; Morrison \& Skiba, 2001). Schools are a place where students learn and are provided with the best possible education. However, many feel that this cannot occur with students who consistently disrupt the learning environment. The easiest response to students who continuously disrupt the learning of others is to remove that student from the traditional classroom setting. By doing so, schools are able to promote a safe learning environment for students and staff (American Academy of Pediatrics, 2013). Principals are responsible for determining the extent of the disruption by the misbehaving student as well as what the most appropriate response to address the misbehavior. The decision to suspend a student shows that "only the removal of the offending student can allow for learning to continue" (Bloomberg, 2003). The principal must base their decision not only on how the discipline consequence is going improve the learning environment, but also how will the 
consequence improve the disciplined, students' behavior moving forward. Much research has been done on students who have been suspended and whether that student's behavior improved as a result of a suspension. Researchers have found that OSS does is not effective and this consequence does not improve student behavior, nor does it deter negative behavior. Skiba and Peterson (1999) found the exclusionary discipline did not deter students from future behavior problems. Students who have been suspended from school are much more likely to be suspended again. Massar, McIntosh, and Eliason (2015) conducted a study and found that almost $72 \%$ of students who were suspended early in the school year received another suspension later that year. The effectiveness of excluding students from the learning environment through the use of out-of-school suspension continues to be questioned as research shows that suspensions have a negative impact on that student academically, behaviorally, socially, and emotionally (Reyes, 2006; Allman \& Slate, 2011; Morrison \& Skiba, 2001; Skiba \& Peterson, 1999; Rausch \& Skiba 2006). The overall impact suspensions have on students is why the use of exclusionary practices is a controversial topic and why its use continues to be questioned by scholars and practitioners.

\section{Data and methods}

\subsection{Data Collection}

This heuristic case study consisted of qualitative and quantitative research methods, particularly a survey and interviews with high school principals and assistant principals in the southeast region of a Midwestern state. There are approximately 68 public school districts within this region. All respondents are currently in a position where they have the authority and responsibility to manage student behavior in a public high school. The 
schools in the southeast region of this Midwestern state were identified through the state Association of Secondary School Principals (ASSP) as well as the state Regional Professional Development Center. The principal's names and email addresses were obtained from a mass group email list that was created by ASSP. A survey through Qualtrics was emailed to principals who currently serve in the role of public high school principal or assistant principal. Principals had two weeks to complete the survey. A reminder email was sent out to encourage principals to complete the survey if they had not already done so.

The survey contained an item which asked if principals would be interested in participating in a follow up interview. There were 16 principals that volunteered to be interviewed. Seven interviews were conducted. There were three principals that the researcher tried to contact to set-up an interview, but was not able to receive a response. Other candidates that volunteered had a close working relationship with the researcher; therefore, they were not contacted to participate in an interview. Interviewed principals were from both large and small schools.

The interviews lasted between 10 and 30 minutes and those that participated were not compensated. Consent forms and interview questions were emailed to principals prior to the interview. Consent forms were signed and scanned back to the researcher. Each principal was informed of the purpose of the interview prior to the interview being conducted. The interviews contained scripted, open-ended questions, allowing the respondents to lead the discussion. The interviewee, when needed, asked for clarification or more information. Each principal was asked the same questions; however, some questions were modified based on the response given by the principals. 


\subsection{Sample Description}

The schools represented in this study are located in 21 counties in the southeast region of this Midwestern state. The largest school enrollment has an approximate student population of 1,832 students and the smallest school enrollment consist of approximately 100 students. The average number of students per school was approximately 550 students in grades 9-12. Student enrollment numbers were collected from the 2018 school year. There were 58 principals or assistant principals that completed the survey. It is possible that some of the principals may work at the same high school. Of those that responded, $29 \%$ were from schools with a population of 1001 or more students, $13 \%$ were from schools with a student population between $250-499$ students, and $12 \%$ were from schools with less than 249 students.

Interviews consisted of six male principals and one female principal. Five of the principals were acting building principals and two of the principals were acting assistant principals. Three of the principals worked at schools with a student population between 900-1000 students. One principal works at a school with approximately 518 students, another principal works at a school with approximately 111 students, and two principals work at schools with a student population between approximately 220-290 students. An attempt was made to interview three principals that work at schools with over 1,000 students, but these principals did not respond to the researcher's request.

\subsection{Data Analysis}

Interviews were audio recorded and conducted over the phone with the exception of one face-to-face interview. Some field notes were taken while the interview was being conducted. The interviews were transcribed and coded using the open coding approach so 
the researcher could identify categories or themes from the data as it relates to the research questions. The focus of the interview questions was: to identify characteristics of principal use of out-of-school suspension, why principals choose to suspend students, characteristics of suspensions, whether suspensions are effective, the use of zerotolerance policies, and what roles other adults played in the decision to suspend a student.

\section{Results}

The purpose of the mixed methods study was to analyze principal use of out-ofschool suspension as a form of discipline for student misbehavior and determine the perceptions of high school principals' use of out-of-school suspension as a form of student discipline. Furthermore, the researcher looked to determine if the use of out-ofschool suspension is more of a result of principal discretion, or mandated policies with pre-determined consequences, as well as identify characteristics that may influence the discretion used by principals when suspending a student out-of-school. In order to conduct this study, principals in the southeast region of a Midwestern state were surveyed and follow up interviews were conducted with current school principals. An analysis of survey data showed that most principals shared the similar beliefs in the use of out-ofschool suspension and the intent to use this form of discipline to address student misbehavior.

\subsection{Education Setting}

Through the interview process, all principals within this study had used out-ofschool suspension as a form of discipline. The main reason for the use of out-of-school suspension was to ensure that other students' learning was not disrupted as a result of the students' misbehavior. Most of the principals discussed how student safety is a factor in 
disciplining students; however, most of the behaviors that were punishable through suspension were less violent offences that did not impact the safety of others. Therefore, the principals stressed the importance of removing the student from the learning environment only when their actions and behaviors were "major discipline issues" that have negatively impacted the learning of others. Kim stated that he uses the phrase "the disruption they cause substantially disrupts the education setting at school" is used when making the decision to suspend a student. This means that a student's behavior has reached a point that, as determined be the principal, the behavior is distracting other students from learning. It is the discretion of the principal which determines if and how the learning environment is interrupted. Often times, it can be determined that the learning environment is being disrupted by a student when the classroom teacher is having to address student misbehavior or the teacher is having to stop providing instruction to address a student that is not following school rules.

\section{2 - Principal Discretion}

Through conducted interviews, all principals felt that they had the autonomy to make discipline decisions that resulted in an out-of-school suspension. Two different principals referenced having the ability to suspend students through use of their discretion in at least $90 \%$ of the discipline infractions that occur in their school. Almost all interviewed principals mentioned that school board policies are written in a way that allows for school leaders to use their discretion when deciding whether to suspend a student. Some of the infractions that were mentioned which could result in a suspension were threats, inappropriate conduct, repeated behavior of the same activity, and disrespect towards staff. These discipline infractions are covered under school board 
policies, but it is up to the principal to determine whether the infraction is serious enough to result in an out-of-school suspension. Almost all the principals stated that these infractions coupled with the disruption to the learning environment were the most important factors when deciding to suspend.

Once the decision was made to suspend, the principals then had to determine the length of the suspension. One constant contributing factor when suspending a student mentioned by the principals is the motivation behind the student's behavior. Many principals discussed how "premeditation" impacted the length of the suspension. The principals felt that if a student had previously been warned, then the suspension would be longer in length. Prior warnings were more associated with student altercations or fights. It was described to the researcher that sometimes staff hear about altercations taking place in school which resulted in those students being "counseled" and warned about the consequences of fighting. If the students ultimately ended up in a fight, then the punishment would be more severe due to the fact that the students were warned previously.

Much discussion from the interviewed principals centered on "engaged students." The principals felt that out-of-school suspension was often the punishment given to students who were "disengaged" in school. These students already lack a motivation to be at school and typically have attendance issues. Therefore, these students are disengaged in school and an out-of-school suspension is only "giving them what they want." Making the decision to suspend these students may not be in the best interest of the student. Other forms of discipline may be more appropriate in order to keep these students in school 
while also holding them accountable for their misbehavior. This is especially true for students who do not have a very good home life.

A student's situation at home was another characteristic that principals considered when determining whether to suspend a student. A few of the principals mentioned that a student's home life may be a contributing factor to the student's behavior that resulted in a suspension. It was also mentioned that the length of the suspension may be less if there was a situation at home that was not good for the student. A student's home life is a direct reflection of their parents or lack thereof.

All interviewed principals mentioned a student's parents in some way. When principals make the decision to suspend a student, they need to communicate their decision with the student's parents. However, if parents do not agree with the school's decision to suspend their child, then the behavior will not be corrected because the parents feel that the school is wrong and this message is communicated to the student. As one principal mentioned, the parents didn't agree, therefore the student "got four free days of school where he hunted and fished and enjoyed their self." Almost all principals realize the importance of developing positive working relationships with parents. This is challenging when having to discipline students. However, one participant, John Paul, creates situations where the parents and students have a choice on the discipline.

Suspensions were intended to be used for serious discipline infractions such as the use of drugs or alcohol. Parents may be given a choice where they can agree to have their student commit to a drug/alcohol treatment program or counseling services. In this situation, an out-of-school suspension is probably not the most appropriate consequence for the student. When dealing with a student that had been drinking alcohol, John Paul 
gave the parents and students a choice. The student "can take three days out or he can go get evaluated for this." The choice provided by John Paul still has an element of punishment involving out-of-school suspension, but the better response from John Paul is to encourage the student to get more specific, much needed help and support.

\section{3 - Zero-tolerance Policies}

All interviewed principals acknowledged the impact zero-tolerance policies have on the decision to suspend a student. The discipline infractions that were identified through interviews as zero-tolerance violations: weapons, drugs, alcohol, threats, racial comments, and destruction of school property. It's important to note that some infractions committed by students are considered safe school violations which are classified as criminal offenses resulting in a student being charged with a crime and call for an automatic long-term suspension. The previously mentioned discipline infractions each result in an out-of-school suspension and are considered infractions that may impact the safety of others while also creating disruptions to the educational setting. School board policies that have been created to address serious offenses in school are necessary inorder to ensure students are safe at school. However, such policies take the decision making and autonomy away from principals. Kim mentioned that zero-tolerance policies "takes you out of it and sometimes that's not good." He continues by saying these policies take away his ability to look at all the facts to determine the best decision to be made. Survey data shows that almost $80 \%$ of school districts have zero-tolerance policies. Of those that responded, $73 \%$ felt that zero-tolerance policies are an effective tool for managing student misbehavior. It must be noted that $10 \%$ of surveyed participants did not have an opinion on the effectiveness of such policies. A few other principals 
empathetically discussed how zero-tolerance policies take away the use of "common sense." If was referenced many times in the interviews that it is challenging to use zerotolerance policies when dealing with "humans" because there are certain circumstances that must be considered when deciding on the most appropriate discipline consequence. One participant, Mary Claire, stated several times that "when you are dealing with humans, not everything fits in a policy." Even considering how zero-tolerance policies may take out the common sense in decision making, all participants discussed the importance of following the policies as established within the student handbook and that have been adapted by the local school board.

\section{4 - Impact on the Decision to Suspend}

The principals that participated in an interview did not feel that out-of-school suspensions had much of an impact on students. Each had their own opinion regarding the impact or lack thereof, but the researcher concludes that the participants did not feel that the suspension given to a student changed that student's behavior. It was mentioned a few times by participants that the infractions that lead to a suspension are committed by students that tend to act out. They further explain that suspensions do not impact students who do not misbehave because those students do not engage in behavior that would result in a suspension. If suspensions had a negative impact on other students, then it can be assumed that suspensions negatively impact the overall school culture. However, based on the data gathered within this study, there was no perceived impact on the school culture.

Only $20 \%$ of surveyed principals felt that suspensions impact the overall school culture. Participants felt that students who consistently misbehave need to be removed 
from the learning environment, so they do not impede the learning of other students. This removal sends a message to other students that there are consequences to negative behavior which could result in an out-of-school suspension.

The impact on other students was not negative; however, suspensions may in fact deter other students from misbehaving. Most of the interviewed participants as well as $71 \%$ of surveyed principals felt that out-of-school suspensions deter other students from misbehaving. However, some feel that students that are focused on earning good grades will not engage in behaviors that will result in an out-of-school suspension. Participant Terry stated that "good students" are worried about their grades and they're not going to do anything that would result in an out-of-school suspension. All interviewed participants agree that suspended students are negatively impacted academically due to the fact that the student is not receiving direct instruction from a classroom teacher nor are they in a learning environment while serving a suspension. Of those surveyed, almost $75 \%$ feel that suspension has a negative impact on that student. It's important to note that $15 \%$ of surveyed principals were neutral on whether OSS had a negative academic impact on the student.

A highly debated topic among school leaders is whether students are allowed to complete school work while suspended and whether they will receive credit for the completed work. Of the principals that were interviewed, $71 \%$ stated that their school district allows students to complete their work for full credit. It should be noted that the researcher in their own experience has noticed that most suspended students do not complete all of the work that was missed due to a suspension. Out-of-school suspensions had the most impact on a student's academic standing more than any other factor. The 
data gathered within this study is inconclusive on whether suspension improves a student's behavior.

Out-of-school suspensions are a reactive discipline practice used as a consequence for student misbehavior. All participants within this study suggest that students are suspended because their actions called for the student to be removed from the learning environment. It was rarely mentioned that a suspension was used to help correct a student's behavior. In fact, most participants did not feel that a student's behavior improved after an out-of-school suspension. Of those surveyed, $42 \%$ were neutral on whether a student's behavior improved and $38 \%$ somewhat agreed that behavior improved after the suspension. Further research aimed at investigating school intervention strategies that are designed to keep students in school and to provide support and transition plans to students who have been suspended may be able to provide more appropriate data on whether suspensions improve student behavior.

\section{Summary}

This study showed that school principals have the freedom to make independent decisions on the most appropriate consequence for student misbehavior. The biggest contributing factor when deciding to most appropriate discipline consequence was based on how much the student misbehavior impacted the learning environment. Each principal has their own educational philosophy as it relates to student discipline. This philosophy helps guide their use of discretion when determining the best approach to manage student misbehavior. The philosophies that guide principals can have an impact on whether to use out-of-school suspension as a form of discipline. The involvement of the school superintendent rarely mentioned by principals in this study. This means that principals 
have the ability to make decisions based on what is best for their school as well as “what's best for students" (personal communication, 2018). The decision to suspend a student out-of-school appeared to be consistent among the participants in this study. Principals feel that suspensions are a necessary consequence to student misbehavior and that it should be used for students who continuously disrupt the learning of others. Data collected in this study will not show if the decision to suspend a student proved to be beneficial. Further research would be necessary to determine the impact a suspension has on a student and whether the suspension has a negative impact on other students or the overall school culture. 


\section{References}

American Academy of Pediatrics. (2013). Out-of-school suspension and expulsion. Council on School Health. Pediatrics 2013; 131; e1000. doi: 10.1542/peds.20123932

Allman, K.L., \& Slate, J.R. (2011). School discipline in public education: A brief review of current practices'. International Journal of Educational Leadership Preparation, V.6 (2).

Blomberg, N. (2003). Effective discipline for misbehavior: In school vs. out of school suspension. Concept: An Interdisciplinary journal of graduate studies. Villanova University.

Department of Elementary and Secondary Education (2018). www.dese.mo.gov

Evans, K.R., \& Lester, J.N. (2012). Zero-tolerance: Moving the conversation forward. Intervention in School and Clinic. 48(2) 108-114. SAGE. DOI: $10.1177 / 1053451212449735$

Hoffman, S. (2014). Zero benefit: Estimating the effect of zero-tolerance discipline policies on racial disparities in school discipline. Educational Policy 28(1) 69-95. SAGE. doi: 10.1177/0895904812453999

Koon, D. S-V., (2013). Exclusionary school discipline; An issue brief and review of literature. The Chief Justice Earl Warren Institute on Law and Social Policy. University of California, Berkeley School of Law. www.warreninstitute.org.

Massar, M.M., McIntosh, K., \& Eliason, B.M., (2015). Do out-of-school suspensions prevent future, exclusionary discipline? Positive Behavior Interventions \& Supports, 2015. 
Morrison, G.M., \& Skiba, R. (2001). Predicting violence from school misbehavior: Promises and perils. Psychology in the Schools, 38(2), 173-184. Doi:10.1002/pits.1008

Reyes, A. H. (2006). Discipline, achievement, and race. Lanham, MD: Rowman \& Littlefield. Reynolds, AJ (1992). Comparing measures of parental involvement and their effects on academic achievement. Early Childhood Research Quarterly, 7(3), 441-462.

Rausch, M. K., \& Skiba, R. J. (2006). Exclusion is not the only alternative: The children left behind project. Discipline, achievement, and race: Is zero-tolerance the answer? Early Childhood Research Quarterly 105-126.

Skiba, R.J., \& Peterson, R. (1999). The dark side of zero-tolerance: Can punishment lead to safe schools? Phi Delta Kappan, 80(5), 372-376.

Skiba, R.J., Chung, C.G., Trachok, M., Baker, T.L., Sheya, A., Hughes, R.L., (2014). Parsing disciplinary disproportionality: Contributions of infraction, student, and school characteristics to out-of-school suspension and expulsion. American Educational Research Journal, 51(4), 640-670. doi: 10.3102/0002831214541670 United States Department of Education (2018). www.2.ed.gov 


\section{SECTION SIX}

SCHOLARLY PRACTITIONER REFLECTION 


\section{Dissertation Influence as an Educator Leader}

Prior to pursuing this doctoral degree, I was serving as a high school principal in a school district that was looking for alternative ways to address student misbehavior instead of using exclusionary practices such as out-of-school suspensions. This involved reading current literature related to out-of-school suspensions and the impact these suspensions have on students. To acquire more knowledge on what occurs at other schools, I contacted principals to see what alternatives they may have been using instead of using out-of-school suspensions as a consequence for student misbehavior. I then began coursework for this doctoral program. During the early stages of this coursework, several of the articles and the literature reviews we were required to do focused on the inequalities in education, more specifically, marginalized students. For the first time in my young educational career, I was enlightened on how so many students in our country are negatively impacted by school discipline policies and procedures.

As I began doing more research, it was evident that students are negatively impacted when suspended from school. In more severe cases, suspensions are necessary especially when the discipline infractions poses potential threats to student safety or when the learning environment is being disrupted. However, there seems to be situations where students are being inappropriately suspended for lengthy periods of times for minor infractions. In these instances, there may be a better approach to addressing that student's behavior. This study has helped me as an educational leader because I have been able to develop a better understanding on the use of OSS as a consequence as well as the perceived positive or negative impact that suspensions may have on students. I have been able to analyze suspensions that I have had a role in and I have been able to identify 
alternative methods to use to address discipline situation rather than just choosing to suspend the student. I have found that principals use suspensions to show students that they are not going to tolerate certain behaviors and that the suspension will send a message to the student(s). The more time I spent reading literature on the use of out-ofschool suspensions, I developed a desire to better understand principal's perception on their use of suspensions. I am not convinced that zero-tolerance policies are an effective strategy to manage student misbehavior. I do believe that the discipline philosophies of school principals can be more effective if principals understand the impact that suspensions have on students; therefore, changing their philosophy on how they use suspensions to address misbehavior. I have found that students who are suspended are negatively impacted academically, because whether they are allowed to receive credit for the work they missed or not, many students will not complete their work while on suspension. Suspensions impact students socially and emotionally and increase the students chances of being suspended again, or may even lead to dropping out. Therefore, it's important for me as a leader to find better and more effective alternatives to suspending students.

My work on student suspensions and the knowledge I have acquired will help me educate and serve as a resource to other principals. It will also allow me to be creative in finding more appropriate consequences that will have more of a positive impact on the behavior of students. I feel that through this research, I can utilize more appropriate consequences to address student misbehavior while also being able to provide supports for overall student improvement. It will now be my goal to work with other principals to foster a similar philosophy and approach to student misbehavior. 


\section{Dissertation Influence as a Scholar}

This dissertation-in-practice challenged me in ways that I never thought was possible. Often times I found myself wanting to research more topics and dive deeper into other areas of student discipline. It was challenging at times to stay focused on my study and the literature that contributed to my study. Exclusionary discipline practice are a controversial topic; therefore multiple research studies exist and are able to show the impact of school exclusion in a variety of ways. I learned through this research that I had to maintain a narrow focus as I went through the process and learned not to lose focus of my research questions and what I was wanting to find out through this study.

This study has showed me that discipline decisions should not be made without being able to analyze data. Also, I have learned that it is important to see what research is available to me that may prove beneficial in my current role of building principal. Far too often, I feel that principals and school leaders make decisions based on what has been done before. However, I have learned that no matter whatever issues we are dealing with in school, there is research out there that can be beneficial to our decision making process. As I worked through this program, I became a better scholar by being able to better understanding the practice of research and how to conduct a study. I realized the importance of being thorough when determining data collection tools and how to analyze the data collected. Also, I feel I have been much more educated in the process of creating effective qualitative and quantitative questions through the use of survey instruments and interviews. I have noticed while serving in my current position of principal, that many of the surveys I get both from our school and others, have questions that are poorly worded. My experience gained from conducting this study showed me how a poorly written 
survey item can have an impact on the data that you are wanting to collect. If questions are not worded properly, you may never receive the correct data to help you make an appropriate decision, or help provide the information you are seeking.

My experience with this dissertation-in-practice and the opportunity to conduct a study of my choice and doing it by myself gives me a sense of credibility with other principal's. This was a challenging process that I had to work through on my own with the support of my dissertation chair. I had to consistently think back on the information I learned through my coursework, take that information and apply it to my study to improve its quality and validity. I learned how to work as a team with group members while realizing that it is not easy to reach a consensus when working as a group. Group work made me realize the importance of working together and this is something that I can apply to my current position. I would encourage all principals to seek to obtain a doctoral degree. It is the most influential educational experience I have ever had and the knowledge I have obtained has made me, and will continue to make me a better leader for our students, school, and community. 


\section{References}

Allman, K.L., \& Slate, J.R. (2011). School discipline in public education: A brief review of current practices'. International Journal of Educational Leadership Preparation, V.6 (2).

American Academy of Pediatrics. (2013). Out-of-school suspension and expulsion. Council on School Health. Pediatrics 2013; 131; e1000. doi: 10.1542/peds.20123932

American Psychologist Association Zero-tolerance Task Force (2008). Are zerotolerance policies effective in the schools? An evidentiary review and recommendations. American Psychologist, 63(9), 852-862. DOI: 10.1037/0003066X.63.9.852.

Arcia, E. (2006). Achievement and enrollment status of suspended students: Outcomes in a large, multicultural school district. Education and Urban Society 38:359-69.

SAGE. doi: 10.1177/0013124506286947

Balfanz, R., Byrnes, V., \& Fox, J. (2014). Sent home and put off-track: The antecedents, disproportionalities, and consequences of being suspended in the ninth grade. Journal of Applied Research on Children: Informing Policy for Children at Risk, 5(2), Article 13.

Baker-Smith, E.C., (2018). Suspensions suspended: Do changes in high school suspension policies change suspension rates? Peabody Journal of Education, 93(2), 190-206. DOI: 10.1080/0161956X.2018.1435043

Bardach, E. (2012). A practical guide for policy analysis: The eightfold path to more effective problem solving (4th Ed.). Los Angeles: Thousand Oaks: Sage; CQ Press 
Bear, G. G., Yang, C., Pell, M., \& Gaskins, C. (2014). Validation of a brief measure of teachers' perceptions of school climate: Relations to student achievement and suspensions. Learning Environments Research, 17(3), 339-354. doi:

$10.1007 / \mathrm{s} 10984-014-9162-1$

Blackmore, J. (2009). Leadership for social justice: A transnational dialogue. Journal of Research on Leadership Education. 4(1).

Blomberg, N. (2003). Effective discipline for misbehavior: In school vs. out of school suspension. Concept: An Interdisciplinary journal of graduate studies. Villanova University.

Brent, J.J. (2016). Placing the criminalization of school discipline in economic context. Punishment \& Society, 18(5) 521-543. SAGE. doi 10.1177/1462474516642858

Cohen, R.W. (2013). Reframing the problem: New institutions and exclusionary discipline in schools. Journal for Educational Controversy V 7: N 1. Article 6. University of Texas at Austin.

Corbin, J., \& Strauss, A. (1994). Grounded theory methodology. Handbook of qualitative research, 17, 273-285

Creswell, J.W. (2009). Research design: Qualitative, quantitative, and mixed methods approaches. ( $3^{\text {rd }}$ Ed.). Los Angeles, C.A. SAGE

Department of Elementary and Secondary Education, (2018). www.dese.mo.gov

Dunbar, C., \& McNeal, L. (2010). In the eyes of the beholder: Urban student perceptions of zero-tolerance policy. Urban Education. 45(3) 293-311. SAGE. doi: $10.1177 / 0042085910364475$ 
Dupper, D.R., Theriot, M.T., \& Craun, S.W. (2009). Reducing out-of-school suspension: Practice guidelines for school social workers. Children Schools. 31(1), p. 6-14 doi:10.1093/cs/31.1.6

Evans, K.R., \& Lester, J.N. (2012). Zero-tolerance: Moving the conversation forward. Intervention in School and Clinic. 48(2) 108-114. SAGE. DOI: $10.1177 / 1053451212449735$

Feld, A. (2013). Discovering statistics using IBM SPSS statistics. (4 ${ }^{\text {th }}$. Ed.). London, UK. Sage.

Findlay, N.M. (2015. Discretion in student discipline: Insight into elementary principal's' decision making. Educational Administration Quarterly. 51(3) p. 472-507. SAGE. doi. 10.177/001316X14523617

Fink, A. (2017). How to conduct surveys: A step-by-step guide. Sage Publications.

Flanagan, W. C. (2007). A Survey-the negative aspects of in and out of school suspensions and alternatives that promote academic achievement. Online Submission. Retrieved from ERIC.

Gentles, S. J., Charles, C., Ploeg, J., \& McKibbon, K. A. (2015). Sampling in qualitative research: Insights from an overview of the methods literature. The Qualitative Report, 20(11), 1772-1789. http://nsuworks.nova.edu/tqr/vol20/iss11/5

Hoffman, S. (2014). Zero benefit: Estimating the effect of zero-tolerance discipline policies on racial disparities in school discipline. Educational Policy 28(1) 69-95. SAGE. doi: 10.1177/0895904812453999 
Horsford, S.D., \& Powell, K.L., (2016) Second chance academy: Alternative school or pathway to prison? Journal of Cases in Educational Leadership, 19(1) 18-17.

\section{SAGE}

Koon, D. S-V., (2013). Exclusionary school discipline; An issue brief and review of literature. The Chief Justice Earl Warren Institute on Law and Social Policy. University of California, Berkeley School of Law. www.warreninstitute.org.

Kowalski, T.J., (2006). The school superintendent: Theory, practice, and cases $\left(2^{\text {nd }}\right.$ Ed.). Thousand Oaks, CA. Sage Publications.

Lauer, P. (2014). Out-of-school suspensions: Consequences and alternatives. RMC Health. Retrieved from rmchealth.org.

Losen, D. J., \& Martinez, T. E. (2013). Out of school and off track: The overuse of suspensions in American middle and high schools. K-12 Racial Disparities in School Discipline. The Civil Rights Project.

Massar, M.M., McIntosh, K., \& Eliason, B.M., (2015). Do out-of-school suspensions prevent future, exclusionary discipline? Positive Behavior Interventions \& Supports, 2015.

Mathews, S.K. \& Agnew, R., (2008). Extending deterrence theory: Do delinquent peers condition the relationship between perceptions of getting caught and offending? Journal of Research in Crime and Delinquency, 45(2), 91-113

Mayer, M.J., \& Jimerson, S.R., (2018). School safety and violence prevention: Science, practice and policy. American Psychological Association.

Merriam, S. B. (2009). Qualitative research: A guide to design and implementation. San Francisco, CA: Jossey-Bass. 
Mirsky, L. (2007). SaferSanerSchools: Transforming school culture with restorative practices. Reclaiming Children and Youth, 16(2), 5-12.

Morris, E. \& Perry, B. L (2014) Suspending progress: Collateral consequences of exclusionary punishment in public schools. American Sociological Review 79:1067-87. Oxford Press. doi: 10.1177/0003122414556308

Morris, E. \& Perry, B. L. (2016). The punishment gap: School suspension and racial disparities in achievement. Social Problems 63(1): 68-86. Advance Access. doi:10.1093/socpro/spv026

Morrison, G.M., \& Skiba, R. (2001). Predicting violence from school misbehavior: Promises and perils. Psychology in the Schools, 38(2), 173-184.

Doi:10.1002/pits. 1008

Ngai, N.P., \& Cheung, C.K. (2005). Predictors of the likelihood of delinquency, A study of marginal youth in Hong Kong, China. Youth and Society, 36(4) 445-470.

Payne, A.A. \& Welch, K., (2017). The effect of school conditions on the use of restorative justice in schools. Youth Violence and Juvenile Justice, 1-17. DOI: $10.1177 / 1541204016681414$

Rausch, M. K., \& Skiba, R. J. (2006). Exclusion is not the only alternative: The children left behind project. Discipline, achievement, and race: Is zero-tolerance the answer? Early Childhood Research Quarterly 105-126.

Reyes, A. H. (2006). Discipline, achievement, and race. Lanham, MD: Rowman \& Littlefield. Reynolds, AJ (1992). Comparing measures of parental involvement and their effects on academic achievement. Early Childhood Research Quarterly, 7(3), 441-462. 
Roby, D. E. (2004). Research on school attendance and student achievement: A study of Ohio schools. Educational Research Quarterly, 28(1), 3.

Seidman, I. (2012). Interviewing as qualitative research: A guide for researchers in education and the social sciences ( $4^{\text {th }}$ Ed.). New York, NY: Teachers College Press.

Shaughnessy, M.A. (2002). School handbooks: Legal considerations. (2 ${ }^{\text {nd }}$ Ed.) National Catholic Educational Association. Washington, D.C. www.ncea.org

Skiba, R.J. (2000). Zero tolerance, zero evidence: An analysis of school disciplinary practice. Policy Research Report, Indiana Education Policy Center, Smith Research Center, August, 2000.

Skiba, R.J., Peterson, R.L., \& Williams, T. (1997). Office referrals and suspension: Disciplinary intervention in middle schools. Education and Treatment of Children, 20(3), 295-315.

Skiba, R.J., \& Peterson, R. (1999). The dark side of zero-tolerance: Can punishment lead to safe schools? Phi Delta Kappan, 80(5), 372-376.

Skiba, R.J., Chung, C.G., Trachok, M., Baker, T.L., Sheya, A., Hughes, R.L., (2014). Parsing disciplinary disproportionality: Contributions of infraction, student, and school characteristics to out-of-school suspension and expulsion. American Educational Research Journal, 51(4), 640-670. doi: 10.3102/0002831214541670

Steinberg, M.P., Allensworth, E., \& Johnson, D.W., (2011). Student and teacher safety in Chicago public schools: The roles of community context and school social organization. May 2011. Consortium of Chicago of School Research at the University of Chicago Urban Education Institute. 
Sullivan, A.L., Klingbeil, D.A., \& Van Norman, E.R. (2013). Beyond behavior: Multilevel analysis of the influence of sociodemographics and school characteristics on students' risk of suspensions. School Psychology Review, 42(1), pp. 99-114.

Szeto, E., \& Cheng, A.Y.N. (2018). How do principals practice leadership for social justice in diverse school settings? A Hong Kong case study. Journal of Educational Administration, 56(1) pp. 50-68. doi: 10.1108/JEA0820160087

Tobin, T.J., \& Vincent, C.G., (2011). Strategies for preventing disproportionate exclusions of African American students. Preventing School Failure, 55(4), $192-$ 201. DOI: $10.1080 / 1045988 X .2010 .532520$

United States Department of Education (2018). www.2.ed.gov

Wallace, J.M., Jr., Goodkind, S.G., Wallace, C.M., \& Bachman, J. (2008). Racial, ethic, and gender differences in school discipline among American high school students: 1991-2005. Negro Educational Review, 59, 47-62. 


\section{Appendix A}

\section{Interview Questions}

1. Have you had to use out-of-school suspension as a form of student discipline?

2. Why do you chose to use out-of-school suspensions?

3. Is your decision to suspend a student out-of-school a result of mandated policies, or are you given the autonomy to use your professional discretion?

4. Can you identify some characteristics that may have impacted your decision to suspend a student out-of-school?

5. Does a student's home life impact whether or not a student is suspended out of school?

6. What are the most common infractions that have resulted in an out-of-school suspension?

a. Can you tell me about a time where you suspended a student because the infraction called for the use of a mandated school policy with the predetermined consequence being out-of-school suspension?

b. Can you describe a time that you chose not to suspend a student even though past instances of this behavior has resulted in out-of-school suspensions?

c. What role do parents, teachers, or other adults play in the decision to suspend a student?

d. Are there times where a student's patronage to individual adults have an impact on whether they are suspended out of school?

e. What role or impact do other principals, assistant principals, superintendents, etc., have on the decision to suspend a student out of school?

7. Do you feel the use of out-of-school suspension is an effective consequence to manage student misbehavior?

8. What do you feel is the main purpose of using out-of-school suspension as a form of discipline?

9. Do you feel that out-of-school suspensions are unnecessarily used?

10. Do you feel that out-of-school suspensions are used too often or too much?

11. What is your opinion on the use of mandated policies, such as zero-tolerance policies?

12. Do you feel that out-of-school suspensions deter other students from misbehaving?

13. In your opinion, do you feel there are alternative forms of discipline that can be used in place of out-of-school suspension?

14. Does your school have transition plans for when a student returns from an out-of-school suspension?

15. Do you have an alternative school?

16. Do you allow students to make up their classwork while on a suspension? 
Appendix B

\section{INFORMED CONSENT}

\section{Purpose of Study:}

The purpose of this study is to analyze principal use of out-of-school suspension as a form of discipline for student misbehavior. Study approval \#20112667.

\section{Principal Investigator:}

Seth Harrell

\section{Institute:}

Southeast Missouri State University

University of Missouri-Columbia

\section{Introduction:}

You have been chosen to participate in an interview which will produce data for this study. This study will help to identify principal perceptions on the of out-of-school suspensions, the characteristics that influence principals decision to suspend, as well as a comparison on the use of out-of-school suspensions in large and small high schools in Southeast Missouri.

\section{Background Information:}

This research will fulfill the dissertation requirements for the Educational Leadership and Policy Analysis Doctoral program through the University of Missouri-Columbia and Southeast Missouri State.

\section{Procedures:}

Participants will be invited to participate in an interview conducted by the principal investigator. In this study, you will be asked a series of open-ended questions, which will be audio recorded. These recordings will be transcribed. The participants name will be changed to a pseudonym in the transcriptions and in the study in order to protect the participant's privacy. All other information or characteristics that might disclose the participant's identity will be changed to further protect the privacy of the participant. This interview will take approximately 30 minutes to conduct.

\section{Possible Risks or Benefits:}

There are no risks to participants of this study. The information and data collected will be used to help school districts determine best practices when deciding to suspend student's out-of-school. It is possible that this study will encourage school districts and principals to analyze school discipline polices to determine best practice for managing student misbehavior.

\section{Right to Refusal to Participate and Withdrawal:}

You are welcome to participate in this study and can withdrawal from this study at any time. Participants may also refuse to answer some or all of the questions. 


\section{Confidentiality:}

Any information obtained by the researcher will remain confidential. Only the principal investigator will have access to the information. The name and identity of participants will not be disclosed at any time.

\section{AUTHORIZATION}

I have read and understand this consent form, and I volunteer to participate in this research study. I understand that I will receive a copy of this form. I voluntarily choose to participate, but I understand that my consent does not take away any legal rights in the case of negligence or other legal fault of anyone who is involved in this study. I further understand that nothing in this consent form is intended to replace any applicable federal, state, or local laws.

Participant's Name (Printed):

Participant's Signature:

Date:

Principal Investigator's Signature:

Date:

\section{CONSENT TO BE AUDIO-RECORDED DURING THE INTERVIEW}

I consent to be audio-recorded during the approximately 10-20 minute interview. I understand I can decline to be recorded at any time.

Participant's Name (Printed):

Participant's Signature:

Date:

Principal Investigator's Signature:

Date: 
Appendix C

Survey Items

Principal use of Out-of-School Suspension as a Form of Student Discipline Q5 - Does your school district have board policies that mandate a predetermined consequence (zero-tolerance) for a violation of certain school rules?

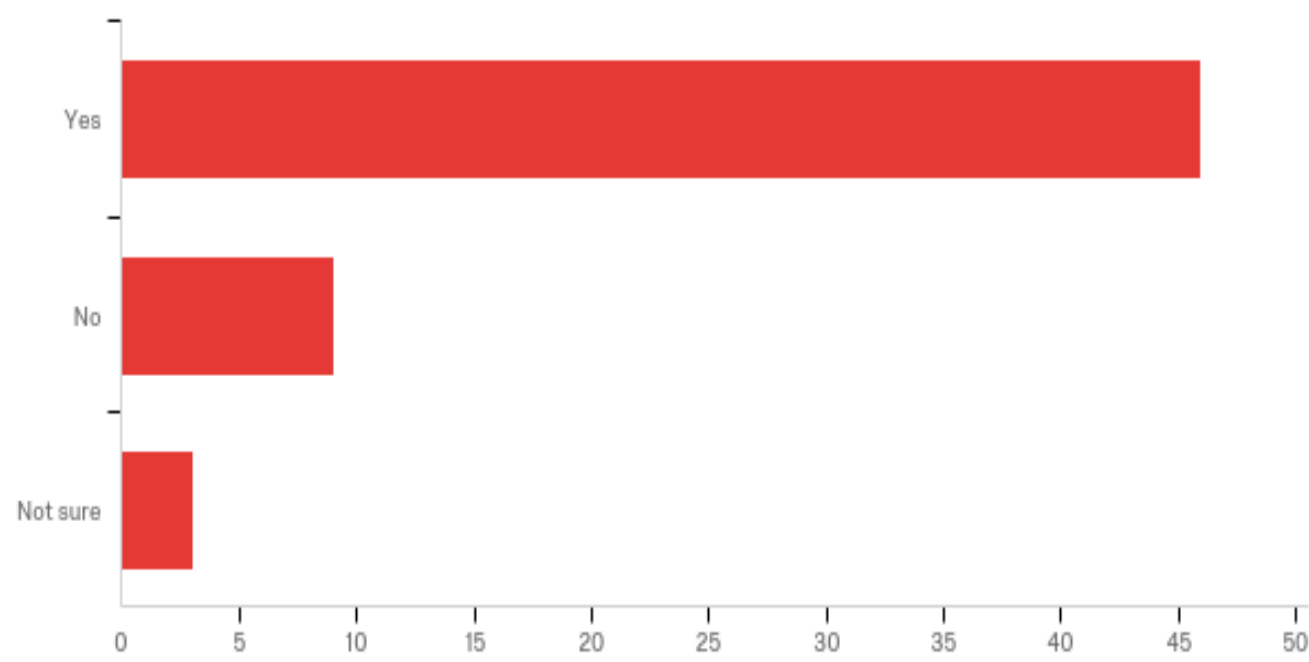

\begin{tabular}{r|r|r|r}
\hline$\#$ & Answer & $\%$ & Count \\
\hline 1 & Yes & $79.31 \%$ & 46 \\
\hline 2 & No & $15.52 \%$ & 9 \\
\hline 4 & Not sure & $5.17 \%$ & 3 \\
\hline & Total & $100 \%$ & 58
\end{tabular}


Q6 - Zero-tolerance policies are an effective student management strategy used to address students who have violated school rules.

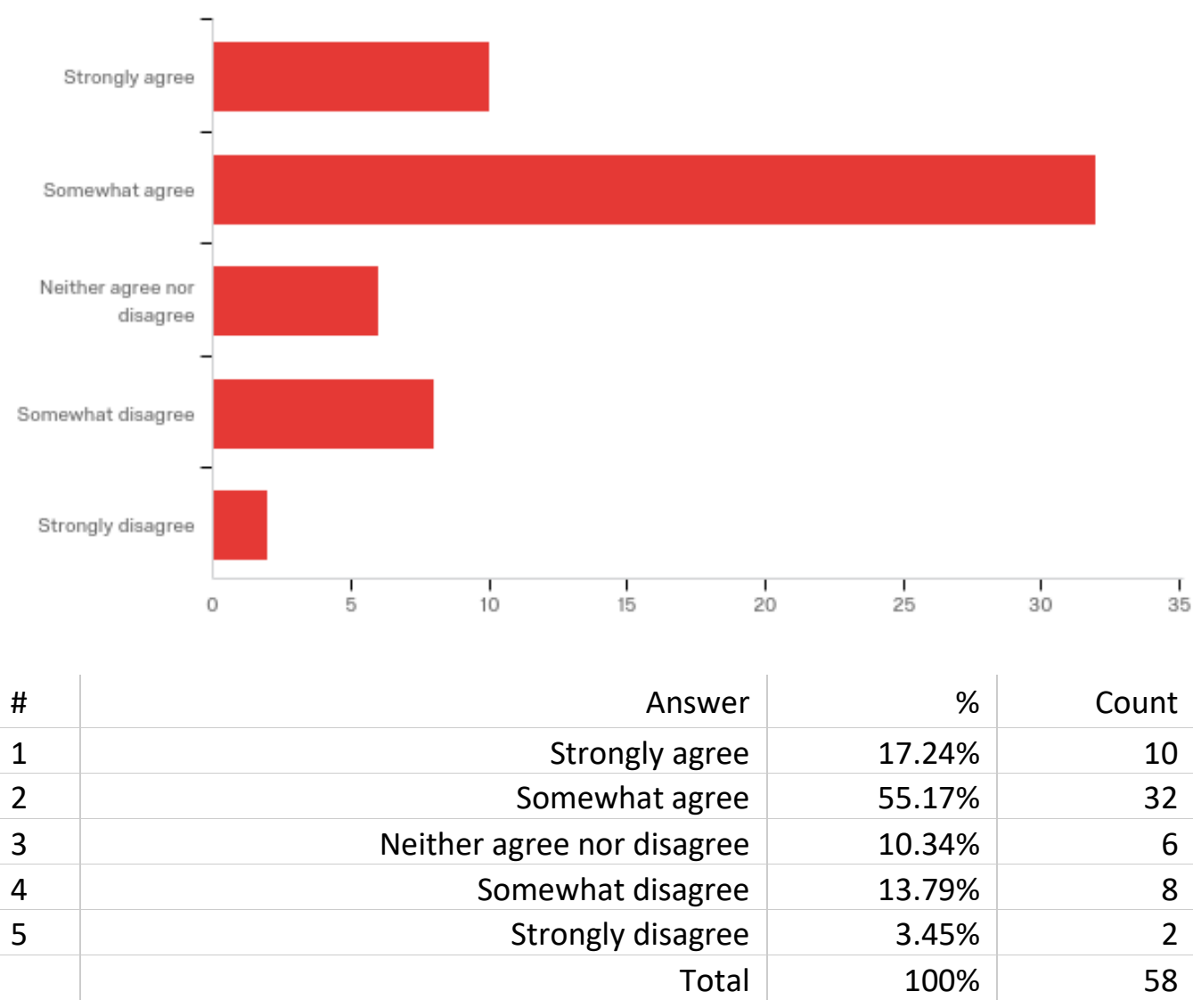


Q7 - Most of the out-of-school suspensions in your school are a result of zero-tolerance policies with predetermined consequences.

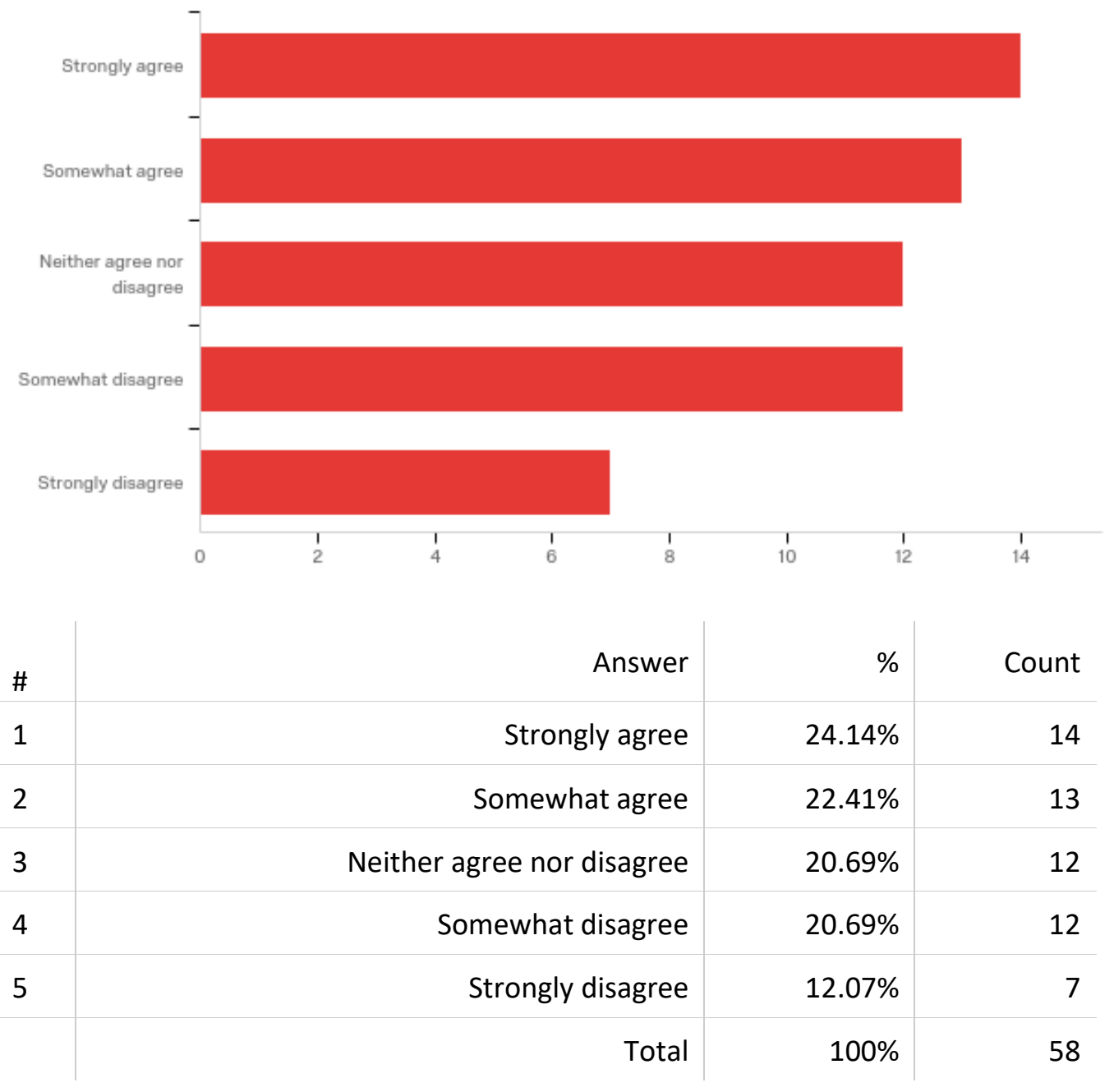


Q8 - Most of the out-of-school suspensions in your school are a result of the use of principal discretion.

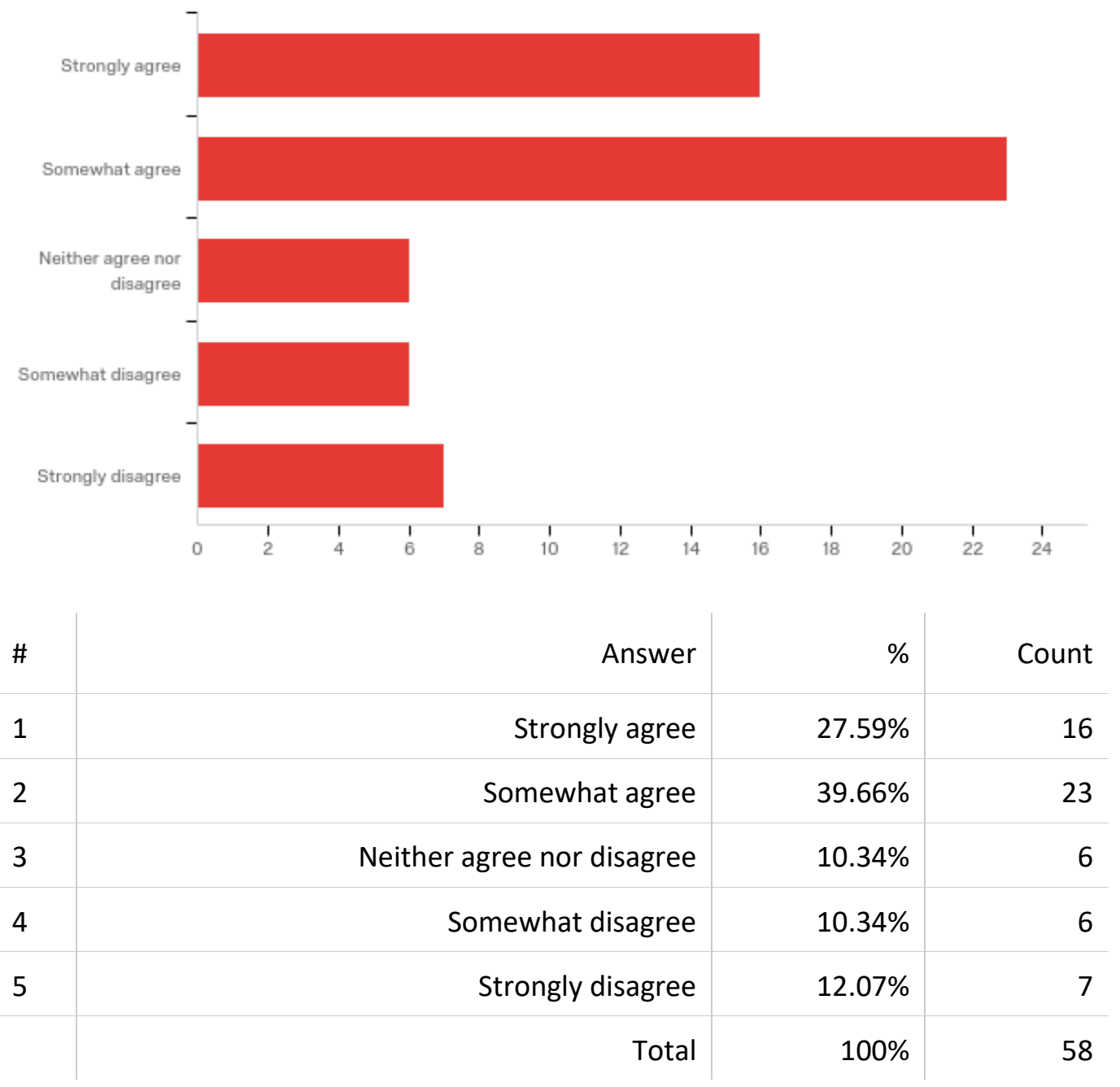


Q3 - Out-of-school suspensions are an effective method used

to address student discipline problems.

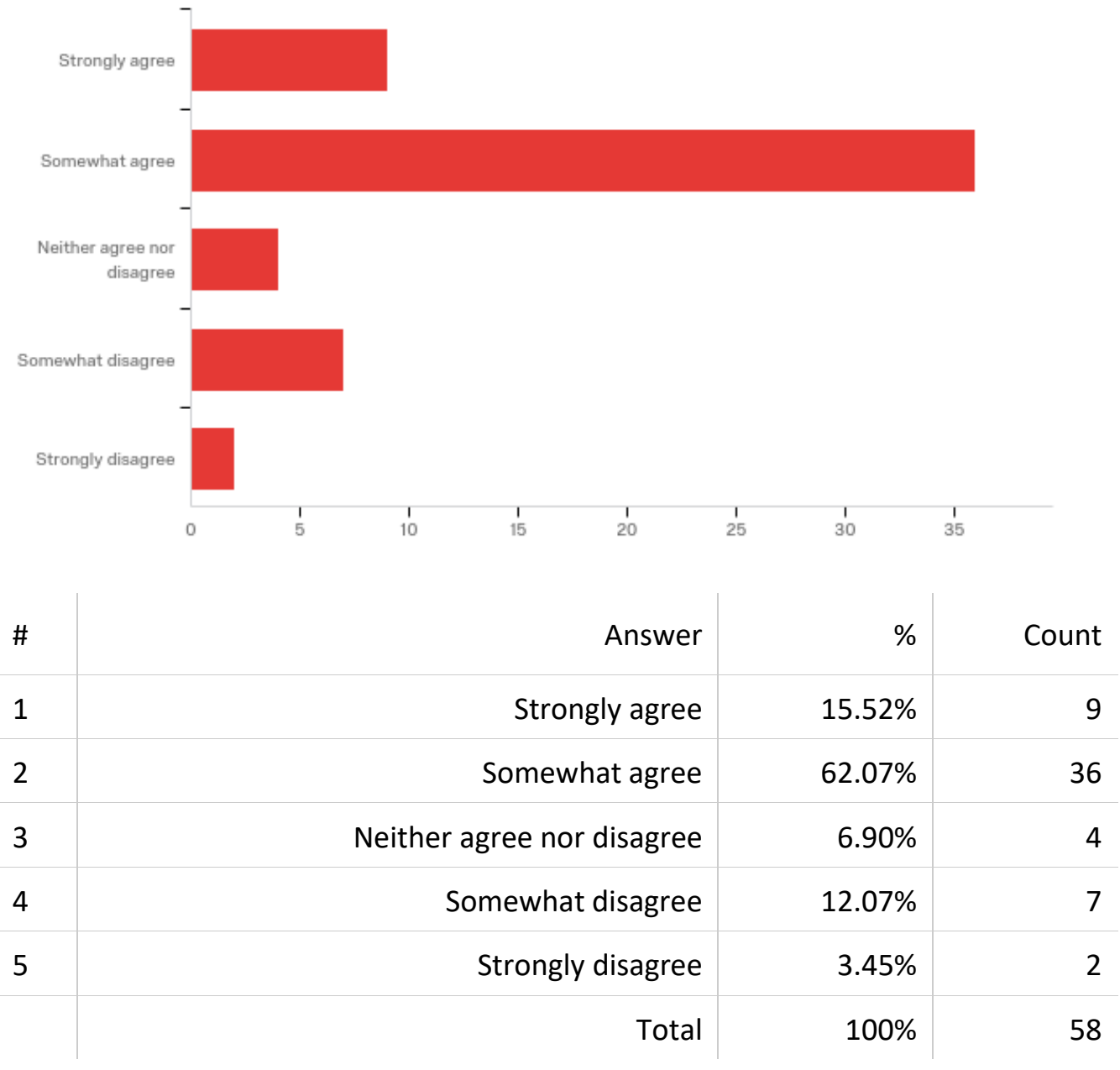


Q4 - Out-of-school suspensions deter students from breaking school rules.

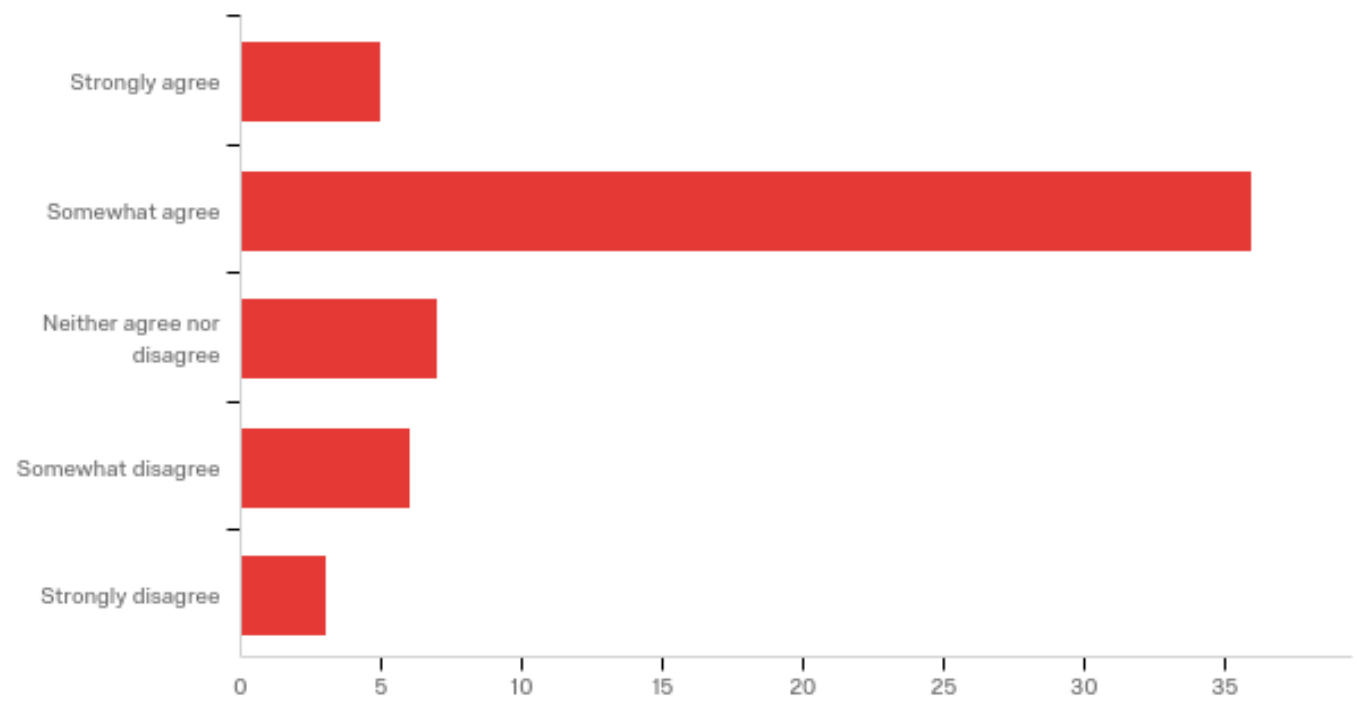

\begin{tabular}{l|r|r|r}
\hline$\#$ & Answer & $\%$ & Count \\
\hline 1 & Strongly agree & $8.77 \%$ & 5 \\
\hline 2 & Somewhat agree & $63.16 \%$ & 36 \\
\hline 3 & Neither agree nor disagree & $12.28 \%$ & 7 \\
\hline 4 & Somewhat disagree & $10.53 \%$ & 6 \\
\hline 5 & Strongly disagree & $5.26 \%$ & 3 \\
\hline & Total & $100 \%$ & 57
\end{tabular}


Q19 - Out-of-school suspensions negatively impact the overall school culture.

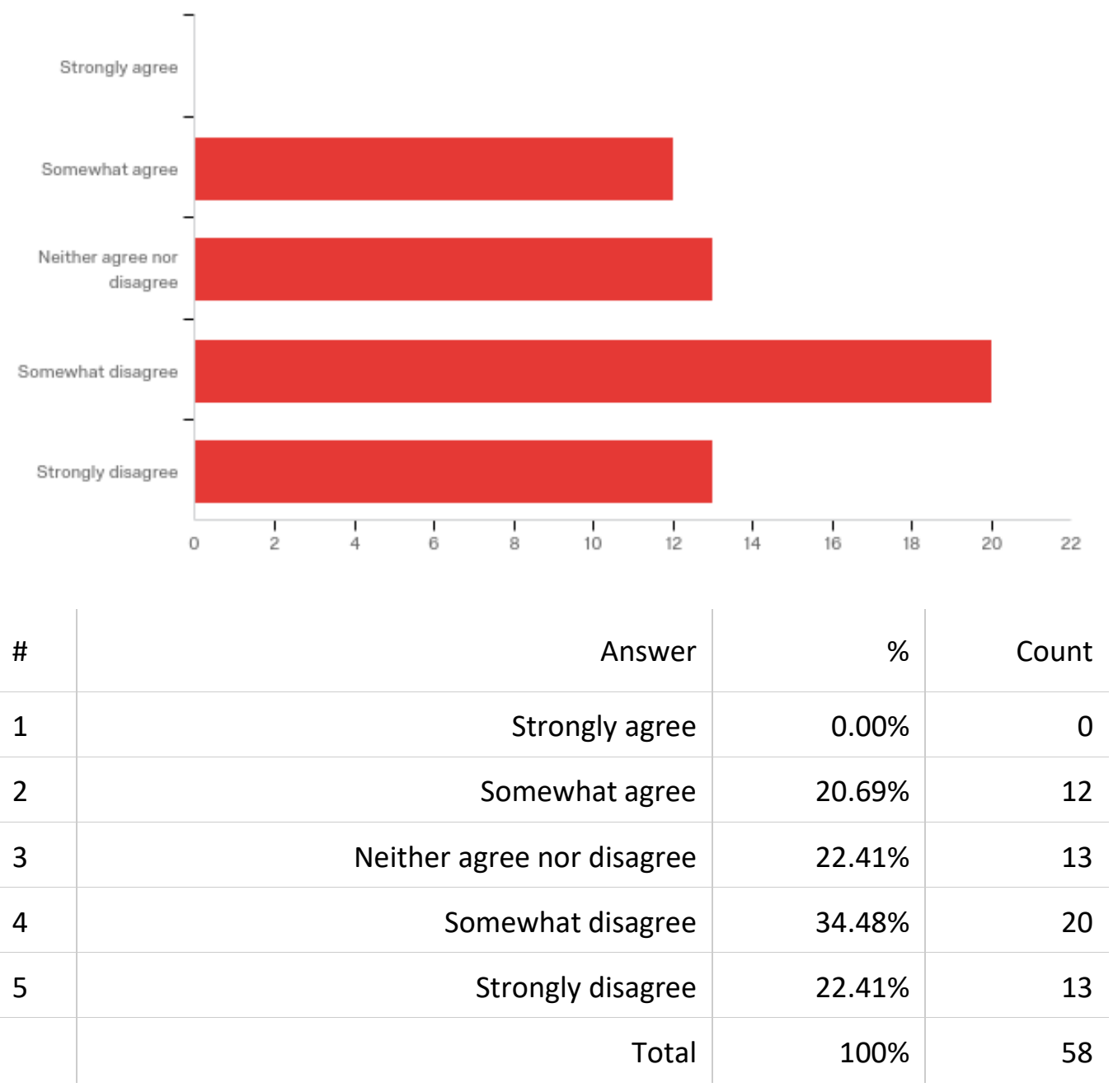


Q20 - Out-of-school suspensions negatively impact students in the classroom or school setting that have NOT misbehaved or violated school rules.

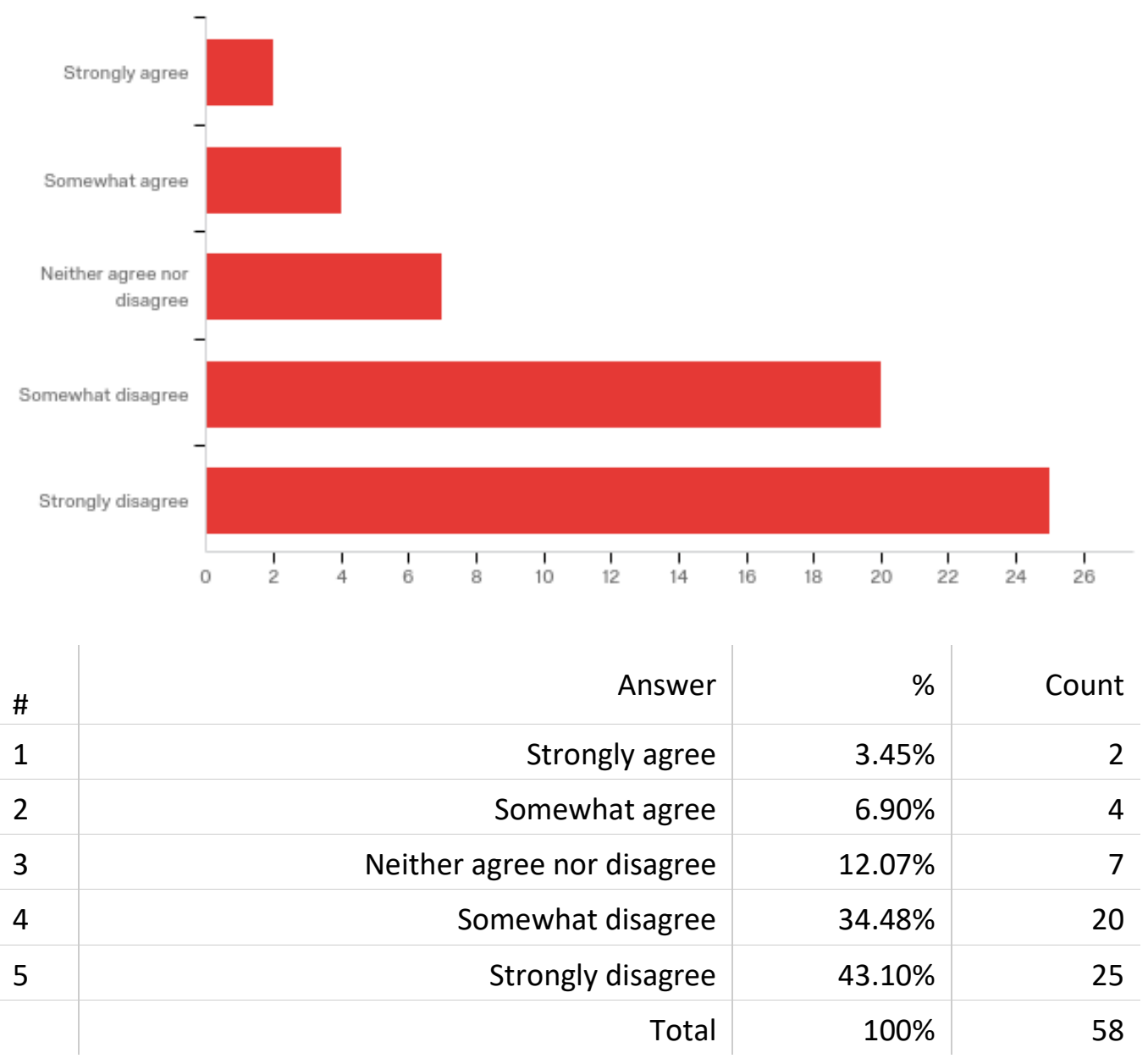


Q21 - Out-of-school suspensions create negative relationships with suspended students and school staff.

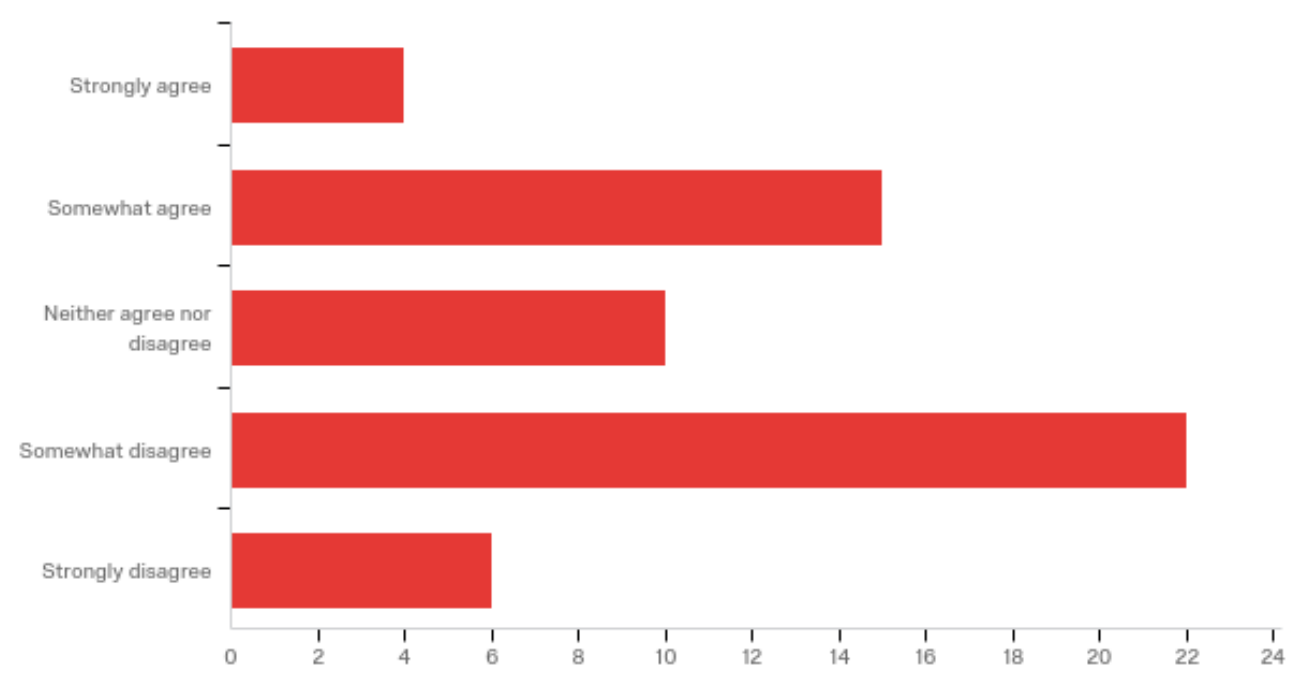

\begin{tabular}{l|r|r|r}
\hline$\#$ & Answer & $\%$ & Count \\
\hline 1 & Strongly agree & $7.02 \%$ & 4 \\
\hline 2 & Somewhat agree & $26.32 \%$ & 15 \\
\hline 3 & Neither agree nor disagree & $17.54 \%$ & 10 \\
\hline 4 & Somewhat disagree & $38.60 \%$ & 22 \\
\hline 5 & Strongly disagree & $10.53 \%$ & 6 \\
\hline & Total & $100 \%$ & 57
\end{tabular}


22 - Out-of-school suspensions have a negative impact on student academic performance.

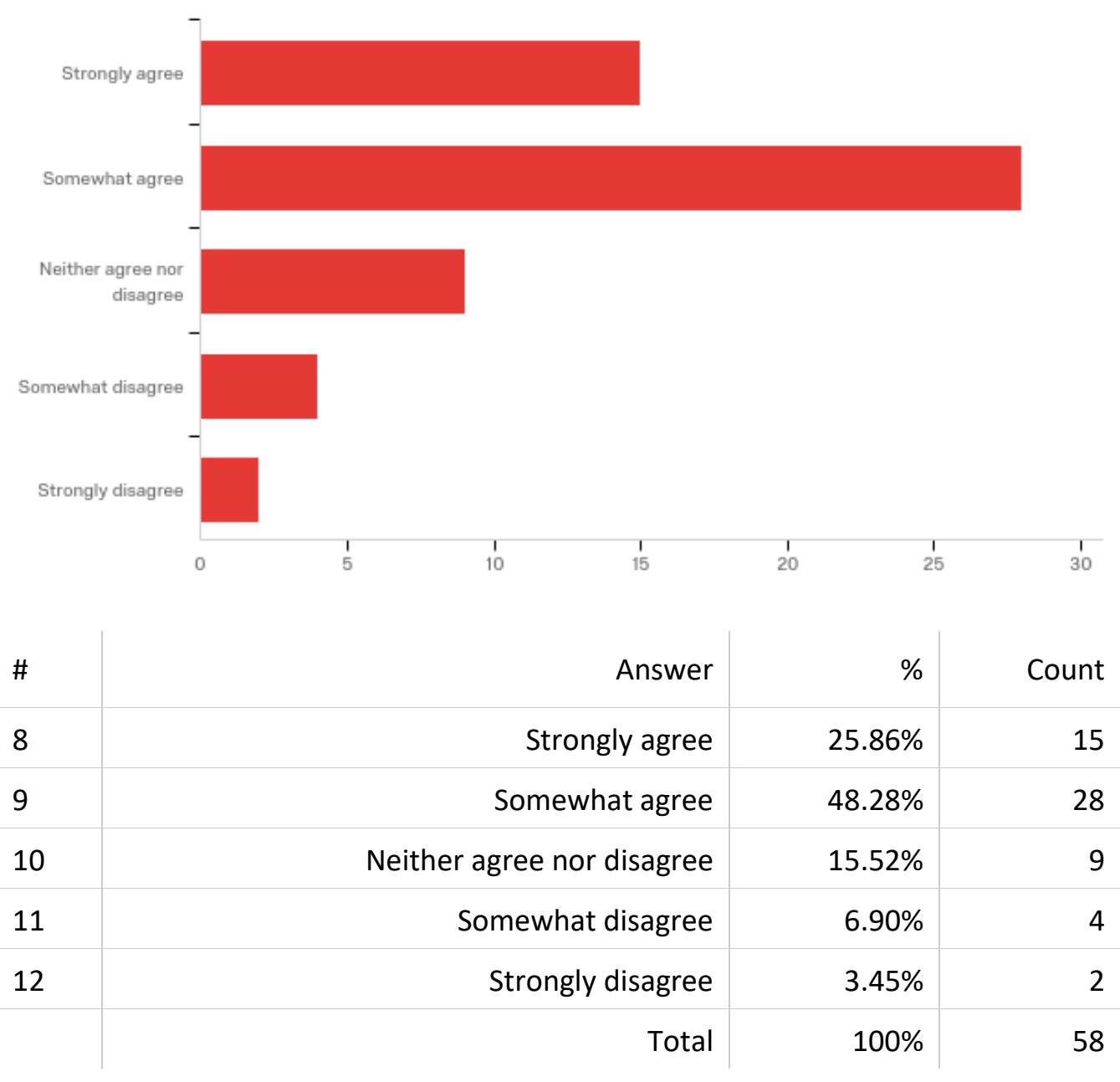


Q23 - Out-of-school suspensions have a negative social and emotional impact on a student.

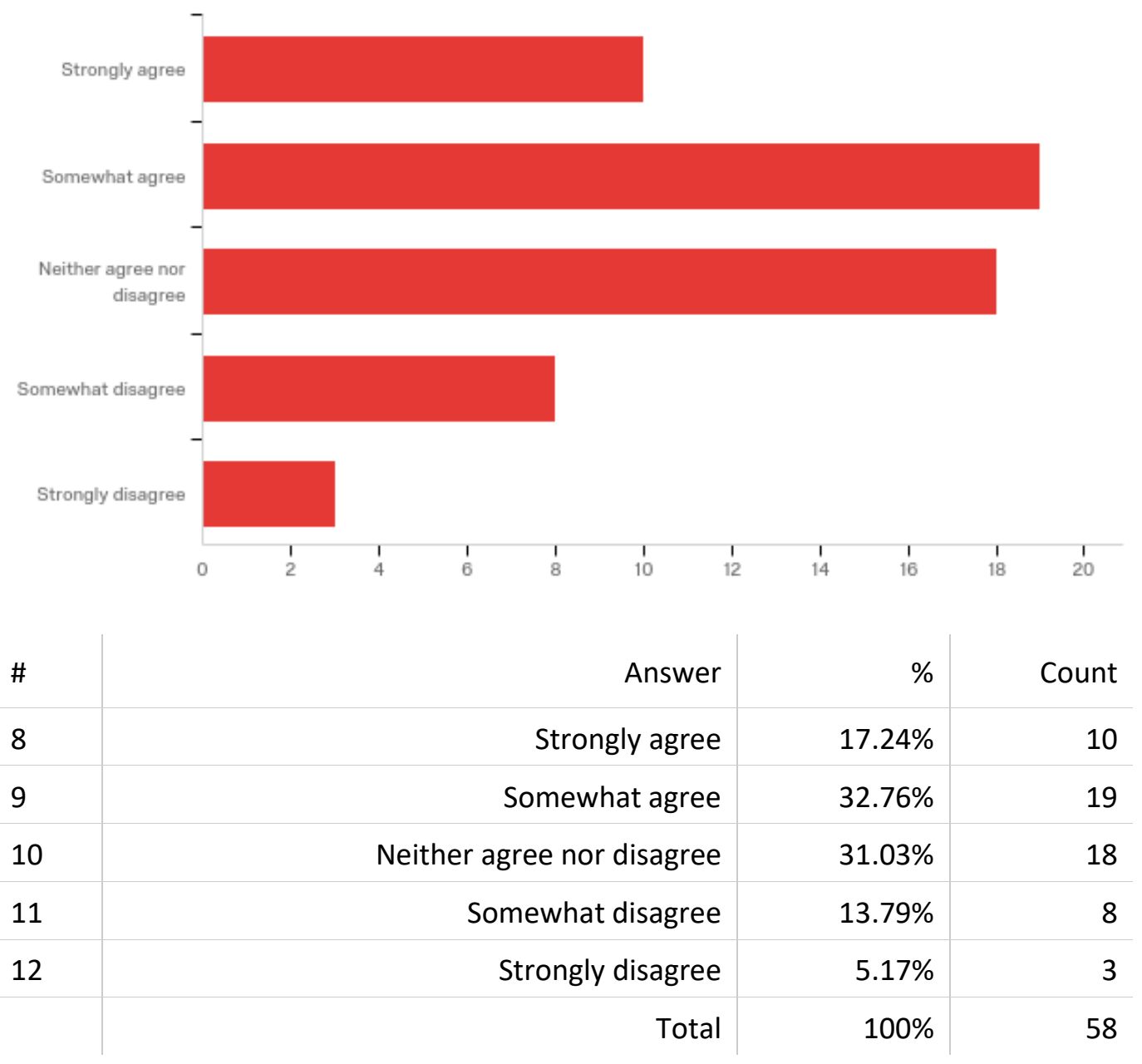


Q9 - The number of students enrolled in a high school impacts the decision to suspend a student out-of-school.

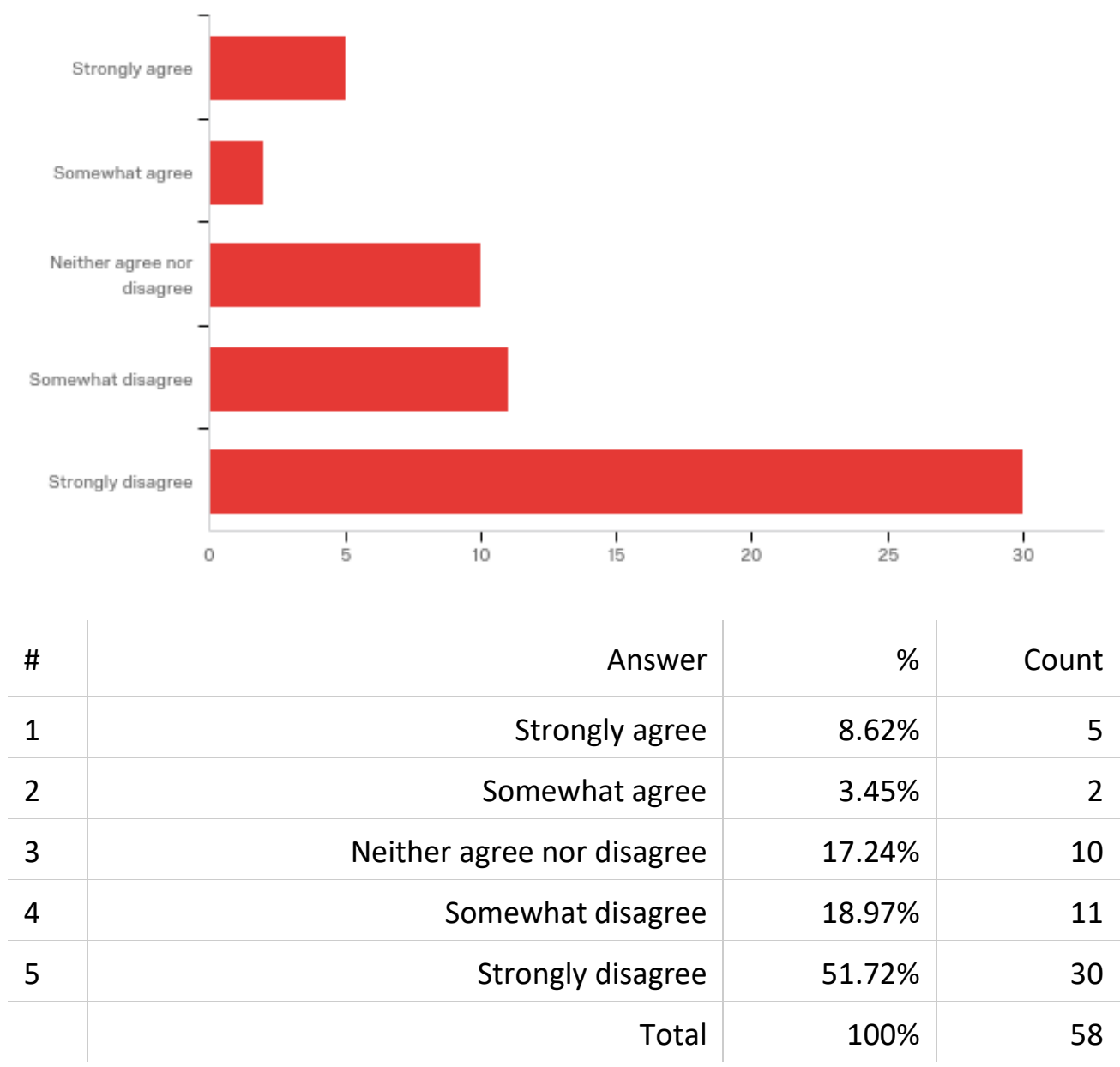


Q10 - Out-of-school suspensions have more of a negative impact in smaller enrollment high schools than in larger enrollment high schools.

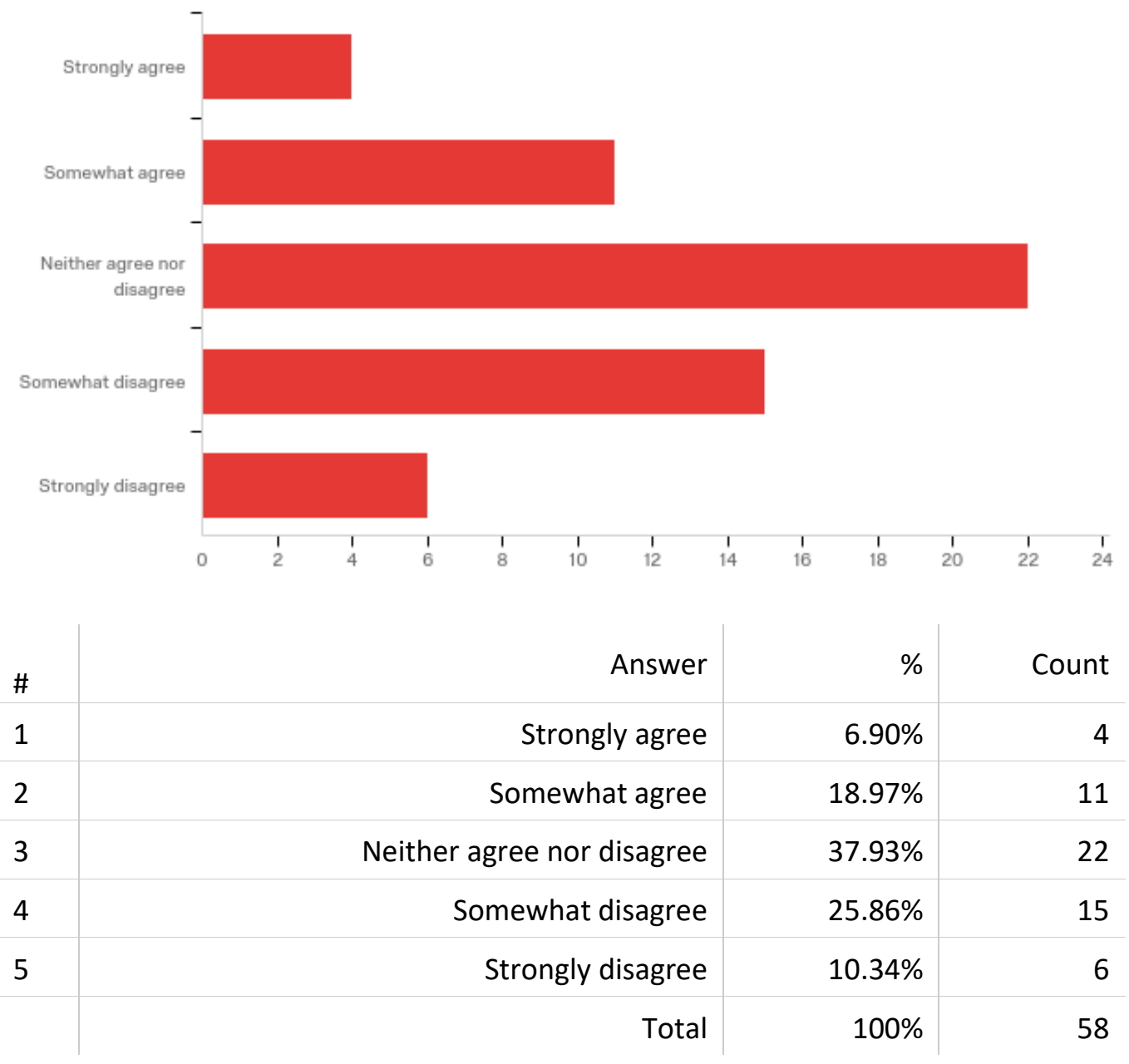


Q11 - Out-of-school suspensions have more of a negative impact in larger enrollment high schools than in smaller enrollment high schools.

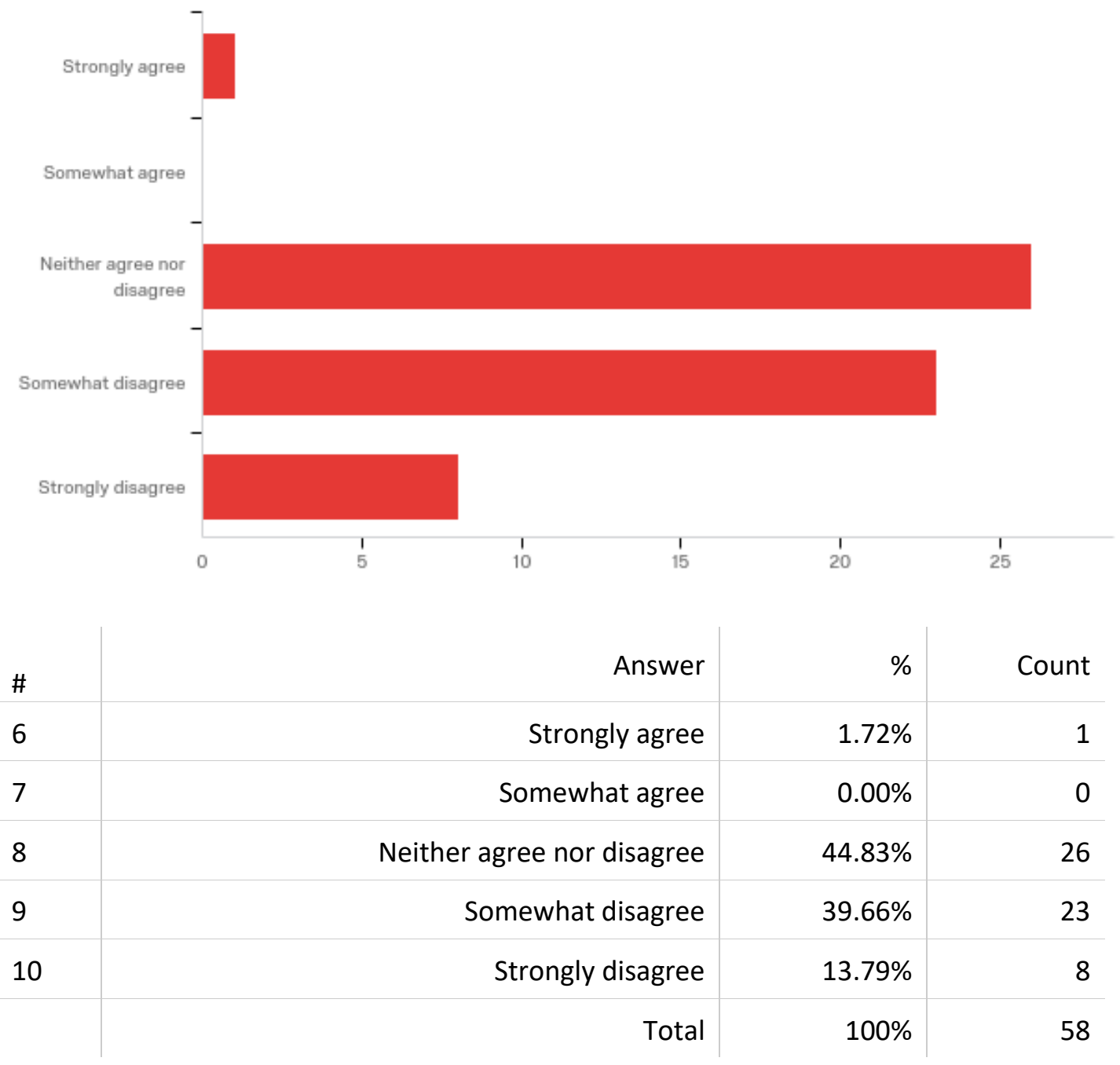


Q15 - In your experience, what is the average number of days a student would be suspended out-of-school for drug or alcohol possession/consumption?

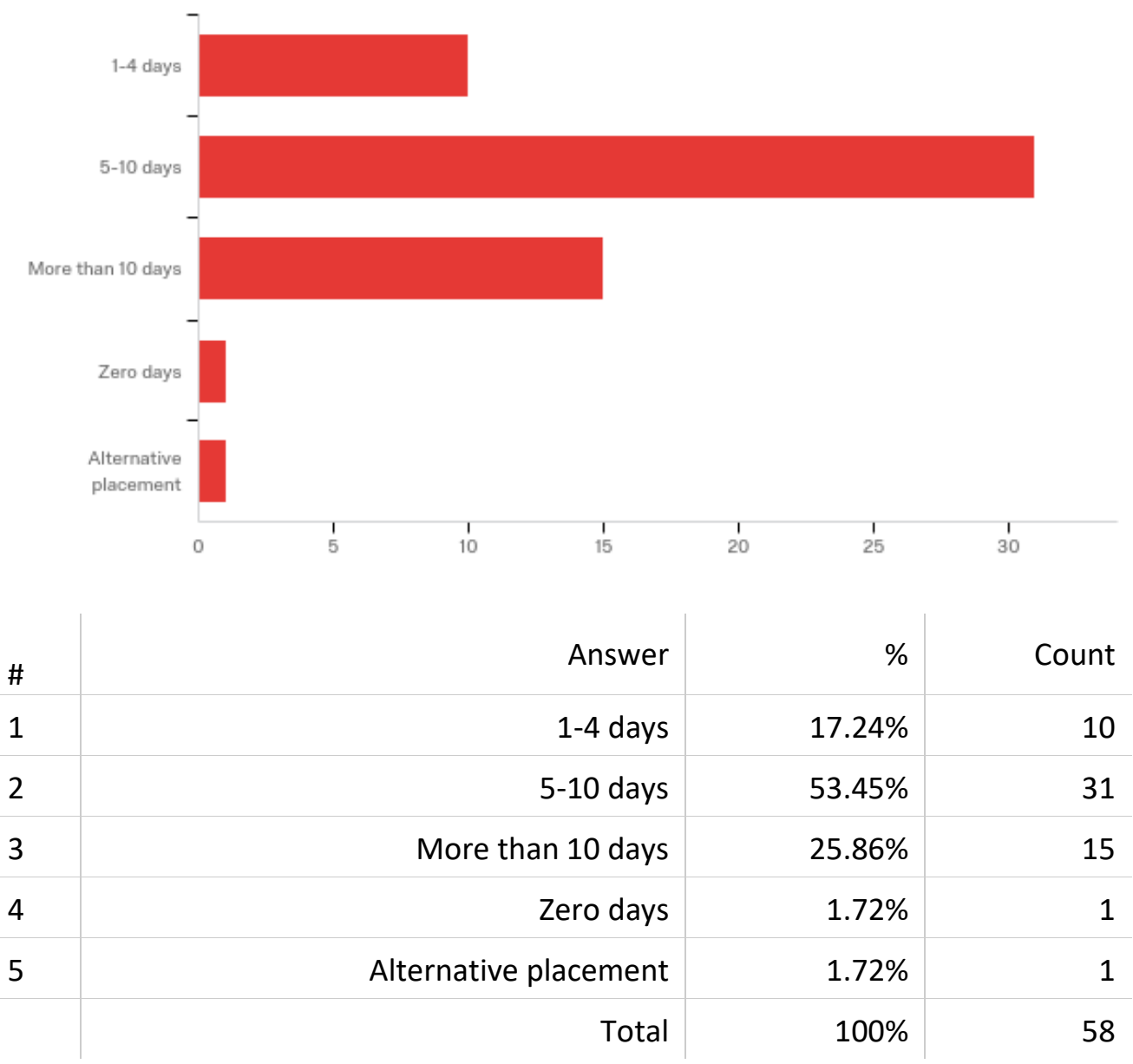


Q16 - In your experience, what is the average number of days a student would be suspended out-of-school for fighting?

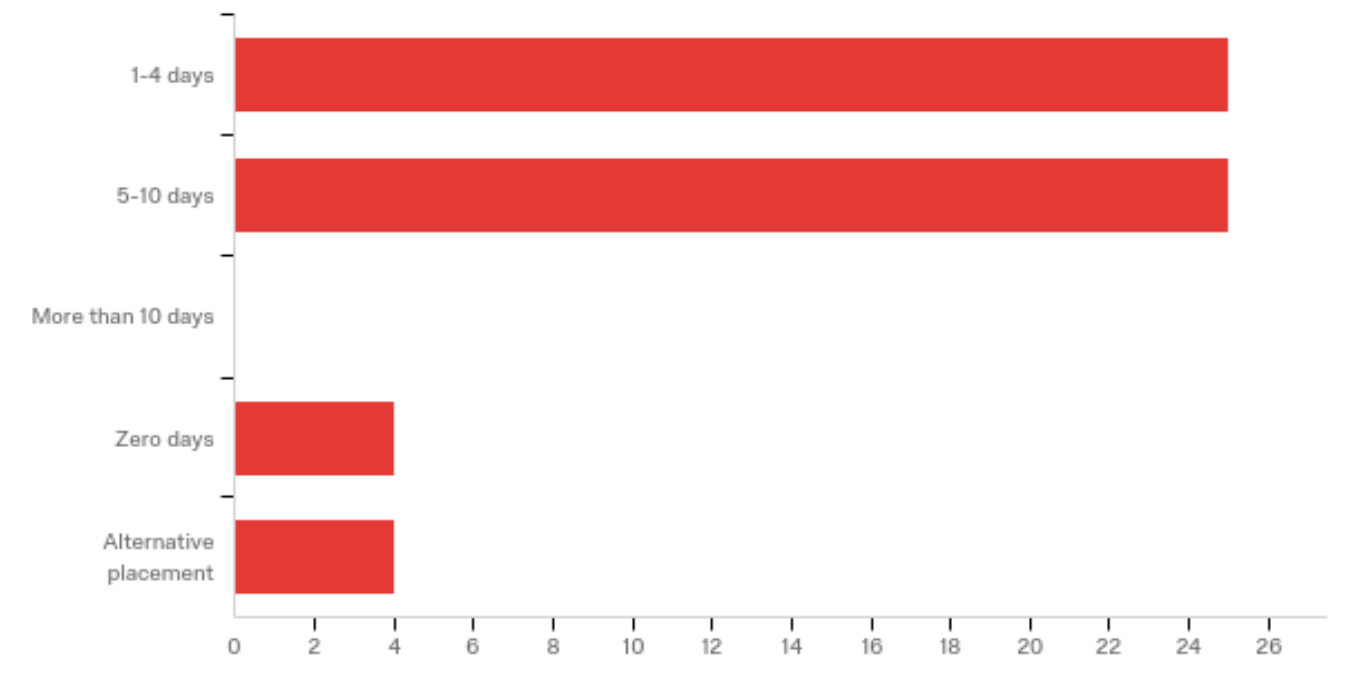

\begin{tabular}{|r|r|r|r}
\hline$\#$ & Answer & $\%$ & Count \\
\hline 1 & $1-4$ days & $43.10 \%$ & 25 \\
\hline 2 & $5-10$ days & $43.10 \%$ & 25 \\
\hline 3 & More than 10 days & $0.00 \%$ & 0 \\
\hline 4 & Zero days & $6.90 \%$ & 4 \\
\hline 5 & Alternative placement & $6.90 \%$ & 4 \\
\hline & Total & $100 \%$ & 58 \\
\hline
\end{tabular}


Q17 - In your experience, what is the average number of days a student would be suspended out-of-school for having a weapon on campus?

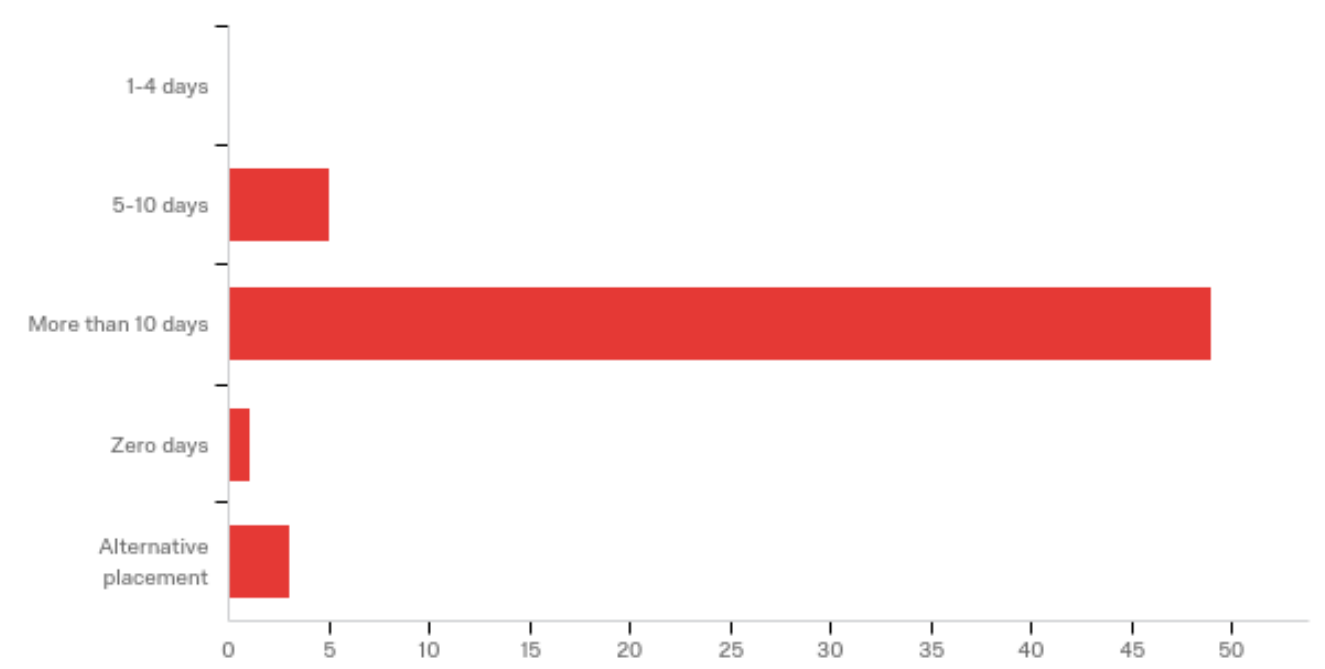

\begin{tabular}{l|r|r|r}
$\#$ & Answer & $\%$ & Count \\
\hline 1 & $1-4$ days & $0.00 \%$ & 0 \\
\hline 2 & $5-10$ days & $8.62 \%$ & 5 \\
\hline 3 & More than 10 days & $84.48 \%$ & 49 \\
\hline 4 & Zero days & $1.72 \%$ & 1 \\
\hline 5 & Alternative placement & $5.17 \%$ & 3 \\
\hline & Tratal & $100 \%$ & 58
\end{tabular}


Q18 - In your experience, what is the average number of days a student would be suspended out-of-school for defiant behavior, insubordination, or disrespect to teachers, staff, and/or administrators.

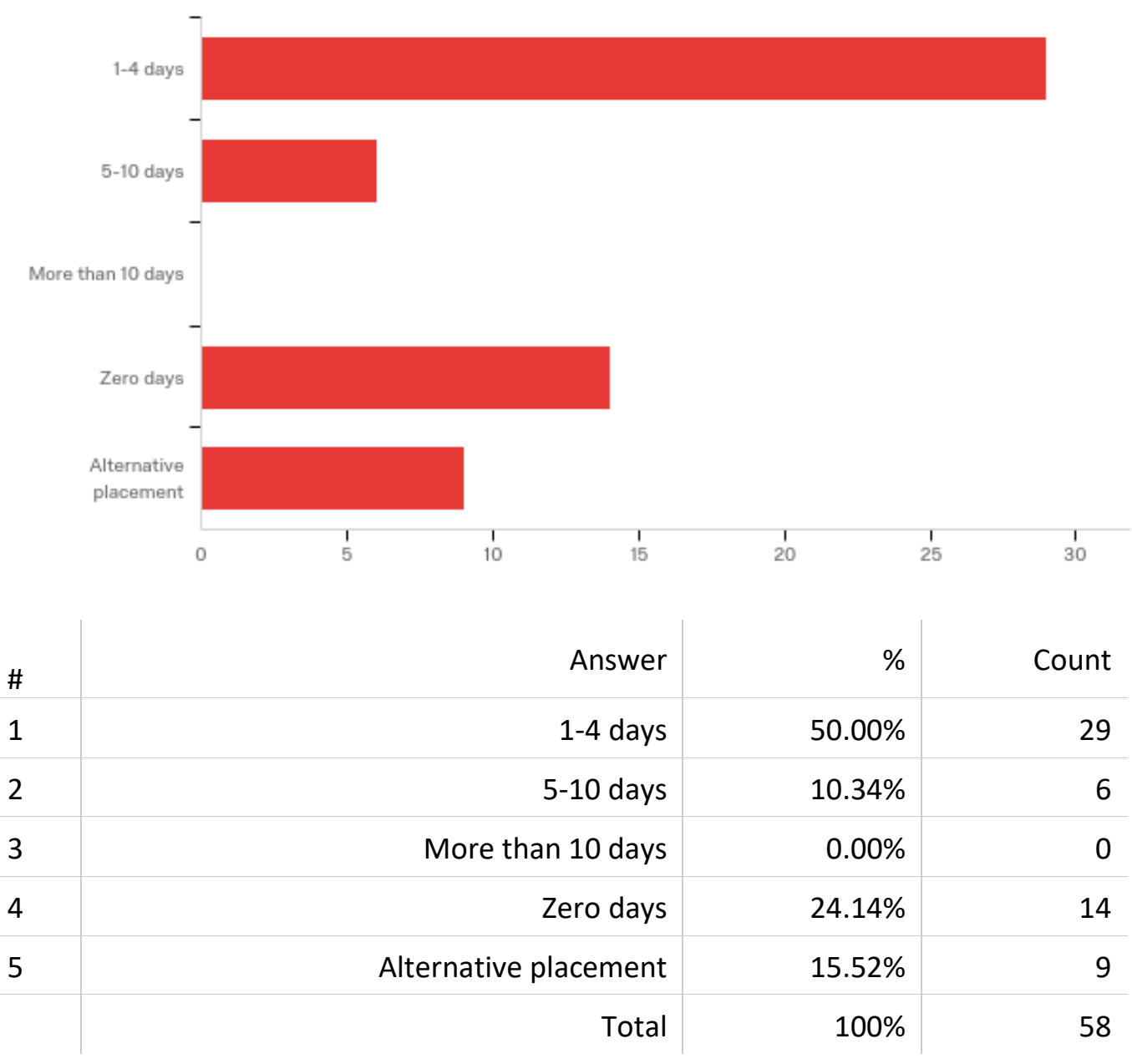


Q26 - School superintendents or upper administration are ALWAYS involved in the decision making process when deciding to suspend a student out-of-school.

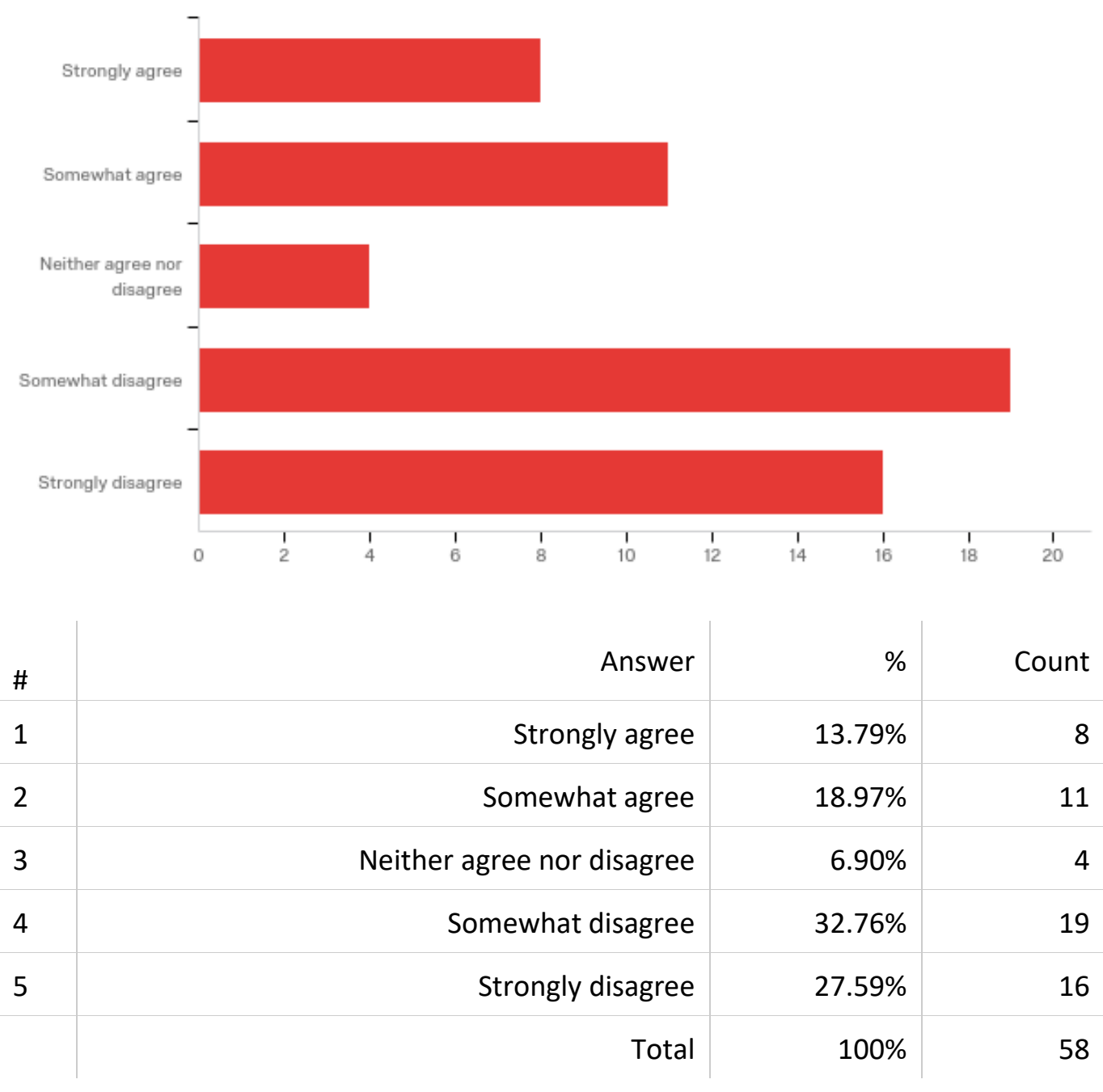


Q27 - Students who return to the traditional classroom setting after serving an out-of-school suspension display an improved attitude.

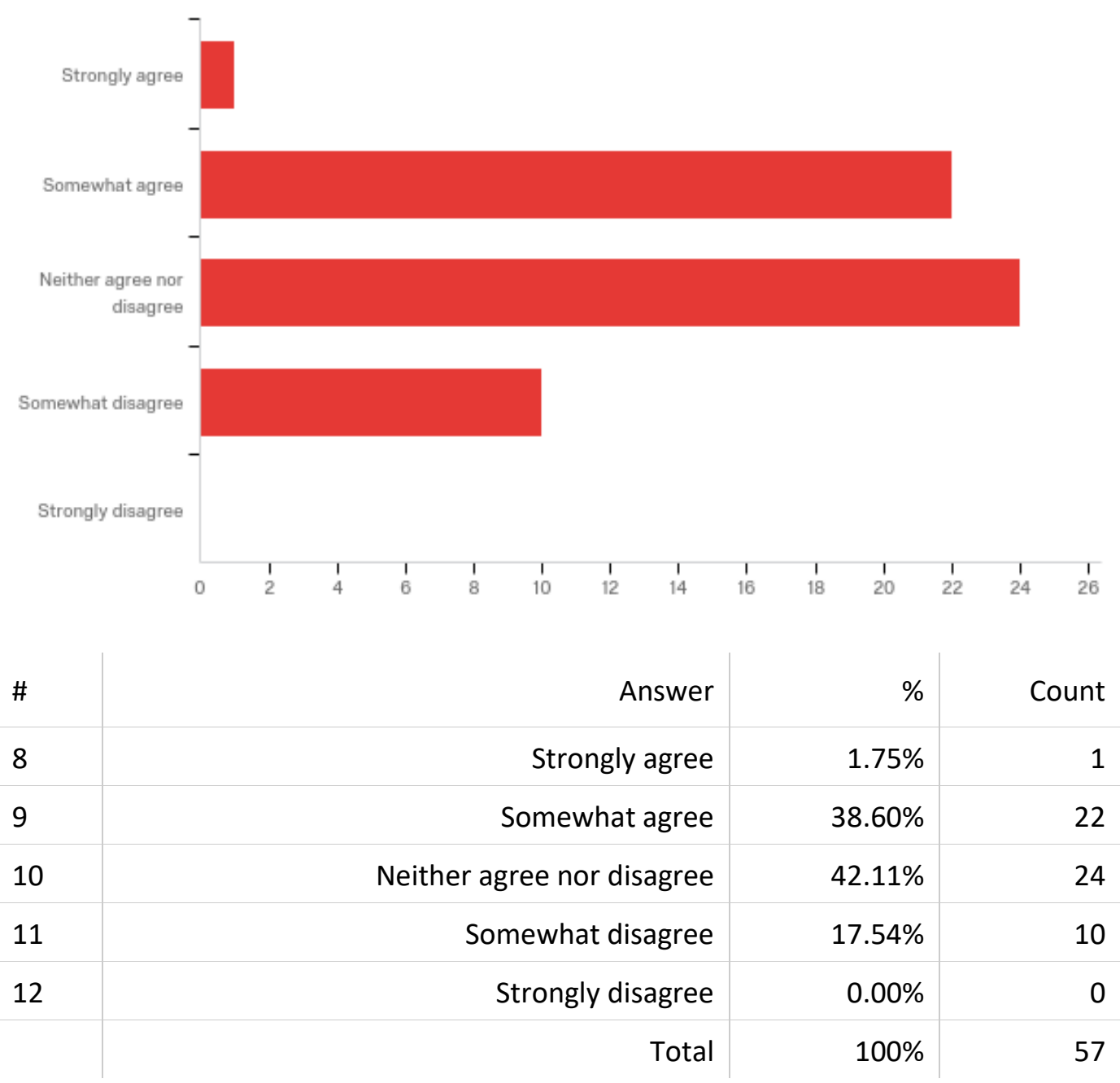


Q30 - Alternatives to out-of-school suspension have proven to be more effective in addressing student misbehavior.

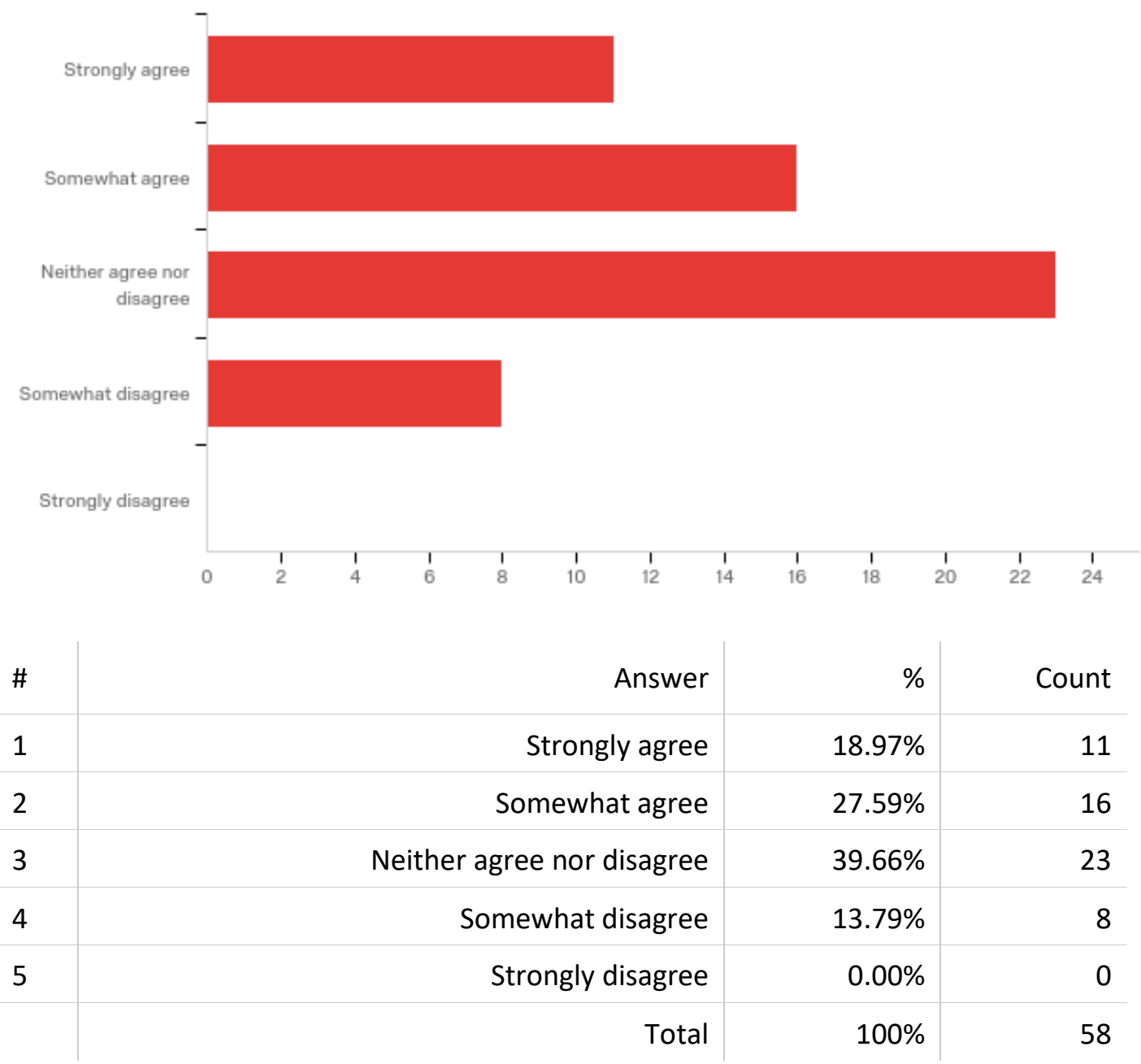


Q32 - Does your school allow students to complete their work/make up the work they have missed while serving an out-of-school suspension? This could be for full or partial credit.

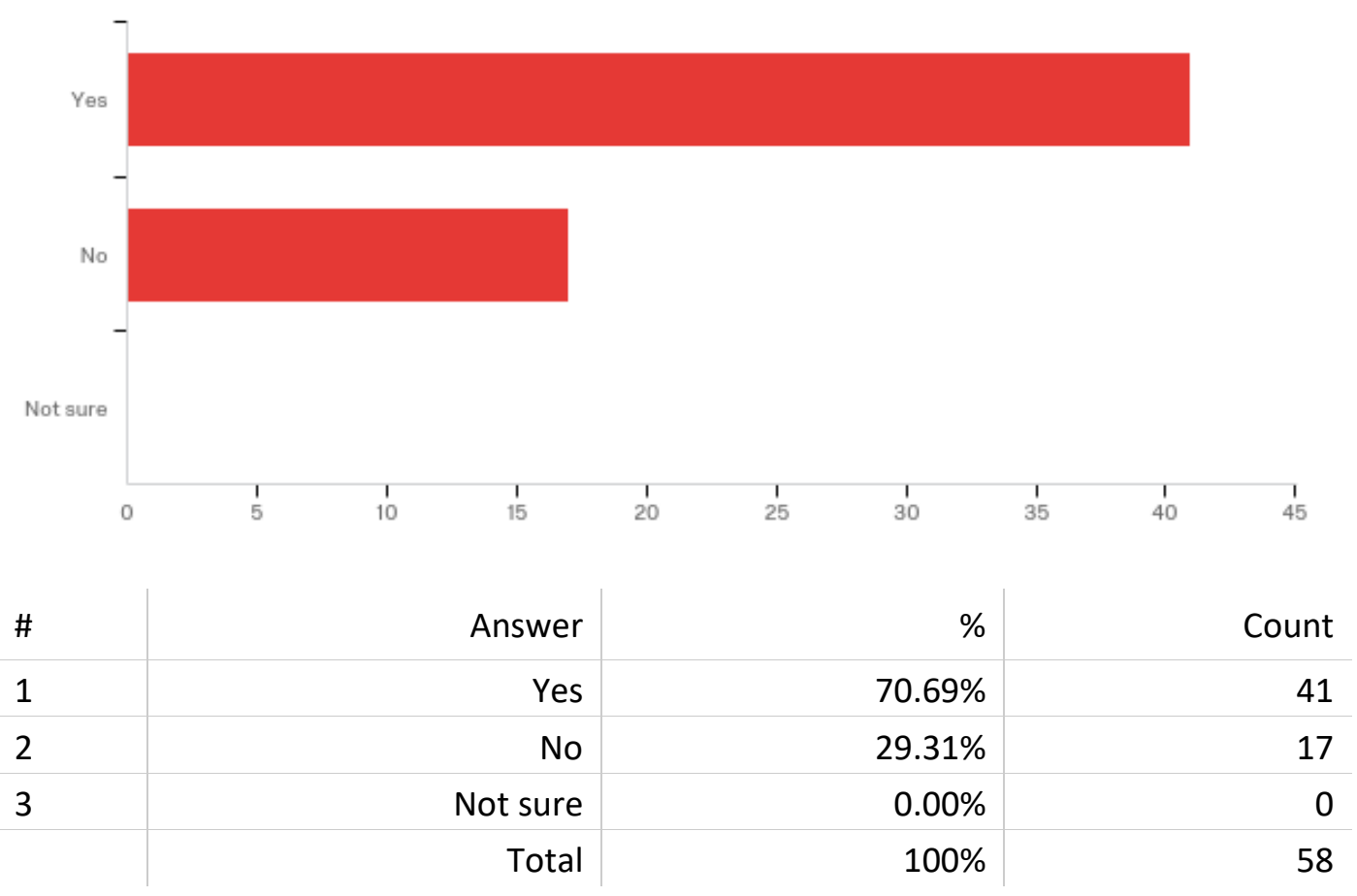


Q33 - When was the last time your school or administrative team reviewed, revised, or modified your discipline practices, policies, or procedures as it relates to out-of-school suspension?

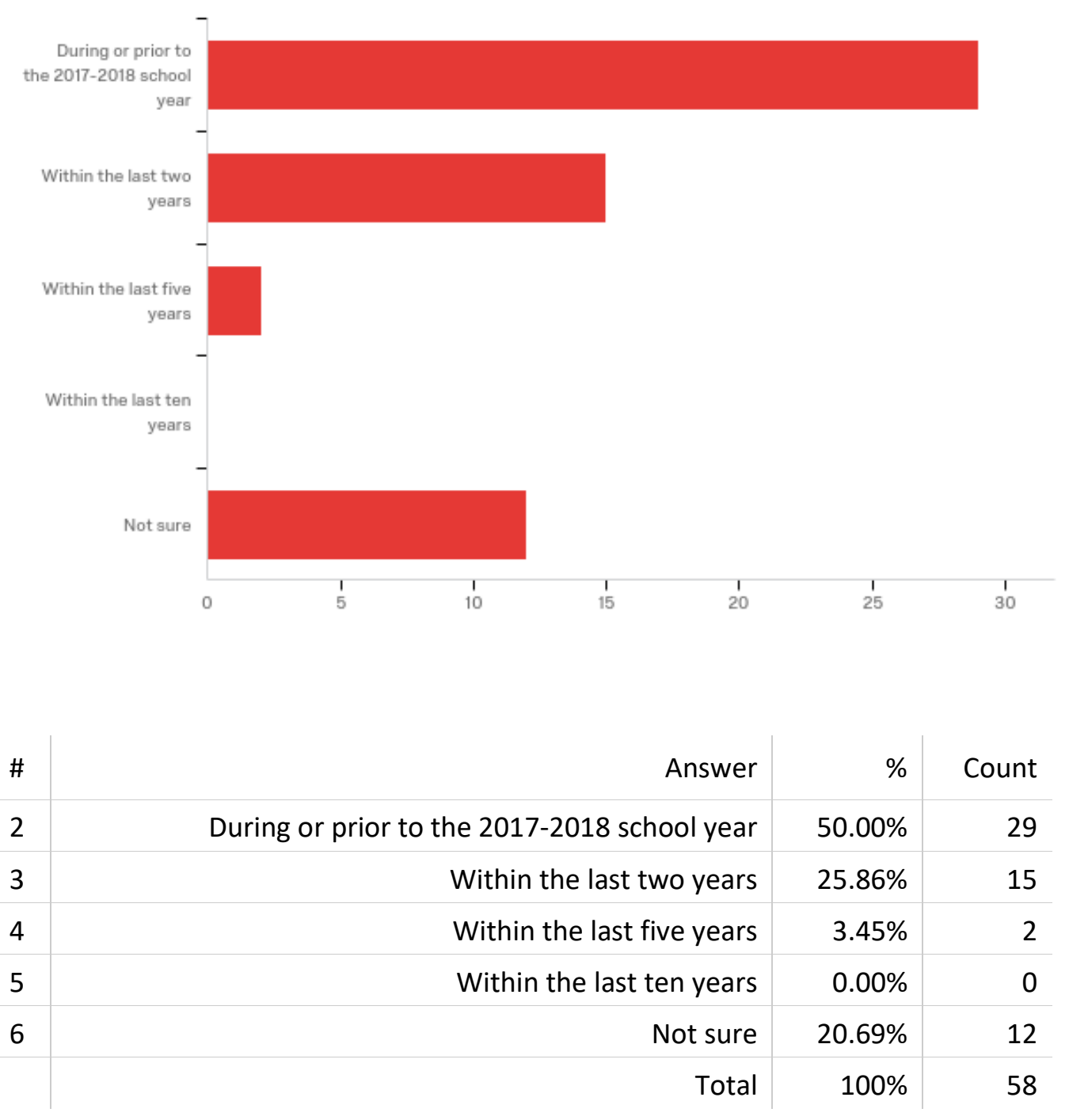


VITA

Seth Harrell has been a life-long Missouri resident and currently serves as a public high school principal. He obtained a Bachelor of Science in Criminal Justice from Southeast Missouri State University. Seth joined the education profession to serve as a teacher and athletic coach. During that time, he continued his education to obtain a teaching certificate. He then went on and obtained a Master of Arts in Secondary Administration from William Woods University. Seth served as a classroom teacher for five years, junior high assistant principal for one year, junior high principal for two years, and is in his fourth year serving as a high school principal. With the completion of this dissertation, he will have earned his Doctorate in Educational Leadership and Policy Analysis through the University of Missouri (MIZZOU). It has been Seth's lifelong goal to obtain a degree form MIZZOU and there's no better way in doing so than earning a degree and being able to write, Dr., in front of his name. 